\title{
Risks and recommendations in WRULD
}

Citation for published version (APA):

van Eijsden-Besseling, M. D. F. (2010). Risks and recommendations in WRULD. [Doctoral Thesis, Maastricht University]. Datawyse / Universitaire Pers Maastricht. https://doi.org/10.26481/dis.20101210me

Document status and date:

Published: 01/01/2010

DOI:

10.26481/dis.20101210me

Document Version:

Publisher's PDF, also known as Version of record

\section{Please check the document version of this publication:}

- A submitted manuscript is the version of the article upon submission and before peer-review. There can be important differences between the submitted version and the official published version of record.

People interested in the research are advised to contact the author for the final version of the publication, or visit the DOI to the publisher's website.

- The final author version and the galley proof are versions of the publication after peer review.

- The final published version features the final layout of the paper including the volume, issue and page numbers.

Link to publication

\footnotetext{
General rights rights.

- You may freely distribute the URL identifying the publication in the public portal. please follow below link for the End User Agreement:

www.umlib.nl/taverne-license

Take down policy

If you believe that this document breaches copyright please contact us at:

repository@maastrichtuniversity.nl

providing details and we will investigate your claim.
}

Copyright and moral rights for the publications made accessible in the public portal are retained by the authors and/or other copyright owners and it is a condition of accessing publications that users recognise and abide by the legal requirements associated with these

- Users may download and print one copy of any publication from the public portal for the purpose of private study or research.

- You may not further distribute the material or use it for any profit-making activity or commercial gain

If the publication is distributed under the terms of Article $25 \mathrm{fa}$ of the Dutch Copyright Act, indicated by the "Taverne" license above, 


\section{Risks and Recommendations in WRULD}

Marjon van Eijsden-Besseling 
ISBN 9789052789910

(C) Copyright Marjon van Eijsden-Besseling, Maastricht 2010

Production: Datawyse / Universitaire Pers Maastricht 


\title{
Risks and Recommendations in WRULD
}

\author{
PROEFSCHRIFT
}

Ter verkrijging van de graad van doctor aan de

Universiteit Maastricht

op gezag van de Rector Magnificus, Prof. mr. G.P.M.F. Mols,

volgens het besluit van het College van Decanen,

in het openbaar te verdedigen op

vrijdag 10 december 2010 om 12.00 uur

door

Marjon Dorothea Ferdinanda van Eijsden-Besseling

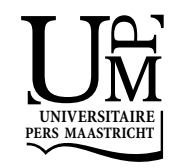




\section{Promotores}

Prof. dr. W.J.A. van den Heuvel

Prof. dr. R.A. de Bie

Prof. dr. J.L. Severens

\section{Copromotor}

Dr. J.B. Staal

\section{Beoordelingscommissie}

Prof. dr. M.H. Prins (voorzitter)

Prof. dr. M.H.W. Frings-Dresen, Academisch Medisch Centrum Amsterdam

Prof. dr. P.H.T.G. Heuts, VU Medisch Centrum Amsterdam

Prof. dr. R.J.E.M. Smeets

Prof. dr. G.H.I.M. Walenkamp 
Opgedragen aan mijn lieve Paul † 



\section{Table of Contents}

[1] General introduction and research questions........................................... 11

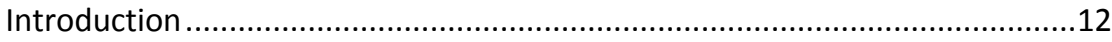

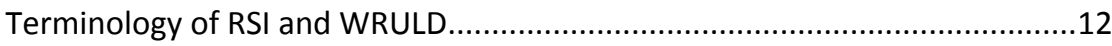

Complaints and patho-physiological mechanisms in non-specific WRULD ......13

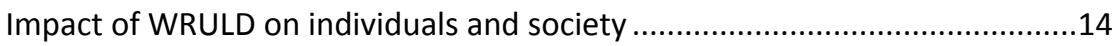

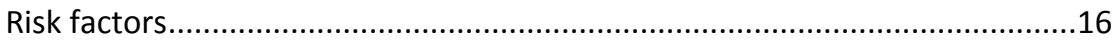

Evidence on prevention and therapy..........................................................17

Background and research questions of this thesis .......................................19

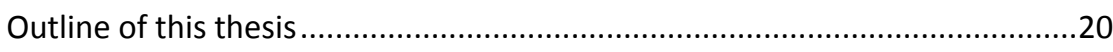

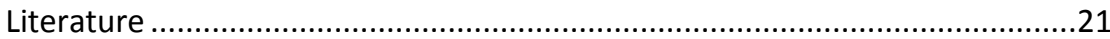

[2] The influence of work and treatment related factors on clinical status and disability in patients with non-specific work-related upper limb

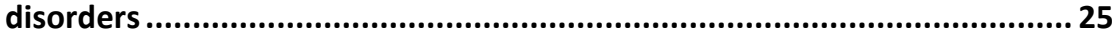

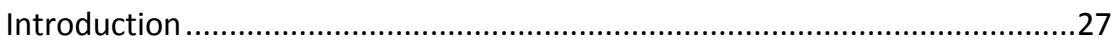

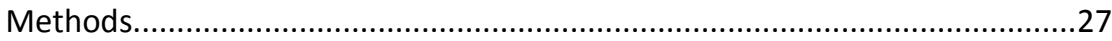

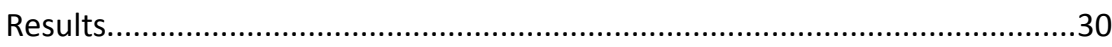

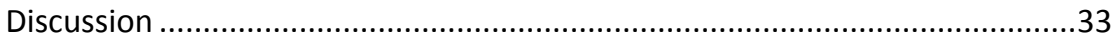

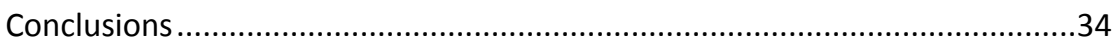

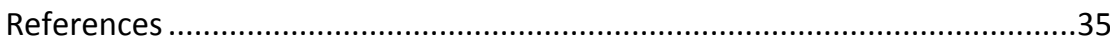

[3] The course of non-specific work-related upper limb disorders and the influence of demographic factors, psychologic factors, and physical

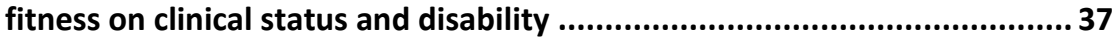

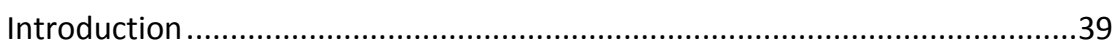

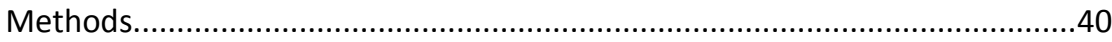

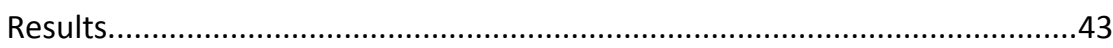

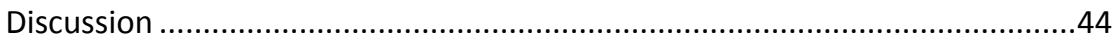

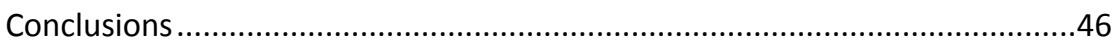

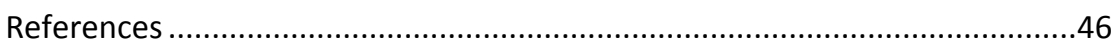

[4] Perfectionism and coping strategies as risk factors for the development of non-specific work-related upper limb disorders (WRULD) ....................... 49

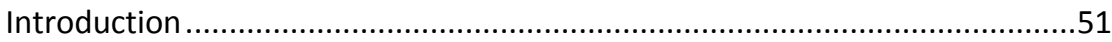

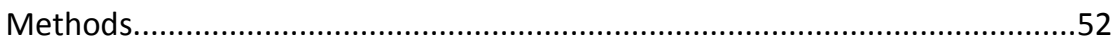

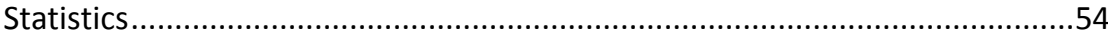

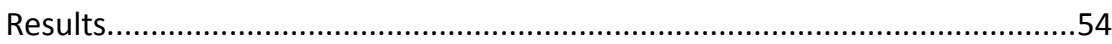




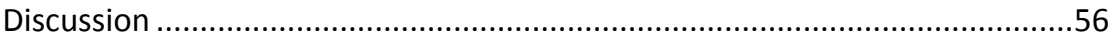

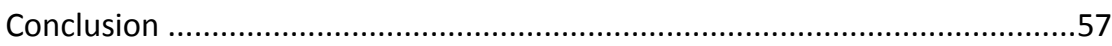

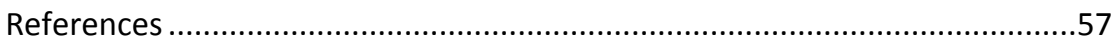

[5] Pain catastrophizing and lower physical fitness in a sample of computer screen workers with early non-specific upper limb disorders; a case-

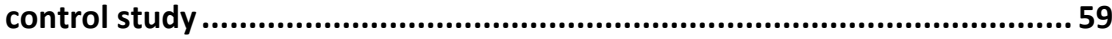

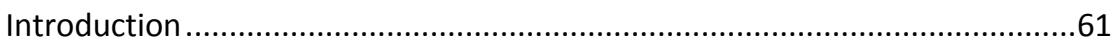

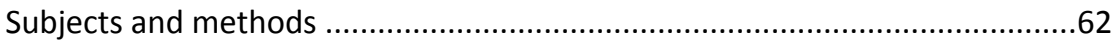

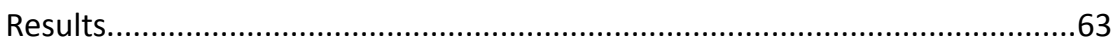

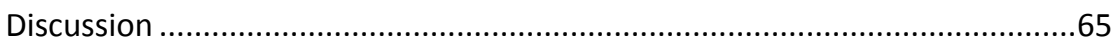

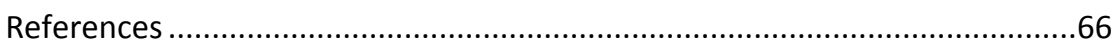

[6] No difference between postural exercises and strength and fitness exercises for early, non-specific, work-related upper limb disorders in visual display unit workers: a randomised trial ......................................69 69

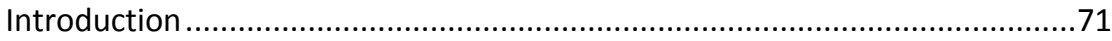

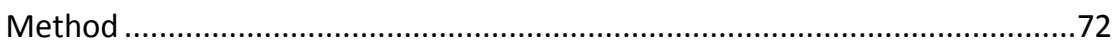

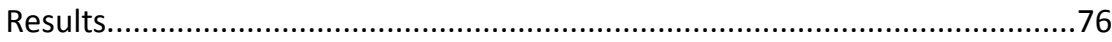

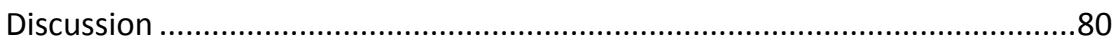

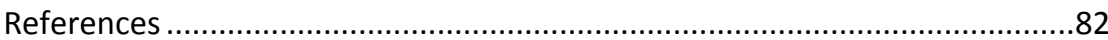

[7] Cost-effectiveness of postural exercise therapy versus physiotherapy in computer screen-workers with early non-specific work-related upper limb disorders (WRULD): a randomized controlled trial ............................. 85

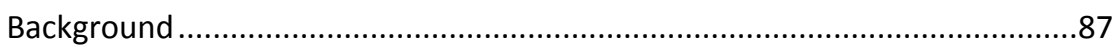

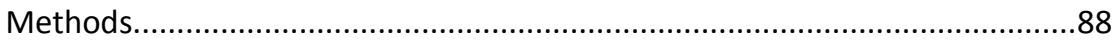

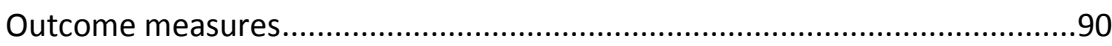

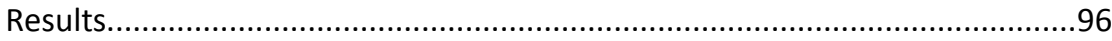

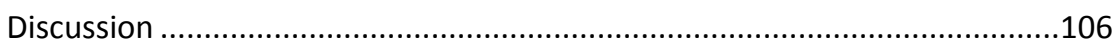

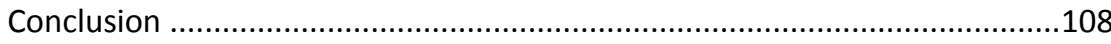

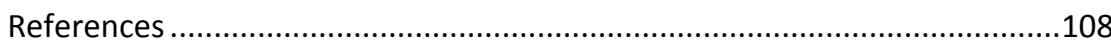

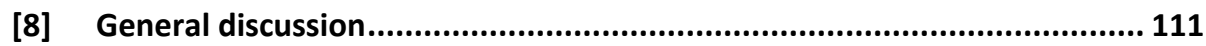

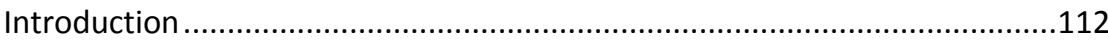

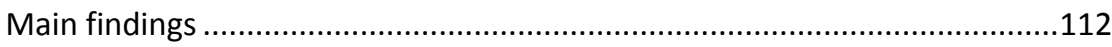

Strengths and weaknesses of the studies................................................114

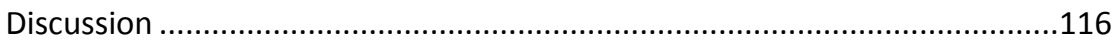

From initial expectations to advancement in understanding ......................119

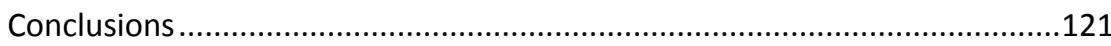

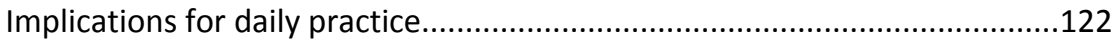




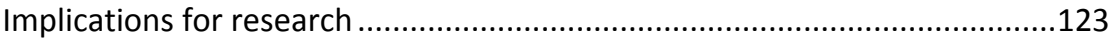

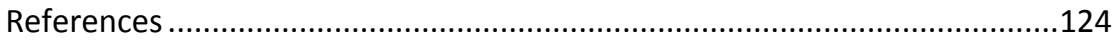

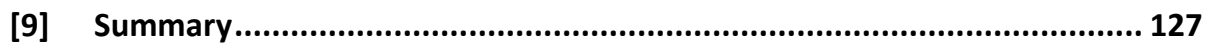

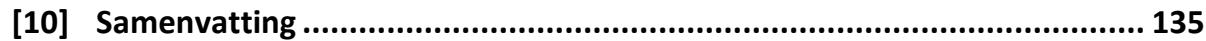

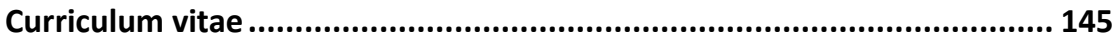

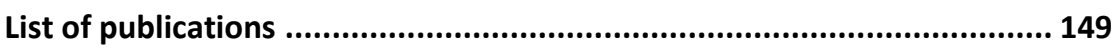

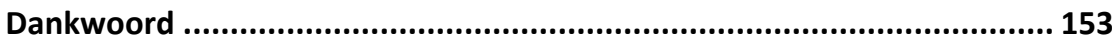





\section{[1]}

General introduction and research questions

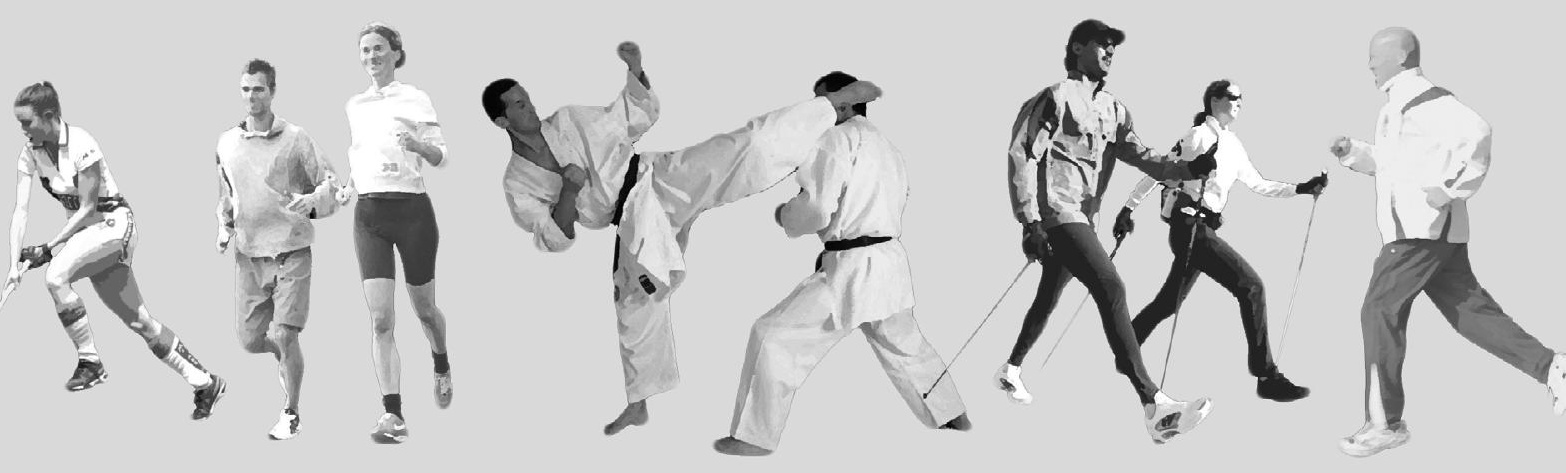




\section{Introduction}

Repetitive Strain Injury (RSI) became a hype in the late nineties of the last century, resulting in high prevalence and a wide variation of therapies. However, the background of this disease is not well understood. Scientific evidence about risk factors, preventive interventions and effectiveness of therapies is incomplete. This thesis aims to contribute to a better understanding of treating computer screen workers with nonspecific work-related upper limb disorders (WRULD), also in an early stage.

In this introductory chapter the background of RSI or WRULD - being the scientifical term- will be explained as well as its consequences for individuals and society and (possible) risk factors. Next the evidence for prevention and therapies is discussed. The chapter will end by explaining the background of this study and its research questions, followed by the outline of the thesis.

\section{Terminology of RSI and WRULD}

At the beginning of the eighties first records about incidence and distribution of RSI (Repetitive Strain Injury) were available from the South of Australia by data from the Australian Bureau of Statistics. ${ }^{1}$

Other terms internationally in use for the same syndrome are OOS (Occupational Overuse Syndrome), CTD (Cumulative Trauma Disorder), CANS (complaints of arm, neck and/or shoulder), WRUEMD (Work Related Upper Extremity Musculoskeletal Disorders) and WRULD (Work Related Upper Limb Disorders). ${ }^{2}$

The Dutch Health Council defines RSI in her report of $2000^{2}$ as follows: "RSI is a medical syndrome affecting the neck, upper back, shoulders, upper and lower arm, elbow, wrist or hand or a combination of those areas. Its effects are restrictive or lead to participation problems. The syndrome is characterized by a disturbance in the balance between load and physical capacity, preceded by activities that involve repeated movements or prolonged periods spent with one or more of the relevant body parts in a fixed position. RSI is always caused by a combination of factors. The definition of RSI adopted by the committee excludes pains and other conditions that are short-lived or acute. As a syndrome RSI necessarily involves a complex of complaints".

In the course of time RSI became - because of the impact on several levels (see below) a burdened term in the Netherlands. Therefore the government ordered to change the term into "CANS" (complaints of arm, neck and shoulder). This move however did not solve the problem as expected.

Because the Coronel Institute for Occupational and Environmental Health in the Netherlands ${ }^{3}$ makes use of the international term WRUEMD, considering RSI / CANS as a work-related disorder, in this thesis we will make use of the shorter term WRULD.

The Dutch Health Council makes no difference between specific (e.g. tennis elbow and carpal tunnel syndrome ${ }^{4}$ ) and non-specific WRULD, the latter having far and away the 
highest prevalence. ${ }^{2,5}$ This makes it difficult to set up methodological sound research projects with respect to WRULD.

In this thesis we make use of the "Criteria Document for evaluation of the workrelatedness of upper extremity musculoskeletal disorders" ${ }^{3}$ to be able to distinguish between specific and non-specific WRULD. The only countries in the world making a difference between specific and non-specific WRULD are Australia, New-Zealand and the Netherlands.

The empirical studies in this thesis exclusively concern non-specific WRULD.

\section{Complaints and patho-physiological mechanisms in non-specific WRULD}

Specific WRULD is characterized by a circumscriptive pattern of complaints like in carpal tunnel syndrome ${ }^{4}$ or tendonitis. The patho-physiological mechanisms are more or less elucidated and world wide medically accepted. The same applies to their treatments.

On the contrary, the patho-physiological background of non-specific WRULD is not yet elucidated.

Suspected mechanisms for the development of non-specific WRULD are long-lasting activities that involve repeated movements or prolonged periods spent with one or more of the relevant parts in a fixed position. ${ }^{2}$

The pattern of complaints for non-specific WRULD is miscellaneous. Pains, tingles, sensation of stiffness and swelling are most common. Complaints usually begin in the dominant arm, suddenly or gradually. In the beginning they are purely related to the work activity. When no action is undertaken, complaints extend to other described parts of the upper body, last also during other activities, become independent of the originally evoking activity and disturb sleep at night. When still no action is undertaken complaints become chronic, can be present 24 hours a day and might be accompanied by development of chronic pain behavior. On the other hand, from daily practice we know nowadays that even in case of chronic pain in loco motor apparatus, especially in case of kinesiophobia, pain can cease secondary when kinesiophobia is addressed effectively. Reassurance, education and graded exposure are important tools then. ${ }^{6}$

Although many hypotheses exist regarding patho-physiology of non-specific WRULD like the Cinderella-hypothesis, ${ }^{7,8}$ the neuromotor noise theory of van Galen ${ }^{9,10}$ seems to make sense because of its link with research done on repetitive strain injury in animal research (monkeys) ${ }^{11}$ and its links with experience in daily clinical practice regarding non-specific WRULD.

Patients with non-specific WRULD caused by sustained use of the computer (and mouse), exhibited in a graphical aiming task deviant movement strategies with co- 
contractions when compared to healthy persons. This occurred even more if these patients had to fulfill double tasks and/or had to fulfill their tasks under stressful conditions. ${ }^{10}$ Recently Huysmans could in her thesis ${ }^{12}$ link her results with those of van Galen. Partial evidence was found for her Precision-Pain Model showing that higher precision demands lead to higher impedance (higher muscle activity) in combination with changes in kinematics, proprioception and task performance in terms of positional precision are impaired in fatigued subjects and in subjects with neck and upper extremity pain and that precision demands could be associated with arm-hand pain. Additionally, Harris reported in $1999^{13}$ that repetitive strain injuries for instance in keyboard operators are accompanied by fluid changes in sensor motor cortex and by pathological pain. He reports that disorganized or inappropriate cortical representation of proprioception may falsely signal incongruence between motor intention and movement, which results in pathological pain in the same way that incongruence between vestibular and visual sensation results in motion sickness.

In this scope it was and still is remarkable in daily practice that computer screen workers diagnosed with non-specific WRULD when returning from holidays, where they did not or less experienced complaints, immediately reported pains and tingles sitting behind their computers even before having touched the keyboard or the mouse.

These findings make "resetting of the brains" by reassurance and graded exposure understandable. This is further developed theoretically in the fear-avoidance model of Vlaeyen ${ }^{14}$ and this model can play an important role in the development and course of non-specific WRULD.

The essence of this model is that a common injury is followed by nociceptive pain. Normally, this pain will cease spontaneously unless catastrophizing thoughts bring a person in the vicious circle of injury, pain, catastrophizing thoughts, and kinesiophobia by anxiety for - in the mean time neuropathic - pain and repeated injury, ending up in avoidance behavior and disuse, distress and depression; all this will be accompanied by the development of disabilities and social handicap.

\section{Impact of WRULD on individuals and society}

In the Netherlands there has been an increase of WRULD in the Dutch working population- especially among visual display unit-workers (computer screen workers) -from 19 to $28 \%$ between 1997 and 2002. ${ }^{2,5}$ Due to expected increase of computer screen workers in the near future by changed nature of work ${ }^{15}$, the prevalence of WRULD among screen workers is expected to increase proportionally. ${ }^{5,16}$

This results in, on the one hand decreased productivity, increased medical consumption and consequently increased costs, on the other hand disability and decreased quality of life. $^{17}$ 
Because computer screen workers represent a large homogeneous group at risk for non-specific WRULD with consequently large impact on individuals and society, they form the study base for this thesis.

Research in 1988 among 229 Australian company workers with chronic pain in the upper limbs showed that $13 \%$ could be classified as specific WRULD and $87 \%$ as nonspecific. $^{18}$

In the Netherlands specific WRULD is estimated to lie between $13-27 \%$ in the working population, while the remainder is classified as non-specific. ${ }^{5}$

\section{Prevalence in relation to vocation and education level}

It is likely that the increased use of personal computers at work is associated with a growing incidence of WRULD. ${ }^{16}$

Especially those workers sitting behind the computer more than 6 hours a day seemed sensitive for the development of WRULD. ${ }^{5,19}$

There seemed no difference in the prevalence of WRULD among computer workers using a mouse or not, ${ }^{20}$ although IJmker recently published that the development of non-specific WRULD could not directly be related to the number of hours computer work per day, however could be related to the use of a mouse. ${ }^{21}$

Non-specific WRULD is not necessarily related to computer work, but the fact that the Netherlands have the highest percentage fulltime computer workers of Europe (35\%) makes the high incidence and prevalence of WRULD understandable. ${ }^{5,19,20,22}$

Other workers sensitive for developing WRULD are for instance musicians, hairdressers, croupiers and plumbers. ${ }^{5}$

The Dutch Central Bureau of Statistics showed in a research project in 2000 that the prevalence of WRULD was higher in low educated workers (29\%) compared to workers with at least a bachelor's degree (19\%). ${ }^{23}$ However, no difference was made between specific and non-specific WRULD-complaints.

\section{Absence from work and costs}

In the Netherlands $8 \%$ of the whole working population takes time off work because of WRULD annually. ${ }^{22}$

Absenteeism of 13 weeks or more lies at $0.44 \%$ yearly, while entry of disability pension is assessed at $0.04 \%$ yearly. $^{24}$

At the end of $200528 \%$ of the total of disability pensions in the Netherlands was spent that year on diseases of loco motor apparatus including WRULD. ${ }^{25}$

The Health \& Safety Executive, a British institution responsible for the regulation of occupational risks to health, estimated that self-reported WRULD resulted in 4.7 million lost working days in 2003/2004. ${ }^{26}$ 
In the USA one third of workers' compensation costs in private industry is estimated to be caused by WRULD and the direct costs, with compensation, exceed US\$20 billion in Washington state alone. ${ }^{27}$

A recent study in the Netherlands in 2005 estimates the total annual costs due to specific and non-specific WRULD at about 2.1 billion Euros, consisting of medical costs, costs due to decreased productivity, absenteeism related to WRULD and disability pensions. $^{28}$

Benchmarking shows, that the total annual costs of cardiovascular diseases in the Netherlands that year comprised 5.5 billion Euros and all diseases of loco motor apparatus inclusive connective tissue diseases 4.2 billion Euros. ${ }^{29}$

That means that half of the total costs, in 2005 spent on diseases of loco motor apparatus inclusive connective tissue diseases, concerned WRULD

\section{Risk factors}

Risk factors for WRULD can be subdivided into work-related physical risk factors, workrelated psychosocial risk factors and personal risk factors. ${ }^{5,16,30,31}$

Previous longitudinal studies among office workers including individual factors as well as estimates of occupational mechanical and psychosocial exposure, and leisure time exposure, have found the most consistent and strongest associations between the duration of mouse use and the incidence of hand-arm symptoms. ${ }^{32}$

Risk factors should be subdivided in risk factors predicting the development of nonspecific WRULD and those predicting the course of non-specific WRULD, because risk factors predicting the development of non-specific WRULD are not necessarily the same as those which are of importance in the course of the disease.

\section{Work-related physical factors}

Much research has been done on physical work-related risk factors.

Systematic reviews show a linear relationship between the occurrence of neck pain and work-related physical risk factors like neck flexion, arm force, arm posture, duration of sitting, twisting or bending the trunk, hand-arm vibration and workplace design ${ }^{33}$ and that shoulder pain is related to repetitive movements and vibration. ${ }^{34}$

A more recent Dutch prospective study in an occupational setting with follow-up of three years showed that sitting at work for over $95 \%$ of the working time was a significant risk factor for developing neck pain. ${ }^{35}$

Another recent Dutch study, in which the relation between physical capacity and workrelated musculoskeletal symptoms was studied, showed that the impact of decreased physical capacity on the development of future complaints in loco motor apparatus is not yet clear. ${ }^{36}$ Moreover, in employees with neck pain, the imbalance between physical capacity and exposure to work-related physical factors was not a stronger predictor 
for the development of future musculoskeletal symptoms than each of these variables separately. ${ }^{36}$

\section{Work-related psycho-social factors}

The SMASH-study (Study on Musculoskeletal disorders, Absenteeism, Stress and Health) shows the linear and nonlinear relations between psychosocial job characteristics, subjective outcomes and sickness absence. ${ }^{37}$

Van den Heuvel ${ }^{31}$ found work-related psychosocial factors to be of large importance in causing work-related upper limb disorders, in particular high task demands and limited social support from colleagues.

A large cross-sectional research by Koenders et al ${ }^{38}$ among 12,950 bank employees showed that job stress was a strong predictor for the development of work-related upper limb disorders.

\section{Personal(ity) factors}

As personal risk factors, effort/ reward imbalance, especially high effort, and over commitment $^{31}$ are found to be important in causing work-related upper limb disorders. A study at Maastricht University among PhD students in 2002 showed that a high trait anxiety accentuates the effect of work-related upper limb complaints as predictor of absenteeism. $^{39}$

It seems that the fear-avoidance model of Vlaeyen - along the road of catastrophisingcan play an important role in the course of non-specific WRULD. ${ }^{40}$

\section{Socio-demographic characteristics}

Women appeared to have more risk to develop non-specific WRULD ${ }^{38,41}$ as compared to men, which might be explained by a difference in effect of exposure to work-related physical and psychosocial risk factors between females and males. ${ }^{42}$

The above mentioned cross-sectional study among bank employees showed also that the low educated employees were more at risk for developing WRULD complaints as compared to their highly educated colleagues. ${ }^{38}$

Little research is available with respect to the age of patients with non-specific WRULD. Above mentioned cross-sectional study reports an increasing percentage of employees with non-specific WRULD among the older ones. ${ }^{38}$

\section{Evidence on prevention and therapy}

Because non-specific WRULD has such a large impact on the total annual health care and societal costs consisting of medical costs, costs due to decreased productivity, 
absenteeism related to WRULD and disability pensions, ${ }^{18}$ primary and secondary prevention of non-specific WRULD urgently need attention. Beyond these aspects of societal and financial importance, personal aspects of disability and quality of life need to be implemented in WRULD-research. ${ }^{17}$

Because non-specific WRULD tends to become chronic very easily, the earlier intervention or information has been given, the better.

Preventive studies only comprise specific WRULD and include mainly electro diagnostic techniques, psychophysical tests and examination of biochemical markers in soft tissue injuries. $^{43}$

Sparse research with sound methodological background is available on the effectiveness of (multidisciplinary) therapies, especially in WRULD- patients with early stages of complaints. $^{44,45,46}$

A recently published systematic review on randomized and non-randomized studies investigating the effect of conservative interventions in (mainly chronic) WRULDpatients showed that the methodological quality of most studies was below scientific standards. ${ }^{47}$

Results of therapy are not conclusive and evidence is conflicting when exercise interventions are compared to no treatment at all. ${ }^{47,48}$

However, limited evidence was found for the effectiveness of exercises when compared to massage, implementing breaks during computer work sessions, massage as supplemental treatment to manual therapy and manual therapy as supplemental treatment to exercises. ${ }^{47}$

One randomized controlled trial showed that chronic sick-listed WRULD-patients benefited from multidisciplinary treatment consisting of psychological and physical sessions ${ }^{49}$; however no differences were found in cost-effectiveness between the multidisciplinary treatment group and the usual care group.

A randomized study aiming to assess the effectiveness of a group-based interactive work style intervention on improving work style behavior among computer workers showed that such an intervention is effective in improving some elements of work style behavior; however, this intervention was ineffective in changing stress outcomes. ${ }^{50}$ Feuerstein et al $(2004,2009)$ also did research on work style and job stress management as secondary prevention. They found that job stress management additionally to ergonomic intervention was not more effective than the ergonomic intervention alone. ${ }^{51}$ Moreover they found that higher scores on a patient-reported job stress measure predicted higher levels of pain at six months. ${ }^{52}$ In the selected studies outcomes were mainly assessed on the impairment level, but rarely on the level of disability or quality of life. ${ }^{17,45,47}$

It may be concluded that evidence from clinical research is scarce and more is needed. 
Besides, as with other medical technologies, prevention and therapy for WRULD should be subjected to critical evaluation. In order to support policy decision making on for instance reimbursement of therapy or development of clinical guidelines, costeffectiveness studies can be performed. ${ }^{53}$

Research and (cost)-effectiveness studies regarding non-specific WRULD need to cover all three groups of well-described risk factors, casu quo the work-related physical and psychosocial risk factors as well as the personal risk factors. ${ }^{5,31,36}$ Beyond outcome measures on the impairment level, outcome measures on disability level and regarding quality of life are urgently requested because they also can predict the final outcome of non-specific WRULD.

\section{Background and research questions of this thesis}

Personal experience in having treated patients with non-specific WRULD complaints in the past 15 years in our department of rehabilitation and physical medicine, being a tertiary referral centre for this patient group, showed that these complaints - if untreated- become chronic very easily.

Literature, as demonstrated in this introductory chapter and daily practice showed that physical and psychosocial work-related risk factors as well as socio-demographic and personality risk factors play an important role in the development and persistence of WRULD complaints. The consequences with respect to, on the one hand personal experienced disability and decreased quality of life, and on the other hand decreased productivity, related absenteeism, increased medical consumption and increased societal costs, are huge.

Therefore we have to try to understand the role of these factors on the course of the disease better. Also evidence of treatment is lacking. Clinical experience seemed to show a favorable effect in patients treated by a combination of exercise and education in order to improve posture and movement habits in relation to everyday activities. We wanted to test this observation in a randomized clinical trial.

Our department has a large well-documented file of these patients, especially for screen workers. This made it worthwhile to start a retrospective study on the course of non-specific WRULD and the influence of, on the one hand work- and treatment related factors and on the other hand socio-demographic, psychological and physical factors on clinical status and functional disability.

The first research question is: what is the course of non-specific WRULD and do workand treatment related factors, socio- demographic, psychological and physical factors predict clinical status and functional disability?

From the very first treatments of WRULD-patients onwards, these patients seemed to have personality traits making them sensitive for developing and persisting non-specific 
WRULD- complaints. Especially they seemed neurotic perfectionists and psychoneurotic people.

A case-control study on the role of neurotic perfectionism was set up in the beginning of this thesis. Later on in the project, the role of catastrophising seemed to overwhelm the role of neurotic perfectionism, reason that another case-control study was started on the role of catastrophising on non-specific WRULD and disability.

The second research question is: do psychological factors play an important role in developing and persisting non-specific WRULD- complaints?

Daily practice seemed to show that in early WRULD-patients, exercise therapy according to Mensendieck / Cesar was more successful as compared to usual care (physiotherapy).

Therefore a randomized controlled trial was set up.

Beyond outcome measures on impairment level, outcome measures on disability level and with respect to quality of life were taken into account.

The third research question is: are postural exercises delivered by postural exercise therapists according to the method of Mensendieck / Cesar more effective in decreasing beginning non-specific WRULD symptoms and in preventing disability and can this therapy be regarded as cost-effective when compared to usual care?

This thesis aims to give physicians and therapists a better understanding of the importance of treating screen workers with non-specific WRULD in an early stage and the way they have to treat them, taking into account all levels of risk factors.

\section{Outline of this thesis}

In the Chapters 2 and 3 the course of non-specific WRULD and the influence of workand treatment related factors as well as socio- demographic, psychological and physical factors on clinical status and functional disability are presented in a retrospective study (research question 1).

The second research question on the role of psychological / personality factors on the development and course of non-specific WRULD is answered in Chapter 4 and Chapter 5.

In Chapter 4 a case-control study is presented, studying screen workers with nonspecific WRULD from our clinic and 2 control groups (chronic pain patients from our clinic and healthy screen workers) on their perfectionism trait, their coping behavior and their psycho neuroticism traits.

Chapter 5 tries to explain how personality factors might cause disability in chronic nonspecific WRULD.

This is done by another case-control study comparing screen workers experiencing disabilities from non-specific work-related upper limb disorders with controls. 
The third research question is answered in Chapter 6 and 7. In a randomized intervention trial with non-specific WRULD-patients in a early stage, the effectiveness of postural exercise therapy according to the method of Mensendieck / Cesar was compared with care as usual (Chapter 6) and also the cost-effectiveness (Chapter 7). Chapter 8 presents the general discussion and conclusions as well as recommendations for daily practice and further research.

\section{Literature}

1. Gun RT. Department of Community Medicine, University of Adelaide, SA. The incidence and distribution of RSI in South Australia 1980-81 to 1986-87. Med J Aust. 1990 Oct 1; 153 (7): 376-80.

2. Health Council of the Netherlands. RSI. The Hague: Health Council of the Netherlands; Publication No 2000/22E. 2000. Retrieved from: http://neurologiadeltrabajo.sen.es/pdf/rsi_report_curso2000_nt.pdf

3. Sluiter JK, Rest KM, Frings-Dresen MHW. Criteria Document for evaluation of the work-relatedness of upper extremity musculoskeletal disorders. Scandinavian Journal of Work, Environment and Health 2001; 27 Suppl 1:1-102.

4. de Krom MC, Knipschild PG, Kester AD, Spaans F. Efficacy of provocative tests of carpal tunnel syndrome. Lancet 1990 Feb 17; 335 (8686): 393-5.

5. Peereboom KJ c.s. RSI Handboek (RSI Handbook) 4th Edition, 2005/2006. Sdu Editors, the Hague, the Netherlands.

6. De Jong JR, Vlaeyen JW, Onghena P, Goossens ME, Geilen M, Mulder H. Fear of movement / (re)injury in chronic low back pain: education or exposure in vivo as mediator to fear reduction? Clin J Pain 2005 JanFeb; 21 (1): 9-17; discussion 69- 72.

7. Sjogaard G \& Sogaard K. Muscle injury in repetitive motion disorders. Clinical Orthopaedics and Related Research 1998; (351): 21-31.

8. Hägg GM. Lack of relation between maximal force capacity and muscle disorders caused by low level static loads. A new explanation model. In Quéinnec Y \& Daniellou F. (eds). Congress of the International Ergonomics Association / IEA, Vol.1. Paris: Taylor and Francis, 1991.p.9-11.

9. Bloemsaat JG, Ruijgrok JM, van Galen GP. Patients suffering from non-specific work-related upper limb disorders exhibit insufficient movement strategies. Acta Psychol (Amst). 2004 Jan; 115 (1): 17-33.

10. Meulenbroek RG, van Galen GP, Hulstijn M, Hulstijn W, Bloemsaat G. Muscular cocontraction covaries with task load to control the flow of motion in fine motor tasks. Biol Psychol. 2005 Mar; 68 (3): 331-52.

11. Byl NN, Merzenich MM, Jenkins WM. A primate genesis model of focal dystonia of the hand in the primary somatosensory cortex in adult monkeys. Neurology 1996; 47: 508-20.

12. Huysmans MA. From precision demands to neck and upper extremity pain. PhD Thesis. University of Amsterdam, 2008.

13. Harris AJ. Lancet 1999 Oct 23; 354 (9188): 1464-6.

14. Vlaeyen JW, Linton SJ. Fear-avoidance and its consequences in chronic musculoskeletal pain: a state of the art Pain 2000 (3): 317-332.

15. Dembe AE. The changing nature of office work: effects on repetitive strain injuries. Occupational Medicine 1999; 14 (1): 61-72 (iii).

16. Staal JB, De Bie RA, Hendriks EJM. Aetiology and management of work-related upper extremity disorders. Best Practice \& Research Clinical Rheumatology 2007; Vol. 21, No 1, pp 123-133.

17. Picavet HSJ, Hoeymans N. Health related quality of life in multiple musculoskeletal diseases: SF-36 and EQ-5D in the DMC3 study Ann Rheum Dis, 2004 63, 723-29.

18. Miller MH, Topliss DJ. Chronic upper limb pain syndrome (repetitive strain injury) in the Australian workforce: a systematic cross sectional rheumatologic study of 229 patients. Journal of Rheumatology 1988 Nov; 15 (11): 1705-12. 
19. Schaeps M, van den Ameele AN. Repetitive Strain Injuries reviewed. (Prevalence of RSI-related complaints as result of computer work) 2001. The Hague: Labour Inspectorate.

20. Blatter BM, Bongers PM, Kraan KO. RSI -complaints in the working population: prevalence and relation with computer work, use of the mouse and other ICT-related factors 2000. TNO Labour, Hoofddorp.

21. IJmker S. Risk factors for arm-wrist-hand and neck-shoulder symptoms among office workers. A longitudinal perspective. PhD Thesis. Body@Work. Amsterdam, 2008.

22. Bongers PM, de Vet HCW, Blatter BM. RSI: Prevalence, aetiology, therapy and prevention. Dutch Journal of Medicine 2002, 19 Okt: 146(42) page. 1971-76.

23. Botterweck A. Arbeidsomstandigheden: werk en gezondheidsaspecten. Gegevens uit Permanent Onderzoek Leefsituatie van het CBS ( Labour circumstances: work and health aspects. Data from Permanent Research Life Circumstances of the CBS), 2000 (www.cbs.nl).

24. Blatter BM, Bongers PM, van den Heuvel SG. The extent of absenteeism and disability for work by WRULD. 2001. Elsevier bedrijfsinformatie, Doetinchem.

25. Ziekteverzuim en arbeidsongeschiktheid samengevat (Absenteeism from work and disability summarized) 2005. From: http://www.rivm.nl/vtv/object_document/o1323n18748.html

26. Health and Safety Commission. Upper limb disorders. Accessed April 2006.Available at: http://www.hse.gov.uk/msd/hsemsd.htm\#uld.

27. Silverstein B, Viikari-Juntura E, Kalat J. Use of a prevention index to identify industries at high risk for work-related musculoskeletal disorders of the neck, back, and upper extremity in Washington state. 1990-1998. American Journal of Industrial Medicine 2002; 41: 149-169.

28. Blatter B, Houtman I, van den Bossche S, Kraan K, van den Heuvel S. Gezondheidsschade en kosten als gevolg van RSI en psychosociale arbeidsbelasting in Nederland (Health effects and costs as consequences of RSI and psychosocial work load in the Netherlands) 2005. TNO Kwaliteit van Leven / Ministerie van Sociale Zaken en Werkgelegenheid. Retrieved oktober 28, 2005, from: http://docs.szw.nl/pdf/129/2006/129_2006_3_8656.pdf

29. RIVM (Rijksinstituut voor Volksgezondheid en Milieuhygiëne). Kosten van ziekten naar diagnose (diagnosis- related total health care costs) 2005. from: http:// www.rivm.nl/vtv/object_class/kvz_kostendiagnose.html

30. Bongers PM, Kremer AM \& ter Laak J. Are psychosocial factors, risk factors for symptoms and signs of the shoulder, elbow, or hand/wrist? A review of the epidemiological literature. American Journal of Industrial Medicine 2002; 41 (5): 315-342.

31. Heuvel van den SG. Work-related neck and upper limb symptoms Amsterdam. Thesis. TNO, 2006.

32. IJmker S, Blatter BM, van der Beek AJ, van Mechelen W, Bongers PM. Prospective research on musculoskeletal disorders in office workers (PROMO): study protocol. BMC Musculoskeletal Disorders 2006; 7:55.

33. Ariëns GA, van Mechelen W, Bongers PM et al. Physical risk factors for neck pain. Scandinavian Journal of Work, Environment and Health 2000; 26 (1): 7-19.

34. Van der Windt DA, Thomas E, Pope DP et al. Occupational risk factors for shoulder pain: a systematic review. Occupational and Environmental Medicine 2000; 57 (7): 433-442.

35. Ariëns GA, Bongers PM, Hoogendoorn WE et al. High quantitative job demands and low coworker support as risk factors for neck pain: results of a prospective cohort study. Spine 2001; 26 (17): 1896-1901 (discussion 1902-1903).

36. Hamberg-van Reenen HH. Physical Capacity and work-related musculoskeletal symptoms. PhD Thesis Body@Work. Amsterdam, 2008.

37. De Jonge J, Reuvers MMEN, Houtman ILD, Bongers PM, Kompier MAJ. Linear and nonlinear relations between psychosocial job characteristics, subjective outcomes, and sickness absence: baseline results from SMASH. J Occ health Psych 2000; 5: 256-68.

38. Koenders PG, Dijkstra L, Bouwman-Brouwer KM, Konijnenberg HS. Een worsteling met de muis A( A wrestling with the mouse). Tijdschrift voor Bedrijfs- en Verzekeringsgeneeskunde (Journal for Occupational and Insurance Medicine) 2006; 14, 2: 57-61. 
39. Roelofs PD. RSI en persoonsgebonden factoren: een oriënterende studie (RSI, personal and personality factors: an explorative study) Maastricht: University (Thesis), 2002. From http://www.unimaas.nl/bestand. asp?id=2275

40. Vlaeyen JW, Linton SJ. Fear-avoidance and its consequences in chronic musculoskeletal pain: a state of the art. Pain 2000 (3): 317-332.

41. Brandt LP, Andersen JH, Lassen CF et al. Neck and shoulder symptoms and disorders among Danish computer workers. Scandinavian Journal of Work, Environment and Health 2004; 30 (5): 399-409.

42. Hooftman WE, van Poppel MN, van der Beek AJ et al. Gender differences in the relations between workrelated physical and psychosocial risk factors and musculoskeletal complaints. Scandinavian Journal of Work, Environment and Health 2004; 30 (4): 261-278.

43. Saxton JM. A review of current literature on physiological tests and soft tissue biomarkers applicable to work-related upper limb disorders. Occupational Medicine 2000; 50 (2): 121-30.

44. Karjalainen KA, Malmivaara AO, van Tulder MW, Roine RP, Jauhiainen S, Hurri HO, Koes BW. Biopsychosocial rehabilitation for upper limb repetitive strain injuries in working age adults. Cochrane Database Systematic Reviews: 2000 (3) CD002269.

45. Konijnenberg HS, de Wilde NS, Gerritsen AA, van Tulder MW, de Vet HC. Conservative treatment for repetitive strain injury. Scandinavian Journal of Work, Environment and Health 2001; 27: 299-310.

46. Verhagen AP, Bierma-Zeinstra SM, Feleus A, Karels C, Dahaghin S, Burdorf L, de Vet HC, Koes BW. Ergonomic and physiotherapeutic interventions for treating upper extremity work related disorders in adults. Cochrane Database Systematic Reviews 2004 (1): CD003471.

47. Verhagen AP, Karels C, Bierma-Zeinstra SM, Feleus A, Dahaghin S, Burdorf A, Koes BW. Exercise proves effective in a systematic review of work-related complaints of the arm, neck, or shoulder. Journal of Clinical Epidemiology 2007; 60: 110.e1-110.e14.

48. Smidt N, de Vet HCW, Bouter LM, Dekker J. Effectiveness of exercise therapy: A best-evidence summary of systematic reviews. Australian Journal of Physiotherapy 2005; 51: 71-85.

49. Meijer EM, Sluiter JK, Heyma A, Sadiraj K, Frings-Dresen MH. Cost-effectiveness of multidisciplinary treatment in sick-listed patients with upper extremity musculoskeletal disorders: a randomized, controlled trial with one year follow-up. International Archives of Occupational and Environmental Health 2006; 79: 654- 664.

50. Bernaards C, Ariëns G, Simons M, Knol D, Hildebrandt V. Improving Work Style Behavior in Computer Workers with Neck and Upper Limb Symptoms. J Occupational Rehabilitation 2008; 18175072 (P.S.E.B.D.)

51. Feuerstein M, Nicholas RA, Huang GD, Dimberg L, Ali D, Rogers H. Job stress management and ergonomic intervention for work-related upper extremity symptoms. Applied Ergonomics 2004; 35 (6): 565-574.

52. Harrington $C B$, Siddiqui $A$, Feuerstein $M$. Workstyle as a predictor of pain and restricted work associated with upper extremity disorders: a prospective study. J Hand Surg Am 2009; 34 (4): 724-31.

53. Velden ME van, Severens JL, Novak A. Economic evaluations of healthcare programmes and decisionmaking; the influence of economic evaluations on different healthcare decision-making levels. PharmacoEconomics $2005 ; 23$ :1075- 1082. 



\section{[2] \\ The influence of work and treatment related factors on clinical status and disability in patients with non-specific work-related upper limb disorders}

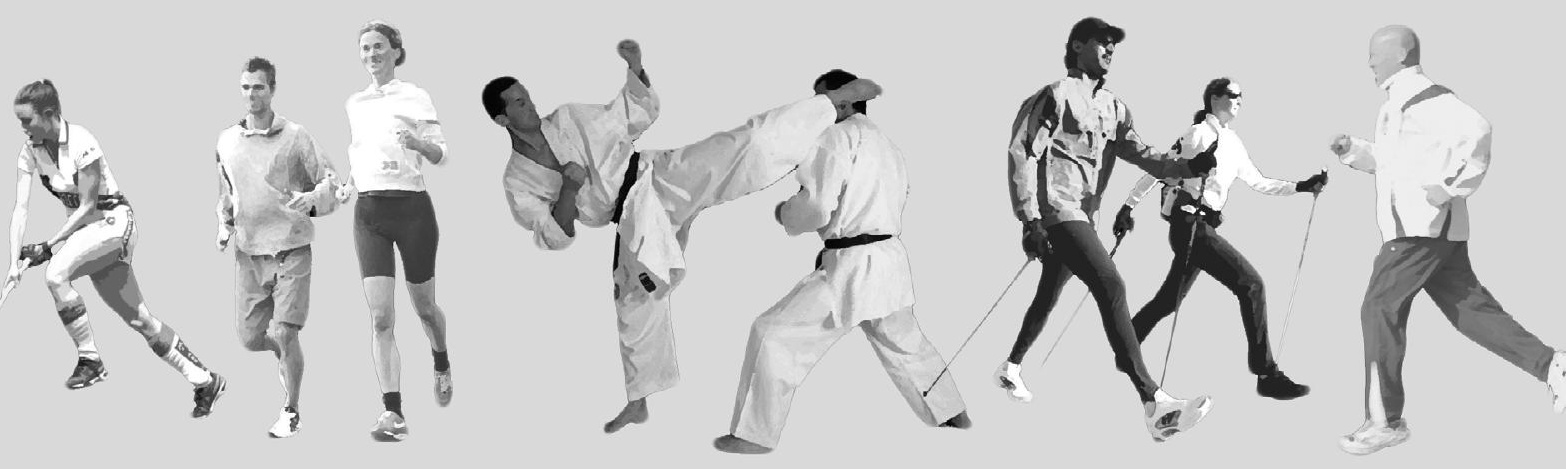

Marjon D. van Eijsden-Besseling, Karien A. van den Bergh, J. Bart Staal, Rob A. de Bie, Wim J. van den Heuvel

Accepted by journal "WORK", May 2010; in press. 


\begin{abstract}
Objective: to assess the influence of work- and treatment -related factors on clinical status and functional disability in patients with non-specific work-related upper limb disorders (WRULD).
\end{abstract}

Participants: 182 computer workers with non-specific WRULD, 18-50 years old, not having specific WRULD nor incomplete medical records.

Methods: Retrospective cohort study among computer workers with non-specific WRULD; average follow-up 4 years. Medical records at time of diagnosis and during treatment period and a follow-up questionnaire were used.

Setting: Outpatient department of Rehabilitation Medicine, University Hospital Maastricht.

Outcome measures: non-specific WRULD (clinical status) and Disabilities of Arm, Shoulder and Hand (DASH) at follow-up.

Results: 103 patients (57\%) returned the questionnaire. Of these, 14\% developed a chronic pain syndrome, $9 \%$ recovered, $77 \%$ worsened slightly.

None of the selected work- and treatment - related factors were significantly associated with clinical status. "Number of working hours per week before diagnosis " was negatively $(b=-0.66, p=0.00)$ and "other therapies during treatment" $(b=8.76, p=$ 0.02 ) positively associated with DASH.

Conclusions: computer workers with non-specific WRULD have a poor prognosis. Working more hours before diagnosis seems not predictive for disability while having undergone other therapies during treatment period does. Prospective cohort studies are recommended to unravel the associations found. 


\section{Introduction}

Approximately $25 \%$ of the employees in the Netherlands suffered from work-related neck, upper back, shoulder, arm or hand complaints. ${ }^{1,2,4,9,13}$ Due to expectations of increasing intensity of computer screen-work, the prevalence of work-related upper limb disorders (WRULD) among screen-workers is expected to increase even more. ${ }^{17,18}$ In 1998, 3000 Dutch employees (four in 10,000) received a disability pension because of work-related upper limb disorders (WRULD). ${ }^{1-3}$ This amount has increased to 6000 employees in $2001{ }^{3}$ Comparable data have been reported for other western developed countries. $^{9,13,18,19}$ In all these countries like in the Netherlands, many suffering from WRULD perform computer work. ${ }^{9,19}$

A work-related upper limb disorder is a syndrome that affects muscles, tendons and nerves in the hands, arms, shoulders, neck and upper back. This study focuses on patients with non-specific WRULD, characterized by pain or tingling sensations located in the hands, arms, shoulders, neck or upper back and not being diagnosed as a tennis elbow, tendonitis, nerve compression etc. ${ }^{18}$ Non-specific WRULD seems to occur as a result of prolonged activation of muscles, due to, among other reasons, poor posture and / or repetitive motions. ${ }^{28}$ As research has shown, WRULD causes significant job problems, absenteeism and reduction in working time and ultimately job loss. ${ }^{3,12,18}$ It seems, that work-related factors are important determinants of the disease, as is indicated by its name. ${ }^{6,18,28}$ However, from literature little is known about the predictive power of work place conditions on the course of the disease and functional disability in non-specific WRULD patients ${ }^{4,28}$ Work-related factors, such as number of working hours, experienced high work load/ job stress and work ergonomics, have their influence on working status and capacity. ${ }^{1,12}$ For clinicians and employers, it is relevant to know which work-related factors are related to the course of non-specific WRULD and functional disability over time. ${ }^{6}$ Moreover, medical overconsumption and previous nonspecific WRULD complaints which end up in disability seem to be associated with a poor outcome of the disease. ${ }^{28}$

Therefore, the purpose of this study was to investigate the influence of work - and treatment - related factors on clinical status and disability related to non-specific WRULD. To do this, a retrospective cohort study among computer screen workers with non-specific WRULD, representing a large homogeneous group at risk, was conducted.

\section{Methods}

This retrospective cohort study consisted of subjects from a group of computer screen workers. They were diagnosed with non-specific WRULD, and medically treated by a physiatrist specialized in this disorder. The project took place at the outpatient department of rehabilitation medicine, University Hospital of Maastricht; a tertiary referral centre for patients with this diagnosis. The medical records of approximately 500 
patients who were diagnosed between 1998 and 2001 were reviewed and patients were checked for eligibility. Inclusion criteria were: aged between 18 and 50 years, performing computer work for at least 20 hours per week, 4 hours per work day at the time of their first WRULD symptoms. We excluded patients with specific WRULD such as carpal tunnel syndrome, as well as those with other diseases or impairments of the musculoskeletal system that were expected to have an influence on non-specific WRULD, such as rheumatic diseases or fibromyalgia.

Eligible patients received a patient information leaflet explaining the purpose of the study in November 2003 (follow-up moment), and were subsequently asked to sign an informed consent form allowing us to use their medical charts for research purposes. Furthermore, they were asked to complete a questionnaire, which was sent within two weeks after they had provided their informed consent. The questionnaire contained questions on the clinical status of their WRULD and their disability level at that moment. The patients' medical charts were retrieved and verified systematically by a checklist registering illness characteristics, socio-demographic characteristics and history of disease. Also, work- and treatment - related factors such as number of hours screen work per day, variation in work tasks, therapies during treatment period (see below) were retrieved from medical records. As a check for response bias, the nonresponding patients were compared with the responding patients with regard to gender, age, stage of non-specific WRULD and duration of the complaints. ${ }^{5}$ This comparison was done by using t-tests, chi-square tests or non-parametric tests dependent on the type of variable that was analysed. Approval for the study design was obtained from the medical ethics committee of Maastricht University Hospital, Maastricht, the Netherlands.

\section{Course of non-specific WRULD}

Patients diagnosed with non-specific WRULD were subdivided into three different stages according to their clinical status at the time they entered the centre. ${ }^{18}$ Stage 1 meant that symptoms were only present during work; in stage 2 , symptoms were not only present during work but also in some leisure time or other daily activities. In stage 3 , symptoms were present day and night and worsened during computer work. The follow-up questionnaire included the clinical status of their WRULD (with the three stages mentioned earlier), and two additional stages: stage 0 indicating that symptoms present at time of diagnosis had since disappeared and stage 4 indicating that symptoms had become more widespread involving other parts of the body (chronic musculoskeletal pain syndrome). This classification allowed us to study the evolution of the patients' clinical status from time of diagnosis until follow-up. ${ }^{23}$ It should be noted that follow-up time varied since diagnosis could have occurred at any time from 1998 until 2001, while the follow-up assessment was in November 2003 for all patients. 
Risk factors of clinical status and disability in non-specific WRULD (independent variables)

\section{Work-related factors}

The work-related factors assessed were number of working hours per week and hours of computer screen work per day (N/sd) before diagnosis, self - experienced high work load before diagnosis (yes/no); self - experienced variation in work tasks with spreading the computer work over the day at diagnosis (yes/no), self - experienced poor work posture at diagnosis ( yes/no) and self - experienced good ergonomic work conditions at diagnosis (yes/no); reduction in number of working hours during treatment $(\mathrm{N} / \mathrm{sd}$ ) and different work during treatment period (yes/no). Assessment was based on data from the medical files and on items from validated questionnaires. ${ }^{7,8,16,17}$ For more details see. $^{21}$

\section{Treatment factors}

Treatment variables were assessed through the medical records and included percentages of non-specialized therapies before diagnosis and percentages of therapies during treatment period. These therapies included multidisciplinary rehabilitation, psychotherapy and "others" i.e. all kinds of treatments not being multidisciplinary rehabilitation or psychotherapy.

\section{Outcome variables}

\section{Dependent variables}

Two outcome variables were assessed at follow-up (November 2003). One outcome variable was the clinical status of non-specific WRULD, as described by the stages 0 through 4 (see above). The other was functional disability determined by the Disabilities of Arm, Shoulder and Hand questionnaire, Dutch Language Version (DASH-DLV) using the 0-100 score range, in which a higher score means a higher level of disability. ${ }^{27}$ The DASH is an internationally accepted functional outcome measurement and was also recently validated for non-specific WRULD. ${ }^{15}$

\section{Analysis}

The associations between independent variables and outcome variables were investigated by means of multivariable linear regression for functional disability, and multinomial logistic regression for clinical status. For both the multilinear regression analysis and the multinomial regression analysis we used the same model building strategy. We first considered the independent variables for the 'therapy' domain (i.e. nonspecialized therapies before diagnosis; multidisciplinary rehabilitation, psychotherapy and having received other therapies during treatment period). A multivariable analysis was conducted including all independent variables of the "therapy" domain as predictor variables. In the next step, the independent variable with the highest $p$-value was 
removed and the model was conducted again until no independent variables remained with $p$ values less than 0.20 . We took a cut-off value of 0.20 since a liberal $p$-value is considered to increase the chance of obtaining true predictors in small datasets, while limiting the bias in selecting coefficients. ${ }^{14,20}$ The same procedure was repeated for the independent variables of the "work" domain (i.e. the number of working hours per week, hours screen work per day and experienced high work load before diagnosis; experienced variation in tasks, poor work posture and good ergonomic work conditions at diagnosis; reduced number of working hours and different work during treatment). It should be noted that in case of the multinomial logistic regression analysis the $p$-values referring to the comparison of stage 4 (widespread pain) with stage 0 (no symptoms) were used to decide whether or not the independent variable had to be removed from the model.

The next step was to include the resulting independent variables from the 'therapy' and the 'work' domains in one model simultaneously. The independent variables with the highest $p$-values were again removed until only independent variables remained with $p$-values lower than 0.20 . The 'explained variance' of each of the final multivariable logistic regression models was calculated by means of $R^{2}$ in the case of the linear regression model and Nagelkerke's $R^{2}$ in the case of the multinomial logistic regression model. To check for collinearity between the different independent variables we calculated the Variance Inflation Factors (VIF) and the Tolerance. Collinearity was assumed to be present if VIF was higher than 10 and Tolerance was lower than $0.1{ }^{11}$ If collinearity was present, the independent variable with the highest correlation coefficient with the outcome measure was used for the multivariable analysis. Data were analyzed using SPSS 15.0 for Windows ${ }^{10}$ and $p$ values $\leq 0.05$ were considered as indicating statistical significance.

\section{Results}

From the 182 patients fulfilling the eligibility criteria and having received the follow-up questionnaire, 107 returned the questionnaire (57\%). Of these, 103 patients were eligible for analysis. Three patients were excluded because of relevant co-morbidity and one patient did not report the number of working hours per week before diagnosis. The data from the medical records of all 182 patients were checked for differences between responders and non-responders on the factors gender, age, stage of nonspecific WRULD and duration of the complaints. No significant differences were found. Table 1 presents the descriptive values of risk factors and outcome variables of the study population. Patients with worse stage of the disease have higher DASH scores (e.g.: $3.0( \pm 2.4)$ in stage $0,27.8( \pm 11.0)$ in stage 2 to 62.8 ( \pm 11.3$)$ in stage 4$)$. 
Table 1. Descriptive values of risk factors and outcome variables (DASH and clinical status) of the study population $(n=103)$

\begin{tabular}{|c|c|c|}
\hline Outcome variables & & \\
\hline Mean DASH total score (sd) & & $31.1( \pm 20.6)$ \\
\hline \multirow[t]{5}{*}{ Clinical status (number of patients in each stage) } & Stage 0 & 9 \\
\hline & Stage 1 & 24 \\
\hline & Stage 2 & 35 \\
\hline & Stage 3 & 20 \\
\hline & Stage 4 & 15 \\
\hline \multicolumn{3}{|l|}{ Independent variables } \\
\hline Non-specialized therapies before diagnosis (yes) & & $67 \%$ \\
\hline Multidisciplinary rehabilitation during treatment period (yes) & & $15 \%$ \\
\hline Psychotherapy during treatment period (yes) & & $25 \%$ \\
\hline Having received other therapies during treatment period (yes) & & $28 \%$ \\
\hline Number of working hours per week before diagnosis $(\mathrm{N})$ & & $38(s d \pm 7.3)$ \\
\hline Hours screen work per day before diagnosis $(N)$ & & $6.9(\mathrm{sd} \pm 2.0)$ \\
\hline Experienced high work load before diagnosis (yes) & & $88 \%$ \\
\hline Variation in tasks at diagnosis (yes) & & $67 \%$ \\
\hline Poor work posture at diagnosis (yes) & & $52 \%$ \\
\hline Good ergonomic work conditions at diagnosis (yes) & & $63 \%$ \\
\hline Reduction in the number of working hours during treatment $(\mathrm{N})$ & & $15 \mathrm{hrs}(\mathrm{sd} \pm 17)$ \\
\hline Different work during treatment period (yes) & & $77 \%$ \\
\hline
\end{tabular}

\section{Course of non-specific WRULD}

At time of diagnosis, 22 patients (22\%) were diagnosed as having non-specific WRULD stage 1, 71 patients (68\%) stage 2 and 10 (10\%) stage 3 (Table 2). At follow-up, $14.6 \%$ of the patients had developed a chronic musculoskeletal pain syndrome (stage 4), while $8.7 \%$ were diagnosed without further non-specific WRULD (stage 0 ). The remaining $77 \%$ had slightly worsened. The average time between diagnosis and questionnaire was 4.4 years with a range from 1.9 to 5.8 years. $^{23}$

Table 2. Course of non-specific work-related upper limb disorders according to clinical status

\begin{tabular}{lcccc}
\hline Clinical status at follow-up & \multicolumn{2}{c}{ Clinical status at baseline } & & \\
& Stage 1 & Stage 2 & Stage 3 & Total \\
\hline Stage 0 - no symptoms & 5 & 4 & 0 & 9 \\
& $22.7 \% *$ & $5.6 \%$ & $0.0 \%$ & $8.7 \%$ \\
Stage 1- symptoms only present at & 7 & 16 & 1 & 24 \\
work & $31.8 \%$ & $22.5 \%$ & $10.0 \%$ & $23.3 \%$ \\
Stage 2 - symptoms at work and & 7 & 27 & 1 & 35 \\
during other daily activities & $31.8 \%$ & $38.0 \%$ & $10.0 \%$ & $34.0 \%$ \\
Stage 3 - symptoms present day and & 1 & 15 & 4 & 20 \\
night & $4.5 \%$ & $21.1 \%$ & $40.0 \%$ & $19.4 \%$ \\
Stage 4 - symptoms extended to & 2 & 9 & 4 & 15 \\
other body parts & $9.1 \%$ & $12.7 \%$ & $40.0 \%$ & $14.6 \%$ \\
Total & 22 & 71 & 10 & 103 \\
& $100.0 \%$ & $100.0 \%$ & $100.0 \%$ & $100.0 \%$ \\
\hline
\end{tabular}

* all percentages total up only vertically 


\section{Clinical status of WRULD and DASH}

\section{Clinical status of WRULD}

According to our model building strategy only "good ergonomic work conditions" and "having received psychotherapy" were retained in the model. However, none of the hypothesized work- and treatment - related variables were significantly associated with the current clinical status (Table 3). Nagelkerke's $\mathrm{R}^{2}$ of the multinomial logistic regression model of the 2 predictors "good ergonomic work conditions" and "having received psychotherapy" was 0.18 .

Table 3. Risks factors for clinical status of patients with non-specific work-related upper limb disorders: results of multinomial logistic regression analysis

\begin{tabular}{lcccc}
\hline & $\begin{array}{c}\text { Unstandardized } \\
\text { regression } \\
\text { coefficient b }\end{array}$ & Odds ratio & $\mathbf{9 5 \%} \mathbf{C l}$ & p-value \\
\hline Stage 1 versus Stage 0 & 1.01 & 2.75 & 0.53 to 14.38 & 0.23 \\
Good ergonomic work conditions & -0.61 & 0.54 & 0.05 to 5.73 & 0.61 \\
Psychotherapy & 1.02 & 2.78 & 0.59 to 12.94 & 0.20 \\
Stage 2 versus Stage 0 & -1.05 & 0.35 & 0.04 to 3.23 & 0.35 \\
Good ergonomic work conditions & -0.10 & 0.90 & 0.18 to 4.46 & 0.90 \\
Psychotherapy & -0.75 & 0.47 & 0.05 to 4.96 & 0.53 \\
Stage 3 versus Stage 0 & & & & 0.19 \\
Good ergonomic work conditions & -1.18 & 0.31 & 0.05 to 1.82 & 0.11 \\
Psychotherapy & -1.90 & 0.15 & 0.02 to 1.53 & 0.15 \\
Stage 4 versus Stage 0 & & & & \\
Good ergonomic work conditions & & & & \\
Psychotherapy & & & & \\
\hline
\end{tabular}

\section{DASH}

The number of working hours per week before diagnosis $\left(b^{*}=-0.66, p<0.01\right.$; *indicates unstandardized coefficient) was significantly associated with a lower score for functional disability on the DASH and having received "other therapies" (other than multidisciplinary treatment and psychotherapy) during treatment period $(b=8.76, p$ $=0.02$ ) was significantly associated with a higher score on the DASH (table 4). Selfexperienced high work load before diagnosis, self-experienced good ergonomic work conditions at diagnosis and multidisciplinary rehabilitation during treatment period were not significantly associated with a higher score on the DASH.

The explained variance of the multivariable regression model consisting of five predictors ( working hours per week, high work load, good ergonomic work conditions, multidisciplinary rehabilitation, other therapies) and functional disability as outcome was 0.52 . 
Table 4. Risks factors for DASH in patients with non-specific work-related upper limb disorders: results of linear regression analysis

\begin{tabular}{lccl}
\hline & $\begin{array}{c}\text { Unstandardized regression } \\
\text { coefficient b }\end{array}$ & 95\% Cl & p-value \\
\hline Working hours per week & -0.66 & -0.86 to -0.45 & $0.00^{*}$ \\
High work load & 7.00 & -3.05 to 15.24 & 0.19 \\
Good ergonomic work conditions & 5.51 & -0.93 to 11.94 & 0.09 \\
Multidisciplinary rehabilitation & 6.30 & -2.65 to 15.24 & 0.17 \\
Other therapies & 8.76 & 1.17 to 16.35 & $0.02 *$ \\
\hline
\end{tabular}

* significant $p$-value $\leq 0.05$

\section{Discussion}

This retrospective cohort study describes the evolution of the clinical status of nonspecific WRULD in a cohort of computer screen workers who attended a tertiary referral centre for this diagnosis. The clinical status of most patients deteriorated in the follow-up period of 4.4 years (with a range from 1.9 to 5.8 years). The prognosis of the patients in this study is relatively poor as only a few patients (9, representing, $8.7 \%$ ) fully recovered from their symptoms, but $14.6 \%$ developed a chronic musculoskeletal pain syndrome and the remaining $77 \%$ had slightly worsened. The clinical status of nonspecific WRULD only improved in a quarter of the patients (Table 2).

The role of the independent variables evaluated in this study (i.e. work - and treatment -related factors), was largely absent. Of these factors, only "good ergonomic work conditions at diagnosis" and "psychotherapy during treatment period" were retained in the model for clinical status. However, both factors were not significantly associated with clinical status at the follow-up moment. Possibly, a larger study sample could have shown significant associations demonstrating a protective influence of good ergonomic work conditions and / or having received psychotherapy. Of the work- and treatment related factors only "the number of working hours before diagnosis" and "having received other therapies during treatment period" were significantly associated with disability status (DASH score). "Working more hours before diagnosis" seems not to predict disability (lower score on the DASH) while "having received other therapies during treatment period" seems to result in disability (higher score on the DASH). Taking into account the responsiveness of the DASH in non-specific WRULD ${ }^{15}$ and our finding of a unstandardized regression coefficient of -0.66 with respect to "having more working hours before diagnosis", only working about 50 hours per week before diagnosis ( 30 hours above the inclusion criterion of 20 working hours) would have resulted in a clinically relevant lower disability at follow-up. However, this study population worked on average 38 ( $s d \pm 7.3$ ) hours per week before diagnosis. 
That "working more hours before diagnosis" seems not to predict disability is in line with the findings of IJmker, showing that long duration of computer work did not predict the occurrence of upper limb disorders. ${ }^{28}$

It might be that "having received other therapies during treatment period", such as regular physiotherapy, postural exercise therapy or a mix of non-directive therapies, are associated with more disability. For instance, by regular physiotherapy and postural exercise therapy, mainly physical aspects are addressed, ${ }^{24}$ while non-specific WRULD are triggered by psychosocial ${ }^{12,28}$ and personality risk factors ${ }^{22,25,26}$ as well as physical ones. ${ }^{28}$ We suggest therefore that all these aspects should be taken into account in the treatment and not only physical ones. Also here our findings are in line with the findings of IJmker, showing that medical overconsumption was associated with a bad outcome of the disease. ${ }^{28}$ However, it should be taken into account that the magnitude of the Beta $(b=8.76 ; p=0.02)$ in this study is only moderate in comparison to the clinically relevant change for an individual person.

The lack of associations between work- and treatment -related factors and the course of non-specific WRULD may be explained by the poor quantification of the workrelated factors and the reliance on self-report questionnaire information and possibly also by a role of other (psychosocial and personal) risk factors, ${ }^{22,25,28}$ which, however, were not studied here.

Study limitations. The poor prognosis of computer screen workers with several stages of non-specific WRULD found in this study may in part be explained by a selection effect as the study population was recruited at a tertiary rehabilitation clinic and may presumably consist of patients at the more severe end of the disease spectrum.

As mentioned above, the poor quantification of the work-related factors and the reliance on self-report questionnaire information could have been a great hindrance for finding significant associations between work- and treatment-related factors and clinical status.

Characteristics at baseline were not found to differ between responders and nonresponders, implying a non-selective response. However, in this study, extrapolation of the findings (outcome measures clinical status and disability) to the total study population is not feasible as data on work- and treatment - related factors were not compared.

Large prospective cohort studies using valid and more objective methods are needed to further unravel the associations between risk factors and WRULD.

\section{Conclusions}

Computer screen workers with non-specific WRULD have a rather poor prognosis. Studying work -related factors as risk factors, only the "number of working hours before diagnosis" showed a reverse association with disability. With respect to treatmentrelated factors, disability was associated with "other therapies during treatment pe- 
riod". No associations were found with clinical status at the follow-up moment. To further unravel the associations found, a large prospective cohort study is suggested.

\section{References}

1. B.M. Blatter, S.G. van den Heuvel, P.M. Bongers, and E. de Vroome, De praktijk van sociaal-medische begeleiding en voorspellers van werkhervatting bij RSI. (Practice of social-medical support and predictors of return to work in WRULD), Doetinchem: Reed Business Information bv. (2003), 1-45.

2. B.M. Blatter, P.M. Bongers, K.O. Kraan and S. Dhondt, RSI-klachten in de werkende populatie: De mate van vóórkomen en de relatie met beeldschermwerk, muisgebruik en andere ICT gerelateerde factoren (WRULD complaints in the working population: prevalence and relation with PC-work, use of mouse and other ICT-related factors), Hoofddorp, the Netherlands: TNO Arbeid, 2000.

3. B.M. Blatter, I. Houtman, S. van den Bossche, K. Kraan and S. van den Heuvel, Gezondheidsschade en kosten als gevolg van RSI en psychosociale arbeidsbelasting in Nederland. (Health effects and costs as consequences of RSI and psychosocial work load in the Netherlands). TNO Kwaliteit van Leven / Ministerie van Sociale Zaken en Werkgelegenheid 2005. Retrieved January 27, 2009, from: http://docs.swz.nl/pdf/129/2006/129_2006_3_8656.pdf

4. P.M. Bongers, Maak werk van RSI (Take pains over WRULD), Inaugural lecture, Amsterdam, Bout \& Zonen, 2003.

5. Central Committee on Research Involving Human Subjects (CCMO), URL: http://www.ccmo.nl, 2005.

6. D.C. Cole and P.L. Hudak, Prognosis of non-specific work-related musculoskeletal disorders of the neck and upper extremity, Am J Ind Med. 29 (1996), 657-668.

7. J. De Jonge, J.A. Landeweerd and G.J.P. van Breukelen, De Maastrichtse autonomielijst: achtergrond, constructie en validering (The Maastricht autonomy list; background, construction and validation process). Gedrag en Org. 7 (1994), 27-41.

8. J. De Jonge, Job autonomy, well-being, and health: a study among Dutch health care workers, Maastricht: University Press, Maastricht, the Netherlands,1995.

9. H. De Kraker and B.M. Blatter, Prevalentiecijfers van RSI-klachten en het vóórkomen van risicofactoren in 15 Europese landen (Prevalence number of WRULD and its risk factors in 15 European countries), Tijdschr Soc Gez zorg (J Soc Health Care) 83 (2005), 8-15.

10. A. De Vocht, Basishandboek SPSS 15 voor Windows (Basic Handbook SPSS for Windows) Utrecht: Bijleveld Press, the Netherlands, 2007, pp.1-256.

11. A. Field, Discovering statistics using SPSS, Third edition, SAGE publications Ltd London, 2009.

12. C.B. Harrington, A. Siddiqui and M. Feuerstein, Workstyle as a predictor of pain and restricted work associated with upper extremity disorders: a prospective study, J Hand Surg Am. 34 (4) (2009), 724-31.

13. Health Council of the Netherlands, WRULD, Publication No. 2000/22, the Hague: Health Council of the Netherlands, 2000.

14. P.H. Helmhout, J.B. Staal, M.W. Heymans, C.C. Harts, E.J. Hendriks and R.A. de Bie, Prognostic factors for perceived recovery or functional improvement in non- specific low back pain: secondary analyses of three randomized clinical trials, Eur Spine J. 19 (4) (2010), 650-9.

15. B.M.A.Huisstede, A. Feleus, S.M.Bierma-Zeinstra, J.A. Verhaar and B.W.Koes, Is the disability of arm, shoulder, and hand questionnaire (DASH) also valid and responsive?, Spine 34 (4) (2009), E 130-8.

16. J. Kennes, RSI bij beeldschermwerkers: cross-sectioneel onderzoek op het GAK Heerlen en Maastricht met behulp van een vragenlijst (WRULD in PC-workers: cross-sectional study at GAK- office Heerlen and Maastricht with the help of a questionnaire), Maastricht: University Maastricht, the Netherlands, 2001.

17. N. Orbon, RSI bij beeldschermwerkers. Baseline-meting van een longitudinaal cohort-onderzoek op het GAK Zuid Limburg (WRULD in PC-workers. Baseline measurement of a longitudinal cohort- study at GAKoffice South- Limburg) Maastricht: Universiteit Maastricht, the Netherlands, 2002.

18. K.J. Peereboom cs, RSI Handboek (RSI Handbook) $4^{\text {th }}$ Edition, The Hague, the Netherlands: Sdu Editors, $2005 / 2006$. 
19. J.B. Staal, R.A.de Bie and E.J.M. Hendriks: Aetiology and management of work-related upper extremity disorders, Best Pract \& Research Clin Rheumat. 21 (1) (2007),123-133.

20. E.W. Steyerberg, M.J. Eijkemans and F.E. Harrell Jr et al, Prognostic modelling with logistic regression analysis: in search of a sensible strategy in small data sets, Med Decis Making 21 (1) (2001), 45-56.

21. K.A.M. Van den Bergh, RSI en dan? Retrospectief cohort onderzoek naar factoren die het beloop van aspecifieke RSI bij beeldschermwerkers op de lange en middenlange termijn bepalen (WRULD and then? Retrospective cohort-study on factors determining the course of non-specific WRULD in PC-workers on the long and middle-long term), Maastricht, University Maastricht, 2004.

22. S.G. Van den Heuvel, A.J. van der Beek, B.M. Blatter, and P.M. Bongers. Workstyle and overcommitment in relation to neck and upper limb symptoms, Int J Behav Med. 14 (1) (2007), 12-20.

23. M.D.F. Van Eijsden-Besseling, K.A.M. van den Bergh, J.B. Staal, R.A. de Bie and W.J.A. van den Heuvel, The course of work-related upper limb disorders and the influence of demographic factors, psychological factors and physical fitness on clinical status and disability, Arch Phys Med Rehab. 91 (6) (2010), 862-867.

24. M.D.F. Van Eijsden-Besseling, J.B. Staal, A. van Attekum, R.A. de Bie and W.J.A. Van den Heuvel, No differences between postural exercises and strength and fitness exercises for early, non- specific, workrelated upper limb disorders in visual display unit workers: a randomized trial, Austr J Phys. 54 (2) (2008), 95-101.

25. M.D.F. Van Eijsden-Besseling, F.P.M.L.Peeters, J.A.W. Reijnen and R.A. Bie, Perfectionism and coping strategies as risk factors for the development of non-specific work-related upper limb disorders, Occup Med. 54 (2) (2004), 122-127.

26. M.D.F. Van Eijsden-Besseling, A. van Attekum, R.A. de Bie and J.B. Staal. Pain catastrophizing and lower physical fitness in a sample of computer screen workers with early non-specific upper limb disorders; a case control study, Industrial Health, Accepted for publication Jan 2010; in press.

27. M.M. Veehof, E.J. Sleegers, N.H. van Veldhoven, A.H. Schuurman and N.L. Van Meeteren, Psychometric qualities of the Dutch language version of the Disabilities of the Arm, Shoulder, and Hand questionnaire (DASH-DLV), J Hand Ther. 15 (2002), 347-354.

28. S. IJmker, Risk factors for arm-wrist-hand and neck-shoulder symptoms among office workers, A longitudinal perspective, PhD Thesis, EMGO (Institute for Research in Extramural Medicine of the VU University Medical Center) Institute, Amsterdam, the Netherlands, 2008. 


\section{[3] \\ The course of nonspecific work-related upper limb disorders and the influence of demographic factors, psychologic factors, and physical fitness on clinical status and disability}

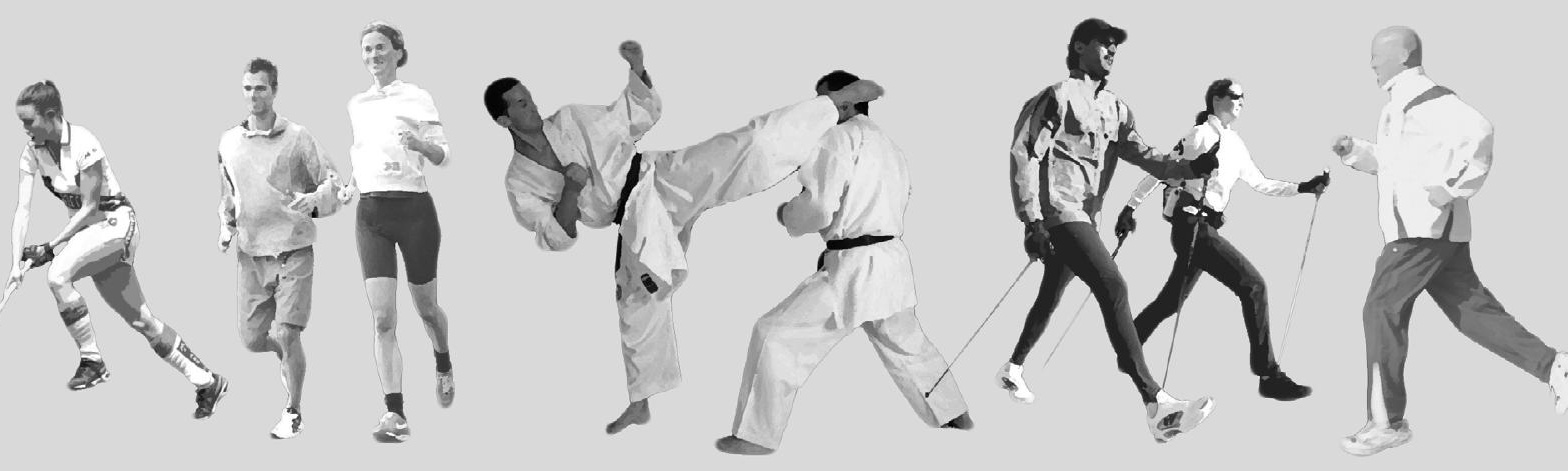

Marjon D. van Eijsden-Besseling, Karien A. van den Bergh, J. Bart Staal, , Rob A. de Bie, , Wim J. van den Heuvel

Published: Archives of Physical Medicine and Rehabilitation 2010; 91 (6); 862-67. 


\begin{abstract}
Objective: To assess the course of nonspecific work-related upper limb disorders (WRULD) and the influence of sociodemographic factors, psychologic factors, and physical fitness on clinical status and functional disability.

Design: Retrospective cohort study with cross-sectional analysis among computer workers with several stages of nonspecific WRULD; average follow-up 4 years. Sociodemographic and medical characteristics were assessed based on medical records at onset and diagnosis. After informed consent at follow-up, participants received a questionnaire assessing psychologic and physical fitness characteristics.

Setting: Outpatient department of rehabilitation medicine, University Hospital Maastricht; tertiary referral center for nonspecific WRULD.

Participants: Computer workers ( $N=182$ ) with nonspecific WRULD, 18 to 50 years, first consultation 1998 to 2001; those with specific WRULD and incomplete medical records and treatment charts were excluded.

Interventions: Not applicable.

Main Outcome Measures: Stage of nonspecific WRULD (clinical status) and Disabilities of Arm, Shoulder and Hand questionnaire [DASH] (functional disability).

Results: A total of 104 patients (57\%) returned the completed questionnaire at followup (November 2003). Fourteen percent developed chronic benign pain syndrome, $9 \%$ recovered. The remaining (77\%) worsened slightly. A higher DASH score was associated with being elderly (unstandardized regression coefficient $[B=.64]$ ), being a woman ( $B$ $=10.42)$, having a lower educational achievement $(B=9.72)$, and poorer selfreported physical fitness level $(B=1.68)$; lower educational achievement and poorer selfreported physical fitness were associated with a more severe clinical status. Psychologic factors did not influence disability or clinical status.
\end{abstract}

Conclusions: The prognosis of computer workers with nonspecific WRULD is not favorable. Those with a lower educational achievement and poorer self-reported physical fitness are at risk for a more severe clinical status and functional disability. Being elderly and a woman are also risk factors for further disability. A prospective cohort study is needed to unravel these relationships. Nevertheless, computer workers with nonspecific WRULD should be encouraged to enter fitness programs. 


\section{Introduction}

The etiology of nonspecific WRULD is unknown, but factors such as physical and psychosocial conditions and personality and sociodemographic characteristics may play a role in the development and course of nonspecific WRULD. ${ }^{1-4}$

Nonspecific WRULD is characterized by pain or tingling sensations located in the arms, shoulders, neck, or upper back without a clear pathophysiologic substrate. ${ }^{5}$ In the Netherlands, medical expenses, decreased productivity, absenteeism, and disability pensions ensuing from specific and nonspecific WRULD result in total costs that are excessive. ${ }^{5}$ In addition, sick-listed employees with this syndrome experience personal distress and decreased quality of life. ${ }^{6}$ Computer screen workers are particularly at risk for nonspecific WRULD. In 2000, the Dutch full-time working population had the highest percentage (33\%) in Europe using computers, ${ }^{5}$ making nonspecific WRULD an important issue to address when studying computer screen workers. In other European countries ${ }^{7}$ and continents, ${ }^{8,9}$ WRULD have also become an important issue and topic for research.

In a case-control study, we found that neuroticism and neurotic perfectionism may be important risk factors in the development of nonspecific WRULD in computer screen workers. ${ }^{2}$ Recently, van den Heuvel ${ }^{3}$ found a relationship between WRULD complaints and an extreme dedication to one's job, while work style (concept "work style" developed by Feuerstein et $\mathrm{al}^{10}$ ) had an intermediate effect. ${ }^{11}$ Extreme job dedication is related to the concept "perfectionism," ${ }^{2}$ in other words, the tendency to execute all activities in a perfect way. Palmer ${ }^{12}$ reports on the growing body of evidence linking WRULD to physical risk factors in the workplace (eg, repetition, duration, short cycle time, awkward posture), physical condition, and also psychosocial factors. He postulated that physically fit people could be at a lower risk for developing nonspecific WRULD.

Psychologic characteristics of interest, other than perfectionism, may be trait anxiety ${ }^{13}$ and (pain) catastrophizing. Patients who catastrophize aggravate pain by incorrect (self) beliefs and inadequate behavior response when in pain. Until now, little research has been done on the relationship between nonspecific WRULD and catastrophizing. ${ }^{14}$ The literature illustrates that, in patients with chronic pain, catastrophizing plays an important role in experienced pain intensity and level of disability. ${ }^{15-17} \mathrm{~A}$ high score on the pain catastrophizing scale was found in computer screen workers with beginning nonspecific WRULD complaints. ${ }^{18}$ Etiologic research in WRULD concentrates on workrelated risk factors, ${ }^{1,19-21}$ but research on psychologic characteristics and sociodemographic factors is limited. $2,3,11,22$

To arrive at a better understanding of the course of nonspecific WRULD and which sociodemographic, psychologic, and physical fitness characteristics influence clinical status and disability, we conducted a retrospective cohort study among computer screen workers who were treated at the department of rehabilitation medicine in our 
hospital. We investigated the course of nonspecific WRULD and in a cross-sectional analysis the influence of sociodemographic, psychologic, and physical fitness characteristics on clinical status and functional disability.

\section{Methods}

This retrospective cohort study with cross-sectional analysis at the end of follow-up was set up among computer screen workers who had been diagnosed with nonspecific WRULD and had undergone medical treatment by a physiatrist specialized in this disorder. The project took place at the outpatient department of rehabilitation medicine, University Hospital of Maastricht; a tertiary referral center for patients with this diagnosis. The medical records of approximately 500 patients who were diagnosed between 1998 and 2001 were reviewed, and patients were checked for eligibility. Inclusion criteria were subjects aged between 18 and 50 years, performing computer work for at least 20 hours per week and 4 hours per day at the onset of their first WRULD symptoms. We excluded subjects with specific types of WRULD, as well as those with other diseases or impairments of the musculoskeletal system. Eligible patients received a patient information leaflet explaining the purpose of the study in November 2003, and were subsequently asked to sign an informed consent form allowing us to retrieve their medical charts for research purposes. Furthermore, they were asked to complete a questionnaire, which was sent within 2 weeks after they had provided their informed consent. The patients' medical charts were retrieved and verified systematically by a checklist registering illness characteristics, sociodemographic characteristics, and history of disease. As a check for selective response, the characteristics of the nonresponding patients were reviewed following the rules of the Central Committee on Research Involving Human Subjects in the Netherlands. ${ }^{23}$

Approval for the study design was obtained from the medical ethics committee of Maastricht University Hospital, Maastricht, the Netherlands.

\section{Course of nonspecific WRULD}

Patients with nonspecific WRULD were subdivided into 3 different stages according to their clinical status at the time they entered our center. ${ }^{5}$ Stage 1 meant that symptoms were only present during work, while in stage 2 , symptoms were not only present during work but also in some leisure time or other daily activities. In stage 3 , symptoms were present day and night and worsened during computer work. After clinical assessment, various types of (usual) care such as postural exercise therapy, physiotherapy, occupational therapy, and/or combined with psychologic counseling were provided. The questionnaire was mailed to the participants in November 2003 and contained questions on the clinical status of their WRULD at that moment. Based on those questions we added 2 stages to the earlier mentioned 3 stages. Stage 0 indicated that symp- 
toms at the time of diagnosis in the meantime had disappeared, and stage 4 indicated that symptoms had become more widespread involving other parts of the body (chronic benign pain syndrome). This classification enabled us to study the evolution of the patients' clinical status from the time of diagnosis until the follow-up measurement. It should be noted that follow-up time varies because patients may have entered our department anytime in the period from 1998 until 2001, whereas the follow-up assessment was in November 2003 for all participants.

\section{Risk factors of clinical status and disability in nonspecific WRULD}

Besides sociodemographic data, retrieved from medical records, the questionnaire combined existing scales and standard questions on psychologic factors and physical fitness. ${ }^{5}$ In the cross-sectional analysis we considered these variables as potential predictors of the clinical status and functional disability of patients with nonspecific WRULD.

Based on the literature, ${ }^{2,3,5,24}$ the sociodemographic risk factors we took into account were sex, age, and education. At the time of diagnosis, educational level was dichotomized whereby a "lower educational achievement" was less than a bachelor's degree. The following validated scales were used to assess psychologic and physical fitness characteristics: (1) The Multidimensional Perfectionism Scale measured (neurotic) perfectionism (range, 35-175); a higher score indicates a higher level of perfectionism, ${ }^{2}$ whereby the validation study reported a Cronbach alpha of $.73 .{ }^{25}$ (2) The Trait Anxiety Inventory assessed trait anxiety (range, 20-80); a higher score indicates increased trait anxiety. ${ }^{13,26,27}$ Cronbach alpha was found to be $.93 .^{13}$ (3) On the Pain Catastrophizing Scale (range, $0-52$ ), a higher score indicates increased pain catastrophizing behavior. $^{28,29}$

Cronbach alpha was reported to vary between .85 and $.93 .^{28,29}$ (4) The Groningen selfreported physical fitness test for the elderly assessed general physical fitness (range, 9 -45); a higher score reflects a lower fitness level. ${ }^{30}$ Cronbach alpha of this scale was reported to be $85 .^{31}$ 
Table 1: Descriptive Values of Risk Factors and Outcome Variables of the Study Population ( $n=104)$

\begin{tabular}{lc}
\hline Variables & Values \\
\hline Outcome Variables & \\
DASH total score & $31.1 \pm 20.6$ \\
Clinical status & \\
$\quad$ Stage 0 & 24 \\
Stage 1 & 36 \\
Stage 2 & 20 \\
Stage 3 & 15 \\
Stage 4 & \\
Risk factors & $39.1 \pm 7.1$ \\
Age (y) & 57 \\
Sex, female & 45 \\
Lower educational achievement & $28.4 \pm 5.9$ \\
Self-reported physical fitness (9-45 points) & $40.5 \pm 11.3$ \\
Trait anxiety (20-80 points) & $20.7 \pm 11.2$ \\
Pain catastrophizing (0-52 points) & $89.8 \pm 23.1$ \\
Perfectionism (35-175 points) & \\
\hline
\end{tabular}

NOTE. Values are mean \pm SD or $n$.

\section{Outcome Variables}

Two outcome variables were assessed at follow-up (November 2003). The first outcome variable was the clinical status of nonspecific WRULD as described by the stages 0 through 4 (see Course of non-specific WRULD). As a secondary outcome variable, we used functional disability as measured with the DASH-DLV (Dutch Language Version) using the 0 to 100 score range, in which a higher score means a higher level of disability. ${ }^{32}$ The DASH is an internationally accepted functional outcome measurement that recently was validated for nonspecific WRULD. ${ }^{33}$

\section{Analysis}

Data were analyzed using SPSS 15.0 for Windows. To check for selective response, $t$ tests and 1-way analysis of variance analyses were conducted on data reflecting illness characteristics, sociodemographic characteristics, and history of disease from the medical charts of respondents and nonrespondents. The associations between risk factors and outcome variables were investigated by means of multivariable linear regression for the outcome variable DASH and multinomial logistic regression for the outcome variable clinical status. To check for collinearity between the different risk factors, we calculated the variance inflation factors and the tolerance. Collinearity was assumed to be present if variance inflation factors were higher than 10; in other words, tolerance lower than 0.1. Correlation coefficients between the risk factors and the outcome variables were calculated. When collinearity was present, the risk factor with the highest correlation with the outcome measure was used. For the outcome DASH, a multivariable analysis was conducted with all potential risk factors as predictor vari- 
ables. For the outcome clinical status, we followed a stepwise approach to increase statistical power, which can be limited when the outcome variable is categorical rather than continuous. We first investigated the bivariate associations between the candidate risk factors and clinical status. Risk factors with a $P$ value less than .20 were entered in the final model. The "explained variance" of each of the multivariable regression models was calculated by means of $R^{2}$ in the case of the linear regression model and Nagelkerke $R^{2}$ in the case of the multinomial logistic regression model.

\section{Results}

From the 182 patients fulfilling the eligibility criteria and having received the follow-up questionnaire, 107 returned the questionnaire, of which 104 were eligible for analysis. Three patients were excluded because of relevant comorbidity. The response rate was $57 \%$.

The medical charts of all 182 patients were checked for differences between respondents and nonrespondents on factors of sex, age, stage of nonspecific WRULD, and duration of complaints. No significant differences were found (data not shown). Table 1 presents the descriptive values of risk factors and outcome variables of the study population.

\section{Course of nonspecific WRULD}

Baseline. At baseline (ie, time of diagnosis), 23 patients (22\%) were diagnosed as having nonspecific WRULD stage 1 , while 71 patients (68\%) were diagnosed as stage 2 , and $10(10 \%)$ as stage 3 . Complaints had been experienced for an average \pm SD of $34 \pm 32$ months. In table 2, the course of clinical status from baseline to follow-up is presented. Follow-up. At follow-up, $14 \%$ of the patients had developed a chronic benign pain syndrome (stage 4), while $9 \%$ were diagnosed without further nonspecific WRULD (stage 0 ). The remaining $77 \%$ worsened slightly; in other words, among patients with symptoms only at work (stage 1 ) at baseline, only $22 \%$ were free of symptoms at follow-up. Among those who had symptoms at work and during other daily activities at baseline (stage 2), 38\% remained in the same category at follow-up, while the situation of $34 \%$ of the study population had deteriorated (see table 2). The average time \pm SD between diagnosis (ie, baseline) and questionnaire was $53 \pm 11$ months.

\section{DASH and clinical status of WRULD}

DASH. A higher DASH score was significantly associated with being elderly, being a woman, and having a lower educational achievement and a poorer self-reported physical fitness (table 3). Trait anxiety, pain catastrophizing, and perfectionism were not significantly associated with a higher score on the DASH (see table 3). The multivariable 
regression model consisting of 7 predictors explained $57 \%$ of the variance in DASH scores.

Clinical status of WRULD. Lower educational achievement and poorer self-reported physical fitness level were significantly associated with a more severe clinical status of WRULD. The odds ratio for lower educational achievement is 10.44 when comparing stage 3 versus stage 0 and 12.10 when comparing stage 4 versus stage 0 . The odds ratio for poorer self-reported physical fitness is 1.31 when comparing stage 3 versus stage 0 and 1.83 when comparing stage 4 versus stage 0 (Table 4). The multinomial logistic regression model consisting of 2 predictors explained $41 \%$ of the variance in clinical status.

Table 2: Course of nonspecific WRULD according to clinical status

\begin{tabular}{lcccc}
\hline & \multicolumn{3}{c}{ Clinical Status at Baseline } \\
Clinical Status at Follow-Up & Stage 1 & Stage 2 & Stage 3 & Total \\
\hline Stage 0 (no symptoms) & $5(21.7)$ & $4(5.6)$ & $0(0.0)$ & $9(8.7)$ \\
Stage 1 (symptoms only present at work) & $7(30.4)$ & $16(22.5)$ & $1(10.0)$ & $24(23.1)$ \\
Stage 2 (symptoms at work and during other daily & $8(34.8)$ & $27(38.0)$ & $1(10.0)$ & $36(34.6)$ \\
activities) & & & & \\
Stage 3 (symptoms present day and night) & $1(4.3)$ & $15(21.1)$ & $4(40.0)$ & $20(19.2)$ \\
Stage 4 (symptoms extended to other body parts) & $2(8.7)$ & $9(12.7)$ & $4(40.0)$ & $15(14.4)$ \\
Total & $23(100.0)$ & $71(100.0)$ & $10(100.0)$ & $104(100.0)$ \\
\hline
\end{tabular}

NOTE. Values are $n(\%)$.

Table 3: Risk factors for DASH in patients with nonspecific WRULD: results of linear regression analysis

\begin{tabular}{lccc}
\hline Risk Factor & $\mathbf{B}^{*}$ & $\mathbf{9 5 \%} \mathbf{C l}$ & $\boldsymbol{P}$ \\
\hline Age (y) & 0.64 & 0.23 to 1.06 & 0.00 \\
Sex, women & 10.42 & 4.12 to 16.72 & 0.00 \\
Lower educational achievement & 9.72 & 15.98 to 3.46 & 0.00 \\
Poorer self-reported physical fitness level & 1.68 & 1.14 to 2.22 & 0.00 \\
Trait anxiety & 0.21 & -0.12 to 0.54 & 0.22 \\
Pain catastrophizing & 0.07 & -0.23 to 0.38 & 0.63 \\
Perfectionism & -0.19 & -0.17 to 0.13 & 0.80 \\
\hline
\end{tabular}

Abbreviation: $\mathrm{Cl}$, confidence interval; *Unstandardized regression coefficient.

\section{Discussion}

The present study demonstrates the course of development of the clinical status of nonspecific WRULD in a cohort of computer screen workers who attended a tertiary referral center for this diagnosis.

All eligible patients were identified by retrieval of their medical records and received a questionnaire by post. Comparisons on demographic characteristics between respondents and nonrespondents revealed no differences.

Although the follow-up time varied in this study population (on the average $53 \mathrm{mo}$ with a range from $23-70 \mathrm{mo}$ ), we investigated the evolution of clinical status of the partici- 
pants by considering their symptom progression. The prognosis of the patients in this study is relatively poor because few patients (only 9 patients, representing 9\%) fully recovered from their symptoms, while $14 \%$ developed a chronic benign pain syndrome and the remaining $77 \%$ worsened slightly (see table 2 ). This study further illustrates that several factors are related with nonspecific WRULD in computer screen workers. Being elderly, being a woman, and having a lower educational achievement and a poorer self-reported physical fitness level were associated with greater functional disability as measured by the DASH questionnaire. Of these variables only lower educational achievement and poorer self-reported physical fitness level appeared to be associated with poor clinical status. The role of education seems consistent and may be explained by inadequate coping styles to deal with the disease. ${ }^{2}$

It should be noted that these analyses are cross-sectional, implying that a poorer selfreported physical fitness level may have preceded the symptoms or instead may be the result of symptom burden. However, these findings present arguments when studying the role of physical fitness to improve health status among nonspecific WRULD patients in line with the findings of Proper et al. ${ }^{34}$ This despite the fact that a recent study illustrated that the role of decreased physical capacity on future musculoskeletal complaints is not yet fully clarified. ${ }^{35}$

The factors "being elderly" and "being female" are apparently predisposing for a high score on the DASH in patients with WRULD.

\section{Study Limitations}

The poor prognosis of computer screen workers with several stages of nonspecific WRULD found in this study may in part be explained by a selection effect, because the study population was selected at a tertiary rehabilitation clinic and may presumably consist of patients at the more severe end of the disease spectrum. On the other hand, these poor prognoses indicate that effective treatment options for these types of pain syndromes are warranted.

A notable finding concerns the role of psychologic characteristics; some of these, such as perfectionism, overcommitment, trait anxiety, and catastrophizing, are considered important triggers for the onset of nonspecific WRULD. ${ }^{2,11,13,36}$

Because the effect of psychologic factors on the course of the disease or disability has not yet been clearly addressed, ${ }^{14}$ their influence remains unclear. In this study, trait anxiety, pain catastrophizing, and perfectionism do not appear to influence disability or clinical status (see table 3). One explanation may be that this study is measuring these psychologic characteristics at follow-up being on the average 53 months after diagnosis was assessed. In this period, various circumstantial factors (lifestyle, social economic situation, psychologic status, social support) may have altered, influencing health status 4 years later. The effect of psychologic characteristics may become less pronounced over time. At the same time, these psychologic characteristics are considered 
to be "traits," implying that they are subject-specific and do not change substantially over time. A recent case-control study among computer screen workers with nonspecific WRULD ${ }^{36}$ shows that, even in case of chronic nonspecific WRULD complaints, not all participants react with pain catastrophizing behavior. Further research on the impact of psychologic and fitness characteristics at the onset and course of nonspecific WRULD is encouraged. In particular, prospective cohort study designs would be preferable.

However, the associations found in this study suggest that stimulation of physical fitness and activity might be a valuable protective strategy against the burden of nonspecific WRULD.

Table 4: Risk factors for clinical status of patients with nonspecific WRULD: results of multinomial logistic regression analysis

\begin{tabular}{|c|c|c|c|c|}
\hline Risk Factor & B* & Odds Ratio & $95 \% \mathrm{Cl}$ & $P$ \\
\hline \multicolumn{5}{|l|}{ Stage 1 versus stage 0} \\
\hline Lower educational achievement & 0.87 & 2.39 & $0.23-25.38$ & 0.47 \\
\hline Poorer self-reported physical fitness level & 0.18 & 1.19 & $0.97-1.45$ & 0.07 \\
\hline \multicolumn{5}{|l|}{ Stage 2 versus stage 0} \\
\hline Lower educational achievement & 1.79 & 5.98 & $0.62-57.55$ & 0.12 \\
\hline Poorer self-reported physical fitness level & 0.22 & 1.25 & $1.03-1.51$ & 0.02 \\
\hline \multicolumn{5}{|l|}{ Stage 3 versus Stage 0} \\
\hline Lower educational achievement & 2.25 & 10.44 & $0.99-110.51$ & 0.05 \\
\hline Poorer self-reported physical fitness level & 0.27 & 1.31 & $1.07-1.60$ & 0.01 \\
\hline \multicolumn{5}{|l|}{ Stage 4 versus stage 0} \\
\hline Lower educational achievement & 2.50 & 12.1 & $0.87-168.7$ & 0.06 \\
\hline Poorer self-reported physical fitness level & 0.61 & 1.83 & $1.40-2.39$ & 0.00 \\
\hline
\end{tabular}

Abbreviation: $\mathrm{Cl}$, confidence interval; *Unstandardized regression coefficient.

\section{Conclusions}

The prognosis of computer screen workers with nonspecific WRULD is not favorable. Those with a lower educational achievement and a poorer self-reported physical fitness are at risk for a more severe clinical status and functional disability. Being elderly and a woman are also risk factors for further disability. Psychologic characteristics did not appear to play a role in predicting the health outcome among these patients. A further prospective cohort study is needed to unravel the intricacy of these relationships. However, the associations found in this study suggest that computer screen workers with nonspecific WRULD should be encouraged to enter fitness programs Table 4.

\section{References}

1. Health Council of the Netherlands. RSI. The Hague: Health Council of the Netherlands; Publication No. 2000/22E., Available at: http://neurologiadeltrabajo.sen.es/pdf/rsi_report_curso2000_nt. pdf. Accessed November 1, 2005. 
2. van Eijsden-Besseling MD, Peeters FP, Reijnen JA, de Bie RA. Perfectionism and coping strategies as risk factors for the development of non-specific work-related upper limb disorders (WRULD). Occup Med 2004;54:122-7.

3. van den Heuvel S. Work-related neck and upper limb symptoms [PhD thesis] 2006; Amsterdam. Toegepast Natuurwetenschappelijk Onderzoek.

4. Feleus A, Bierma-Zeinstra SM, Miedema HS, et al. Prognostic indicators for non-recovery of nontraumatic complaints at arm, neck and shoulder in general practice- 6 months follow-up. Rheumatology 2007;46:169-76.

5. Peereboom KJ, et al. RSI handboek. 4th ed. The Hague, the Netherlands: Sdu Editors; 2005/2006.

6. Sluiter JK, Frings-Dresen MH. Quality of life and illness perception in working and sick-listed chronic RSI patients. Int Arch Occup Environ Health 2008;81:495-501.

7. Cabeças JM. Occupational musculoskeletal disorders in Europe: impact, risk factors and preventive regulations. Enterprise Work Innovation Stud 2006;2:95-104.

8. Yassi A. Repetitive strain injuries. Lancet 1997;349:943-7.

9. Feuerstein M, Nicholas RA, Huang GD, Dimberg L, Ali D, Rogers H. Job stress management and ergonomic intervention for work-related upper extremity symptoms. Appl Ergon 2004;35:565-74.

10. Feuerstein M, Nicolas RA, Huang GD, Haufler AJ, Pransky G, Robertson M. Work style: development of a measure of response to work in those with upper extremity pain. J Occup Rehabil 2005;15:87-104.

11. van den Heuvel SG, van der Beek AJ, Blatter BM, Bongers PM. Workstyle and overcommitment in relation to neck and upper limb symptoms. Int J Behav Med 2007;14:12-20.

12. Palmer K. Pain in the forearm, wrist and hand. Best Pract Res Clin Rheumatol 2003;17:113-35.

13. Roelofs PD. RSI en persoonsgebonden factoren: een oriënterende studie [RSI, personal and personality factors: an explorative study] [thesis]. Maastricht: Maastricht University; 2002.

14. Karels $\mathrm{CH}$, Bierma-Zeinstra SM, Burdorf A, Verhagen AP, Nauta AP, Koes BW. Social and psychological factors influenced the course of arm, neck and shoulder complaints. J Clinical Epidemiol 2007;60:839-48.

15. Severeijns R, van den Hout MA, Vlaeyen JW, Picavet HS. Pain catastrophizing and general health status in a large Dutch community sample. Pain 2002;99:367-76.

16. Sullivan MJ, Stanish W, Waite $H$, Sullivan M, Tripp DA. Catastrophizing, pain and disability in patients with soft-tissue injuries. Pain 1998;77:253-60.

17. Lame IE, Peters ML, Vlaeyen JW, Kleef M, Patijn J. Quality of life in chronic pain is more associated with beliefs about pain than with pain intensity. Eur J Pain 2005;9:15-24.

18. van Eijsden-Besseling MD, Staal JB, van Attekum A, de Bie RA, van den Heuvel WJ. No differences between postural exercises and strength and fitness exercises for early, non-specific, workrelated upper limb disorders in visual display unit workers: a randomized trial. Aust J Physiother 2008;54:95-101.

19. Sluiter JK, Rest KM, Frings-Dresen MH. Criteria document for evaluation of the work-relatedness of upper extremity musculoskeletal disorders. Scand J Work, Environ Health 2001;27(Suppl 1):1-102.

20. Most IG. Psychosocial elements in the work environment of a large call center operation. Occup Med 1999;14:135-47.

21. MacFarlane GJ, Hunt IM, Silman AJ. Role of mechanical and psychosocial factors in the onset of forearm pain: prospective population based study. Br Med J 2000;321:1-5.

22. Picavet HS, van Gils HW, Schouten JSAG. Klachten van het bewegingsapparaat in de Nederlandse bevolking. Prevalenties, consequenties en risicogroepen [Complaints of locomotor apparatus in the Dutch population. Prevalence, consequences and risk groups]. 2000; Bilthoven: Rijksinstituut voor Volksgezondheid en Milieu hygiene. RIVM-rapport 266807002.

23. Guidelines according to Central Committee on Research Involving Human Subjects. Available at: http://www.ccmo.nl. Accessed: May 2005.

24. Bongers PM. Inaugural lecture. Maak werk van RSI [Take pains over WRULD]. Amsterdam: Bout \& Zonen; 2003.

25. Flos $\mathrm{CH}$. Validiteit en betrouwbaarheid van de Multidimensionaal Perfectionisme Schaal [Validity and reliability of the "Multidimensional Perfectionism Scale"] [thesis]. Maastricht: Maastricht University, FdGW [Faculty of Health Sciences]; 1998. Faculty FdGW no. 1998317. 
26. van der Ploeg HM, Defares PB, Spielberger CD. Handleiding bij de zelfbeoordelingsvragenlijst ZBV. Een Nederlandse bewerking van de Spielberger State-Trait Anxiety Inventory STAI-DY [Manual to the self assessment questionnaire. A Dutch version of the Spielberger State-Trait anxiety inventory STAI-DY]. Lisse: Swets \& Zeitlinger B.V.; 1980.

27. Iwata N, Mishima N, Shimizu T, et al. Positive and negative affect in the factor structure of the State-Trait Anxiety Inventory for Japanese workers. Psychol Rep 1998;82:651-6.

28. van Damme S, Crombez G, Vlaeyen JW, Goubert L, van den Broek A, van Houdenhove B. De Pain Catastrophizing Scale: psychometrische karakteristieken en normering [Psychometric characteristics and standards]. Behav Ther 2000;33:209-19.

29. Sullivan MJ, Bishop SR, Pivik J. The pain catastrophizing scale: development and validation. Psycholog Assess 1995;7:524-32.

30. van Heuvelen MJ, Kempen GI, Ormel J, de Greef MH. Selfreported physical fitness of older persons: a substitute for performance-based measures of physical fitness? J Aging Phys Health 1997;5:298-310.

31. Lemmink K, Kemper H, de Greef M, Rispens P, Stevens M. Reliability of the Groningen Fitness Test for the Elderly. J Aging Phys Activity 2001;9:194-212.

32. Veehof MM, Sleegers EJ, van Veldhoven NH, Schuurman AH, van Meeteren NL. Psychometric qualities of the Dutch language version of the disabilities of the arm, shoulder and hand questionnaire (DASH-DLV). J Hand Ther 2002;15:347-54.

33. Huisstede BM, Feleus A, Bierma-Zeinstra SM, Verhaar JA, Koes BW. Is the disability of arm, shoulder, and hand questionnaire (DASH) also valid and responsive. Spine 2009;34: E130-8.

34. Proper KI, Staal JB, Hildebrandt VH, van der Beek AJ, van Mechelen W. Effectiveness of physical activity programs at worksites with respect to work-related outcomes. Scand J Work Environ Health 2002;28:7584.

35. Hamberg-van Reenen HH. Physical capacity and work-related musculoskeletal symptoms [PhD thesis]. Amsterdam: EMGO Institute; 2008.

36. van Eijsden-Besseling MD, van Attekum A, de Bie RA, Staal JB. Pain catastrophizing and lower physical fitness in a sample of computer screen workers with early non-specific upper limb disorders; a case control study. (Published Special Edition EJP: no.136 Abstract book congress Pain in Europe 6; Lisboa 2009) Accepted for publication in Industrial Health Jan 2010; in press. 


\section{[4]}

Perfectionism and coping strategies as risk factors for the development of non-specific work-related upper limb disorders (WRULD)

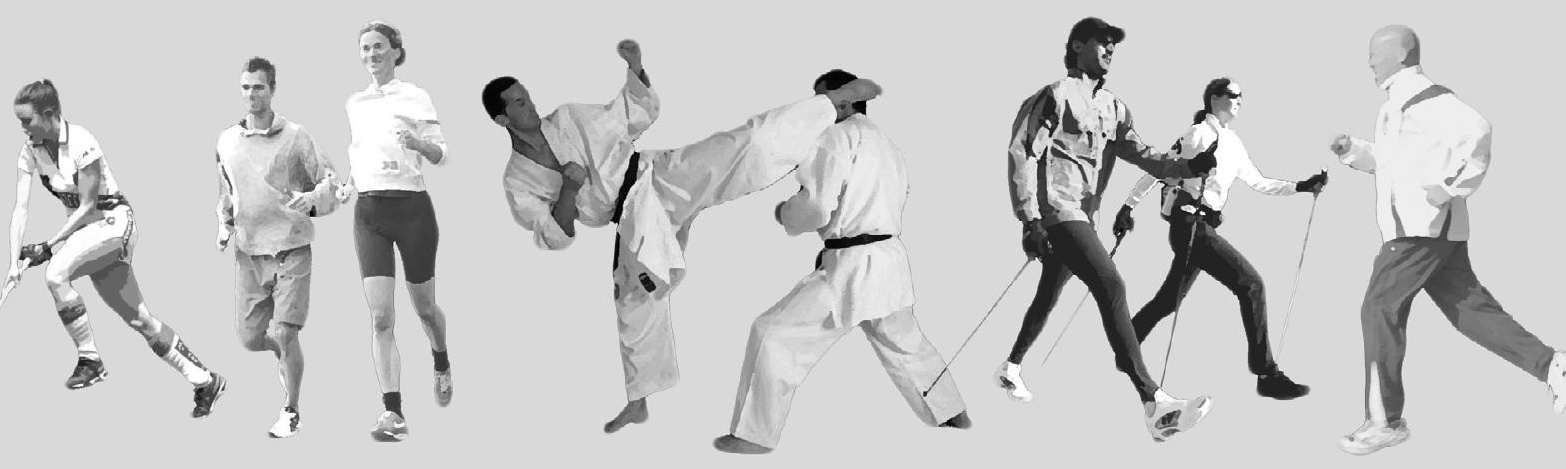




\begin{abstract}
Background: The incidence of non-specific work-related upper limb disorders (WRULD) is rising throughout western society. Literature and our own WRULD file (>1200 patients) revealed that both physical and psychosocial work-related factors are major causes of non-specific WRULD. It also appeared that non-specific WRULD was more likely to develop in patients with neurotic-perfectionist personalities.

Aim: To see if, alongside physical and psychosocial work-related factors, personality factors play an important role in developing non-specific WRULD.

Method: This was a case-control study with two control groups, comparing 45 computer workers with non-specific WRULD with 45 computer workers free from upper limb disorder (first control group) and 42 chronic pain patients (second control group). Main questionnaires administered were: the Utrecht Coping List (UCL), measuring coping-styles; the Multidimensional Perfectionism Scale (MPS), measuring neurotic perfectionism; and the Symptom Check List (SCL-90), measuring general psychological complaints (psychoneuroticism). The SCL-90 was added because of its known high correlation with neurotic perfectionism.
\end{abstract}

Results: Logistic regression analysis revealed significant differences in SCL-90 scores $\left(\chi^{2}\right.$ $=17.2, P<0.0001)$, thereby potentially negating the significance of the higher neurotic perfectionism in the non-specific WRULD group. A second control group of chronic pain patients, with prospective high score on the SCL-90, was added. Logistic regression showed that, after controlling for psychoneuroticism, non-specific WRULD patients had more neurotic perfectionist traits $\left(\chi^{2}=22.83, P<0.0001\right)$. There were no significant differences in mean UCL scores $(P>0.05)$.

Conclusion: Alongside physical and psychosocial work-related factors, psychoneuroticism and neurotic perfectionism appear to be important risk factors for developing non-specific WRULD. 


\section{Introduction}

Repetitive strain injury (RSI) is an increasing problem for the working population of the Netherlands, particularly amongst computer workers ${ }^{1}$ and the same is true for other highly industrialized and computerized countries, resulting in high sick pay for those unable to work. ${ }^{2}$

A report on RSI published by the Health Council of the Netherlands in $2000^{3}$ gave the following description of RSI, or work-related upper limb disorder (WRULD) as it is often called in British medical literature:

$R S I$ is a medical syndrome affecting the neck, upper back, shoulders, upper and lower arm, elbow, wrist or hand, or a combination of these areas. Its effects are restrictive or lead to participation problems. The syndrome is characterised by a disturbance in the balance between load and physical capacity, preceded by activities that involve repeated movements or prolonged periods spent with one or more of the relevant body parts in a fixed position. $R S I$ is always caused by a combination of factors.

In other words, the committee's definition of RSI excludes pain and other conditions that are short-lived or acute.

As a syndrome, RSI always involves a complex of complaints. To conform to this definition and to exclude specific forms of RSI such as tendinitis, the synonymous terms 'aspecific RSI' and 'non-specific WRULD' will be used. ${ }^{4,5}$ The term 'RSI' is still used in the Netherlands because of its worldwide currency. This article is only concerned with nonspecific WRULD. $^{6}$

Risk factors fall into three categories: physical (work-related) risk factors, such as bad posture; psychosocial (work-related) risk factors, such as lack of social support; and personal risk factors, such as an ineffective approach to stress management. ${ }^{3,5}$

From the literature ${ }^{7-9}$ and from our large cohort of patients with non-specific WRULD (>1200 patients), it became clear that poor posture and poor ergonomic design of equipment and tools are at least partly responsible for non-specific WRULD. However, the impression gained in clinical practice was that full postural and ergonomic adaptation of the workplace did little to reduce the number of complaints. Indeed, it is known that ergonomic interventions are more effective when psychosocial aspects of the jobs are taken into account. ${ }^{10}$ An analysis of our non-specific WRULD cohort strongly indicated that known psychosocial and psychological factors ${ }^{10-14}-$ and especially such personality factors as neurotic perfectionism and coping strategies - could be additional risk factors in the development and persistence of non-specific WRULD. ${ }^{15}$ Nearly all of the new non-specific WRULD patients told us, when asked during structured history taking, that they were very precise persons, incapable of dealing with heavy workload and/or tight deadlines. As a result, over the last few years each patient's degree of perfectionism has been assessed with the Multidimensional Perfectionism Scale (MPS), which measures neurotic perfectionism. 
Moreover, these same patients told us they had high work standards and would ignore the workload and onset of non-specific WRULD symptoms, despite knowing that these symptoms could become chronic in a few months.

Apart from standard therapies such as physical therapy and occupational therapy, these patients also received rational emotive therapy (RET) ${ }^{16}$ and advice on time management and assertiveness. RET is a type of cognitive therapy and is defined as the therapy which helps patients to replace irrational beliefs with rational assumptions.

Little research has been done so far on the personal ity structure of the non-specific WRULD patient. ${ }^{11,12,15,17}$ If the non-specific WRULD patient has the trait of perfectionism or is hampered by inadequate coping strategies, or both, prevention and primary inter vention for non-specific WRULD should be adapted to the personality type.

The research question for this study is therefore whether perfectionism and/or inadequate coping skills are additional risk factors in developing non-specific WRULD.

\section{Methods}

This study is a case-control study with two control groups. The sample was taken from personal computer (PC) workers working at the computer with or without the use of a mouse for $>20 \mathrm{~h}$ a week and for at least $4 \mathrm{~h}$ a day, and from chronic pain patients with generalized pain above and below trunk level. The latter sample included patients with fibromyalgia syndrome, distinguished by special tender points above and below the girdle and right and left side of the body.

The sample consisted of men and women aged 18-65. The case group consisted of PC workers diagnosed with non-specific WRULD at our clinic, which is a tertiary referral centre for non-specific WRULD patients.

Inclusion took place in accordance with the earlier given description of non-specific WRULD $^{3-5}$ where the symptoms lasted $>6$ weeks. The first control group was composed of PC workers as described above who did not have non-specific WRULD symptoms. This control group was mainly selected from colleagues of the case group and at random from the personnel of Maastricht University and a large company. Both groups were therefore homogeneous regarding workplace, pace of work and daily use of the computer.

The third group (second control group) was composed of chronic pain patients from our clinic who were not PC workers (see Table 1). This group was included because, as chronic pain patients, they had somatopsychological problems ${ }^{18}$ but did not suffer from non-specific WRULD and were not PC-workers. 
Table 1. Demographic and illness characteristics of case and control groups

\begin{tabular}{lccc}
\hline & $\begin{array}{c}\text { Non-specific WRULD } \\
(\mathbf{n}=\mathbf{4 5})\end{array}$ & $\begin{array}{c}\text { Healthy controls } \\
(\mathbf{n}=\mathbf{4 5})\end{array}$ & $\begin{array}{c}\text { Pain patients } \\
(\mathbf{n}=\mathbf{4 2})\end{array}$ \\
\hline Age & $36(7.3)$ & $33(8.3)$ & $43(9.4)^{\mathrm{a}}$ \\
Sex (\% female) & 69 & 71 & 57 \\
Education level & $5.8(1.8)$ & $5.1(1.7)$ & $3.5(2.7)^{\mathrm{a}}$ \\
Hours at computer & $6.5(1.6)$ & $6.2(1.5)$ & $1.1(2.5)^{\mathrm{a}}$ \\
Duration of complaints (months) & $35(21)$ & & $33(48)$ \\
\hline
\end{tabular}

Values are mean values (SD); ${ }^{\mathrm{a}}$ One way ANOVA, $\mathrm{P}<0.05$.

We expected that this group would score high on the Symptom Check List (SCL)-90, ${ }^{18}$ but had additional reasons for wanting to know how this group would behave on the Multidimensional Perfectionism Scale (MPS) (see later).

Based on the assumed differences between cases and control groups of at least 25 points on the MPS with alpha $=0.05$ and a power of $80 \%$, we needed at least 43 patients in each group. We aimed to include 50 persons in each group to allow for dropouts. $^{19}$

In the event, 45 non-specific WRULD patients (group 1), 45 people without upper limb disorder (group 2) and 42 chronic pain patients (group 3) were included. For patients who refused to be included, some demographic data and data from history taking were registered to exclude possible selection bias in the final study base.

Demographic and illness characteristics of the study and control groups were taken into account, namely age, gender, level of education, use of computer and duration of complaints. Table 1 shows a good match between the groups with respect to gender and the duration of the complaints.

The patients in the chronic pain group were significantly older than in the other two groups, had a lower standard of education $(P<0.05)$ and spent much less time each day at the computer than the people in groups 1 and 2 .

After obtaining their informed consent, the people in all the groups were sent a set of four questionnaires, as follows.

1. A questionnaire for biographic, demographic and medical history data relevant to non-specific WRULD.

2. The MPS, Dutch version. This was originally an American scale measuring the degree of neurotic perfectionism. ${ }^{20}$ Hamachek $^{21}$ drew a distinc tion between 'normal' perfectionists, who set high standards for themselves yet, 'Feel free to be less precise as the situation permits' and 'neurotic' perfectionists, who also set high standards but allow themselves little room for mistakes. They never feel that anything is done completely or well enough. A Dutch version of the test was made and tested for reliability and validity by our research group before use. ${ }^{22}$ The Dutch version consists of 29 items and five subscales and is used as a multidimensional construct. The following subscales are included: concern over mistakes; personal standards; parental expectations; parental criticism; and doubt about actions. The 29 
items are scored from 1 to 5 . The higher the score, the greater the degree of neurotic perfectionism. The total score is a good representation of the different subscores. It takes $10-15$ min to fill out. MPS scores are not influenced by age or gender.

3. The Hopkins Symptom Check List (SCL)-90. This scale is in worldwide use for measuring recently experienced physical and psychological distress and for screening psychopathology, defined as psycho- neuroticism ${ }^{18,23}$ and takes 20 min to complete. This list was used because the literature shows a high correlation between the SCL-90 and MPS scores. ${ }^{20}$ It consists of 90 items, scored from 1 to 5 , subdivided into nine subscales. The higher the score, the greater the degree of psychoneuroticism. The total score is a good representation of the different subscores. The score for a non-pathological person can be expected to lie between 100 and 120 . A score of 260 points to existing depression.

4. The Utrecht Coping List (UCL). ${ }^{24}$ This list was used because coping styles can also be influenced by psychoneuroticism and because of the expectation from clinical practice that perfectionists would have inadequate coping strategies. This list consists of 47 items subdivided into seven subscales, measuring seven different types of coping strategy. For this reason, all subscales had to be taken into account separately. It takes $\sim 10 \mathrm{~min}$ to complete.

All procedures followed the ethical standards of the Medical Ethics Committee of the University Hospital Maastricht.

\section{Statistics}

The demographic and illness characteristics of the study and control groups were analysed by the one-way analysis of variance (ANOVA) method $(P<0.05)$.

First of all, the MPS-subscales and total score, the SCL-90 subscales and total score and the UCL subscales were analysed for the three groups. Then, because of the good internal consistency of the instruments as a whole, we continued with the MPS total score and the SCL-90 total score. ${ }^{23}$ The UCL subscales, representing different ways of coping, were analysed separately.

The case-control groups were also compared with each other by the one-way ANOVA method ( $P<0.05$; Bonferroni correction was used because more than two groups were involved). Finally, we used logistic regression analysis to look at differences in perfectionism between patients with non-specific WRULD and both control groups while controlling for their overall SCL-90 scores.

\section{Results}

Table 2 shows that the non-specific WRULD group is significantly more neurotic perfectionist than the two control groups. It also shows that the healthy control group was 
significantly less psychoneurotic than the two groups with symptoms. Although the non-specific WRULD patients had the same coping styles as the healthy controls, the chronic pain group used coping strategies that were less active than the non-specific WRULD group. The chronic pain group also has a more passive coping style than the healthy control group.

Table 2. MPS, SCL-90 and UCL scores for case and control groups

\begin{tabular}{|c|c|c|c|}
\hline & $\begin{array}{c}\text { Non-specific } \\
\text { WRULD }(n=45)\end{array}$ & $\begin{array}{l}\text { Healthy controls } \\
\qquad(n=45)\end{array}$ & $\begin{array}{l}\text { Pain patients } \\
\quad(n=42)\end{array}$ \\
\hline MPS total score (neurotic perfectionism) & $70.0(25.3)$ & $56.6(18.2)$ & $54.9(17.1)$ \\
\hline SCL-90 total score (psychoneuroticism) & $145.9(41.3)$ & $115.6(27.7)$ & $164.2(49.7)$ \\
\hline \multicolumn{4}{|l|}{ UCL (coping styles) } \\
\hline Active coping $^{c}$ & $19.5(3.6)$ & 18.8 (3.9) & $17.6(3.0)$ \\
\hline Palliative reaction & $18.8(3.6)$ & $17.6(3.2)$ & $18.3(3.2)$ \\
\hline Avoidance & $15.9(3.6)$ & $16.7(4.3)$ & $15.4(3.1)$ \\
\hline Looking for social support & 13.9 (3.9) & $13.8(3.3)$ & $12.8(3.6)$ \\
\hline Passive reaction pattern ${ }^{d}$ & $11.9(3.2)$ & $11.0(2.9)$ & $13.0(4.0)$ \\
\hline Expression of emotions & $5.9(1.9)$ & $6.7(1.6)$ & $6.1(1.9)$ \\
\hline Sedative thoughts & $13.0(2.8)$ & $12.0(2.4)$ & $12.5(2.3)$ \\
\hline
\end{tabular}

Values are mean values (SD). One-way ANOVA (Bonferroni correction). ${ }^{\mathrm{a}} \mathrm{P}<0.05$ between non-specific WRULD and other groups. ${ }^{b} \mathrm{P}<0.05$ between healthy control and other groups. ${ }^{\mathrm{C}} \mathrm{P}<0.05$ between nonspecific WRULD and pain group. ${ }^{d} \mathrm{P}<0.05$ between healthy control and pain group.

In a logistic regression analysis, we first compared the patients with non-specific WRULD to the healthy control group on their level of perfectionism and did the same for their SCL-90 scores. As can be seen in Table 3, only the SCL-90 scores were significantly different between the groups. Next, we used the same approach to compare patients with non-specific WRULD to chronic pain patients (Table 4). Here, patients with non-specific WRULD appeared to be more perfectionistic, despite their lower SCL90 scores.

Table 3. Logistic regression for non-specific WRULD and healthy control groups ${ }^{a}$

\begin{tabular}{lccc}
\hline & $\boldsymbol{B}$ & SE & $\boldsymbol{P}$ \\
\hline SCL-90 sumscore & -0.0270 & 0.0098 & 0.0006 \\
MPS sumscore & -0.0052 & 0.0137 & 0.7018 \\
\hline
\end{tabular}

${ }^{\mathrm{a}} \chi^{2}=17.17, \mathrm{df}=2, \mathrm{P}<0.0001$.

Table 4. Logistic regression for non-specific WRULD and chronic pain patients ${ }^{\mathrm{a}}$

\begin{tabular}{lccc}
\hline & $\boldsymbol{B}$ & SE & $\boldsymbol{P}$ \\
\hline SCL-90 sumscore & 0.0226 & 0.0075 & 0.003 \\
MPS sumscore & -0.0544 & 0.0145 & $<0.0001$ \\
\hline
\end{tabular}

${ }^{\mathrm{a}} \chi^{2}=22.83, \mathrm{df}=2, \mathrm{P}<0.0001$. 


\section{Discussion}

The incidence of non-specific WRULD is increasing in stressful and highly industrialized Western societies. ${ }^{2,3}$ It may be no coincidence that less industrialized countries such as Greece, where the working day is also split by a long lunch break, report very few cases of WRULD. ${ }^{25}$

This study was carried out because observations from our non-specific WRULD clinic pointed to personality traits - particularly neurotic perfectionism-as additional risk factors for developing non-specific WRULD. ${ }^{20}$

We therefore hypothesized that patients suffering from non-specific WRULD would have inadequate movement strategies, ${ }^{6}$ that such inadequate strategies develop preferentially amongst people under high task stress who ignore breaks and high work pace ${ }^{6}$ and that people with this behaviour would tend to show neurotic perfectionism. The results indeed show that PC workers from our sample are significantly more neurotic perfectionist than PC workers without non-specific WRULD.

Logistic regression analysis, however, showed that these significant differences in neurotic perfectionism were potentially negated by the differences in SCL-90 scores. In other words, PC workers with non-specific WRULD were, above all, more psychoneurotic than PC workers without non-specific WRULD. This means that they suffered primarily from psychological and physical complaints. Because the variable tested was the MPS, measuring neurotic perfectionism, we conclude that our hypothesis is accepted. To further confirm our hypothesis, we used a second control group consisting of chronic pain patients, who would be expected to score high on the SCL-90. ${ }^{18}$ By logistic regression analysis we could show that patients with non-specific WRULD are significantly more neurotic perfectionist than chronic pain patients, despite not having the higher SCL-90 scores we would expect from the literature. ${ }^{20}$

There were, against expectation, no significant differences in coping mechanisms between non-specific WRULD patients and the healthy controls.

On the other hand, the pain patients used coping strategies that were significantly less active than the non-specific WRULD patients and had a more passive coping style than the healthy control group.

The MPS originally consisted of six subscales. The subscale 'Organization' of the MPS had to be removed because of psychometric inconsistencies; that is, it reduced the internal consistency of the MPS. Despite this, the internal consistency of the subscales and the questionnaire was, on the whole, good. ${ }^{22}$

Although there was a high correlation between the subscales 'Parental expectations' and 'Parental criticism', these two subscales were left separate as in the original version, leaving five subscales. The fact that there were three missing values in the healthy control group for each subscale of the UCL was of little consequence for the project, as the UCL list was not the main variable. 
To put the results of this study into practice, every new patient diagnosed as having non-specific WRULD would be encouraged to fill in the SCL-90 and MPS questionnaires. A patient with non-specific WRULD who scored $>260$ on the SCL-90 should be referred for psychiatric screening. ${ }^{20}$

In our daily practice, patients with non-specific WRULD and a total score $>75$ on the Dutch version of the MPS are sent to a psychologist or psychotherapist to learn how to deal with their neurotic perfectionism.

\section{Conclusion}

This study shows that while neurotic perfectionism may be an additional risk factor for developing non-specific WRULD, the correlation could be accounted for by psychoneuroticism experienced as general physical and psychological complaints.

Although unlikely, the study does not rule out the possibility that the presence of psychoneuroticism and neurotic perfectionism was caused by non-specific WRULD.

To exclude confounding by psychoneuroticism, a prospective study is needed on the causal relationship between non-specific WRULD and psychoneuroticism/ neurotic perfectionism after allowing for the physical and psychosocial work-related factors. Nevertheless, there is good reason to direct prevention and primary intervention of non-specific WRULD primarily at those PC workers with psychoneurotic and neurotic perfectionist personalities.

\section{References}

1. Blatter B, Bongers PM. Work Related Neck and Upper Limb Symptoms (RSI): High Risk Occupations and Risk Factors in the Dutch Working Population, report 4070117/r9800293. Hoofddorp: TNO Work and Employment, 1999.

2. Repetitive Strain Injury Association. Report. England, July 2002.

3. Health Council of the Netherlands. RSI, Publication No. 2000/22. The Hague: Health Council of the Netherlands, 2000.

4. Harrington JM, Carter JT, Birrell L, Gompertz D. Surveillance case definitions for work related upper limb pain syndromes. Occup Environ Med 1998;55:264-271.

5. Sluiter JK, Rest KM, Frings-Dresen MHW. Criteria Document for Evaluation of the Work-relatedness of Upper Extremity Musculoskeletal Disorders. Amsterdam: Coronel Institute for Occupational and Environmental Health, Academic Medical Centre, University of Amsterdam, 2000.

6. Bloemsaat G, Ruijgrok J, van Galen GP. Patients suffering from a specific WRUED exhibit insufficient movement strategies. Acta Psychol 2003; in press.

7. Shaw WS, Feuerstein M, Lincoln AE, Miller VI, Wood PM. Ergonomic and psychosocial factors affect daily function in workers' compensation claimants with persistent upper extremity disorders. J Occup Environ Med 2002;44:606-615.

8. Feuerstein M, Shaw WS, Lincoln AE, Miller VI, Wood PM. Clinical and workplace factors associated with a return to modified duty in work-related upper extremity disorders. Pain 2003;102:51-61.

9. Shaw WS, Feuerstein M, Miller VI, Lincoln AE. Clinical tools to facilitate workplace accommodation after treatment for an upper extremity disorder. Assist Technol. 2001;13:94-105. 
10. Most IG. Psychosocial elements in the work environ- ment of a large call center operation. Occup Med 1999;14:135-147.

11. Macfarlane GJ, Hunt IM, Silman AJ. Role of mechanical and psychosocial factors in the onset of forearm pain: prospective population based study. Br Med J 2000;321:1-5.

12. Weigert BJ, Rodriquez AA, Radwin RG, Sherman J. Neuromuscular and psychological characteristics in subjects with work-related forearm pain. Am J Phys Med Rehabil 1999;17:545-551.

13. van Galen GP, van Huygevoort M. Error, stress and the role of neuromotor noise in space-behaviour. Biol Psychol 2000;51:151-171.

14. van Galen GP, Muller MLTM, Meulenbroek RGJ, Van Gemmert AWA. Forearm EMG response activity during motor performance in individuals prone to increased stress reactivity. Am J Ind Med 2002;41:406-419.

15. Frost RO, Marten PA. Perfectionism and evaluative threat. Cognit Ther Res 1990;14:559-572.

16. Ellis A. Group rational-emotive and cognitive-behavioral therapy. Int J Group Psychother 1992;42:63-80.

17. Tyrer SP. Repetitive strain injur y. Pain Rev 1999;6:155-166.

18. Hardt J, Gerbershagen HU. Cross-validation of the SCL-27: a short psychometric screening instrument for chronic pain patients. Eur J Pain 2001;5:187-197.

19. Pocock SJ. Clinical Trials. Chichester: John Wiley, 1991.

20. Frost RO, Marten $P$, Lahart $C$, Rosenblate R. The dimensions of perfectionism. Cognit Ther Res 1990;14:449-468.

21. Hamachek DE. Psychodynamics of normal and neurotic perfectionism. Psychology 1978;15:27-33.

22. Flos CHGM, Peeters FPML, van Eijsden M. The 'Multidimensional Perfectionism Scale'; reliability and validity of the Dutch translation, unpublished manuscript, 2000.

23. Arrindell WA, Ettema JHM. Klachtenlijst Symptom Check List (SCL-90). Lisse: Swets \& Zeitlinger BV, 1986.

24. Schreurs PJG, van de Willige G. Dealing with Problems and Events (UCL, Utrecht Coping List). Lisse: Swets \& Zeitlinger BV, 1988.

25. van Eijsden-Besseling MDF, Peeters FPML. Perfectionism and coping strategies as risk factors for the development of RSI. In: 3rd Mediterranean Congress of Physical Medicine and Rehabilitation, abstract. Athens, 2000. 


\section{[5] \\ Pain catastrophizing and lower physical fitness in a sample of computer screen workers with early non-specific upper limb disorders; a case-control study}

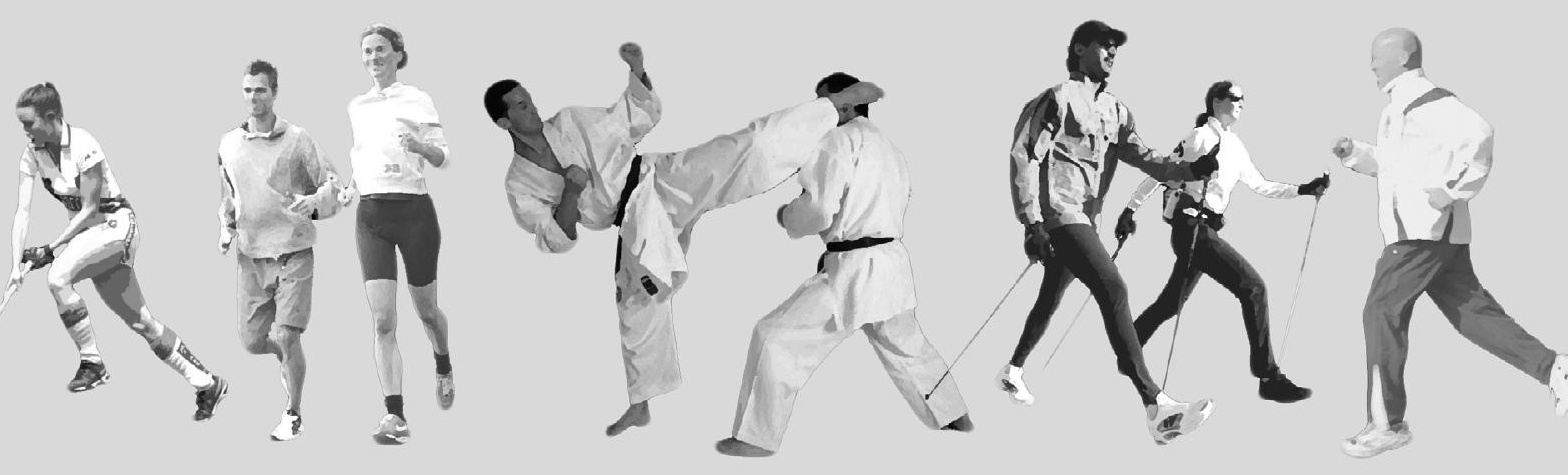

Marjon D.F. van Eijsden-Besseling, Antonius van Attekum, Rob A. de Bie, J. Bart Staal

Accepted by "Industrial Health", January 2010; in press. 


\begin{abstract}
Objectives: In computer workers psychological factors and physical fitness may play an important role in the onset and course of non-specific work-related upper limb disorders (WRULD) beyond socio-demographic factors. Based on our experiences in daily practice we assumed that pain catastrophizing and other psychological variables such as perfectionism, anxiety state and trait, and low physical fitness, are possibly associated with the occurrence of WRULD.

We aim to study the association between pain catastrophizing, perfectionism, anxiety (state and trait), physical fitness, sex and level of education and the occurrence of WRULD, controlling for age as a confounder.

Methods: Eighty-eight computer workers with early non-specific WRULD, who had been recruited for an intervention study, were compared with 31 healthy computer workers (controls) recruited from different departments of a university. This crosssectional case-control study examined the influence of aforementioned variables on WRULD by means of logistic regression analyses.

Results: Among the different predictor variables investigated, pain catastrophizing (OR=1.37; $95 \% \mathrm{Cl} 1.17$ to 1.59$)$ and lower physical fitness had a positive relationship with WRULD (OR=0.65; $95 \% \mathrm{Cl}$. 0.48 to 0.87 ).
\end{abstract}

Conclusions: According to this study, pain catastrophizing and lower physical fitness seem to be associated with early non-specific WRULD in computer workers. Prospective studies are needed to unravel these relationships. 


\section{Introduction}

Previous studies have shown that non-specific work-related upper limb disorders (WRULD) among computer screen workers develop as a result of extended screen work. ${ }^{1-3 .}$ However, contrary to this, a recent longitudinal cohort study among office workers in the Netherlands showed that long duration of computer work did not predict the occurrence of upper limb disorders. ${ }^{4}$ In general, previous research on existing associations between physical, ${ }^{4,5}$ psychosocial $^{4,6-8}$ and psychological ${ }^{4,7,9}$ risk factors, and the development of upper limb disorders showed mixed results. Psychosocial factors, especially moderate to low reward and low task variation, appeared to have an association with the onset of upper limb disorders. ${ }^{4,7}$ A large cross-sectional study among bank employees showed that job stress was strongly associated with the development of upper limb disorders. ${ }^{8}$ With respect to psychological risk factors, especially abelledmitment, ${ }^{4,7}$ psycho neuroticism and neurotic perfectionism ${ }^{9}$ showed a relationship with the onset of upper limb disorders. In a study among PhD students with upper limb disorders it had been shown that a high score on the Trait Anxiety Inventory (STAI

2) was associated with sooner absenteeism from work and self-perceived disability. ${ }^{10}$ Demographic data further indicate that persons suffering from non-specific WRULD are often highly educated, have long working days, and are over 30 years of age with an over-representation of women. ${ }^{4,11,12}$ It appears that beyond socio-demographic factors, primarily psychosocial and psychological factors play a role in the onset and course of upper limb disorders.

We conducted a randomized trial among computer screen workers with early nonspecific upper limb disorders in which one group received postural exercise therapy and the other group regular physiotherapy. We showed that at one year follow-up still $45 \%$ suffered from upper limb complaints. ${ }^{12}$ A remarkable finding in this study was the high score at baseline on the Pain Catastrophizing Scale (PCS) for both groups. ${ }^{12}$ Since physically oriented interventions, also in early stages of non-specific upper limb disorders, ${ }^{12}$ are not able to eliminate upper limb disorders, further research needs to focus on psychosocial and psychological factors. With regards to low back pain, Sullivan previously demonstrated the relation between pain catastrophizing and chronic pain, while Vlaeyen explains why pain becomes chronic during the process of catastrophizing. $^{13,14}$

In order to gain more insight into the relationships between psychological-, physical-, demographic characteristics and beginning upper limb disorders, we conducted a casecontrol study among computer screen workers by means of comparing the baseline characteristics of the participants in our previously conducted randomized controlled trial with the baseline characteristics of a control group of non-cases.

The main research question in the present study is therefore: are computer screen workers with early non-specific work-related upper limb disorders (WRULD) more sus- 
ceptible to catastrophizing abelled, more anxious and neurotic perfectionists and less physically fit compared to non-cases?

\section{Subjects and methods}

The baseline characteristics of 88 employed computer screen workers with early nonspecific upper limb disorders who participated in a randomized controlled trial ${ }^{12}$ (cases) were compared with the characteristics of a control group of 31 employed computer screen workers (controls).

As a result, the inclusion criteria for participants in this randomized controlled trial and for being a case in this case-control study were: being a computer screen worker employed for more than 3 months and working at least 4 hours per day and 20 hours per week, between 20 and 45 years of age and experiencing early non-specific upper limb disorders with a duration of symptoms between 2 weeks and 3 months. ${ }^{12}$ Early nonspecific work-related upper limb disorders (WRULD) were defined as: pains and tingles in upper back, neck, shoulders, arms or hands related and restricted to computer screen-work, not yet present during other daily activities and not labelled as a specific diagnosis such as tennis elbow or carpal tunnel syndrome. The inclusion of the cases took place between May 2003 and February 2005. They were recruited by means of advertisements in local newspapers, through personal contact with occupational physicians of large companies, and by mailing to general practitioners. ${ }^{12}$ The control group consisted of computer screen workers who did not have any past or present upper limb disorders. They were recruited among employees of several departments, staff and PhD students of Maastricht University between November 2007 and June 2008. In order to be included they had to perform computer work for at least 4 hours per day and 20 hours per week for at least 3 months to make them comparable to the cases. Recruitment took place by advertisements at the different departments. Potential participants for the control group were recruited and finally selected by the same occupational physician (AvA) who performed the selection of the participants of the randomized controlled trial in 2003, 2004 and 2005.

All participants of the present study completed a baseline questionnaire that consisted of a general section on socio-demographic characteristics and specific questionnaires on psychological and physical risk factors. The time taken to fill out the questionnaire was approximately twenty minutes. Socio-demographic characteristics comprised sex, age and level of education. Participants were abelled as "highly educated" if they had at least a bachelor's degree.

\section{Psychological and physical risk factors}

Additionally to the aforementioned socio-demographic factors, validated specific questionnaires were used to assess psychological and physical risk factors. These potential 
psychological risk factors were: pain catastrophizing as assessed with the Pain Catastrophizing Scale (PCS, range $0-52$ points); ${ }^{15}$ anxiety as assessed with the State (1) respectively Trait (2) Anxiety Inventory (STAI 1 \& 2, range 20-80 points of both subscales) ${ }^{16)}$ and (neurotic) perfectionism as assessed with the slightly adjusted Multidimensional Perfectionism Scale, (MPS, range $29-145$ points) according to Flos. ${ }^{17}$ For physical fitness the self-reported fitness on the Groningen Fitness Questionnaire (range 9-45 points) ${ }^{18}$ has been used.

All participants gave written informed consent and the research protocol was ethically approved by the Medical Ethics Committee of the University Hospital Maastricht.

\section{Statistical analysis}

Data were checked for completeness and normality. Continuous variables were compared between cases and controls using the independent samples t-test and dichotomous variables using the chi-square test. Associations between risk factors and WRULD were estimated by using unconditional logistic regression.

The influence of the following predictors on WRULD was investigated by means of logistic regression analysis: pain catastrophizing, state and trait anxiety, perfectionism, physical fitness, sex and level of education. First, the bivariate associations between the variables and WRULD were investigated. Second, the variables were simultaneously incorporated in a multivariable logistic regression model while adjusting for age, which was considered a potential confounder. Since four continuous predictors were used in our logistic regression model it is necessary to investigate whether the assumption of the linearity of the relationship between the logit and these predictors is violated. We therefore added predictors to the model that are interactions between the continuous predictors and the log of it self. Any significant interaction indicates that the main effect violates the assumption of linearity of the logit. ${ }^{19}$ We used a cut-off value of $p<0.10$ for significance of these interaction terms. The explained variance of the multivariable logistic regression model was calculated by means of Nagelkerke's $R^{2}$. In general in this study, values of $p<0.05$ were considered statistically significant and data were analyzed by using SPSS statistical software (Version 15.1; SPSS Inc, Chicago, III).

\section{Results}

Initially, 78 employees volunteered to participate as a control subject in this study. However, the questionnaires showed that 47 of them had experienced non-specific upper limb pain (WRULD) in the past or had still some pain at present. They were therefore excluded from the study and this resulted in a control group of 31 participants. Data from the case and control groups were complete except for some missing values. 
Table 1. Distribution of socio-demographic, psychological and physical risk factors in the case and control group

\begin{tabular}{|c|c|c|c|}
\hline & $\begin{array}{l}\text { Case group } \\
\quad(n=88)\end{array}$ & $\begin{array}{l}\text { Control group } \\
(n=31)\end{array}$ & p-value \\
\hline Sex (male/female) & $38 / 50$ & $17 / 14$ & 0.26 \\
\hline Education (high/low) & $59 / 29$ & $21 / 9$ & 0.60 \\
\hline Age (yr), mean (SD) & $34.0(7.7)$ & $42.1(9.3)$ & 0.00 \\
\hline Pain Catastrophizing Scale (0-52), mean (SD)* & $24.0(6.6)$ & $9.8(8.3)$ & 0.00 \\
\hline State Anxiety Inventory (20-80), mean (SD)* & $33.0(9.7)$ & $32.0(6.8)$ & 0.54 \\
\hline Trait Anxiety Inventory (20-80), mean (SD)* & $34.9(9.8)$ & $31.9(7.2)$ & 0.08 \\
\hline Multidimensional Perfectionism Scale (29-145), mean (SD)* & $63.0(17.4)$ & $59.2(21.7)$ & 0.39 \\
\hline Self-reported physical fitness $(9-45)$, mean $(S D)^{*}$ & $26.8(2.4)$ & $29.6(3.6)$ & 0.00 \\
\hline
\end{tabular}

* The higher the score, the more the attribute applies

Table 1 shows the values of the socio-demographic, psychological and physical factors of both the case and control group. The socio-demographic data showed a significant difference in age between the case and control group. The mean age in the control group was higher. There were no differences in sex and level of education between both groups.

Table 2. Results of the bivariate logistic regression analyses on risk factors of WRULD*

\begin{tabular}{lcccc}
\hline Risk factor & B & OR & $\mathbf{9 5 \% ~} \mathbf{~ I ~}$ & p-value \\
\hline Pain Catastrophizing Scale (0-52) & 0.28 & 1.32 & 1.19 to 1.47 & 0.00 \\
State Anxiety Inventory (20-80) & 0.01 & 1.01 & 0.97 to 1.06 & 0.60 \\
Trait Anxiety Inventory (20-80) & 0.04 & 1.04 & 0.99 to 1.09 & 0.13 \\
Multidimensional Perfectionism Scale (29-145) & 0.01 & 1.01 & 0.99 to1.04 & 0.34 \\
Self-reported physical fitness (9-45) & -0.33 & 0.72 & 0.61 to 0.85 & 0.00 \\
Education (high/low) & -0.24 & 0.79 & 0.32 to 1.93 & 0.60 \\
Sex (male/female) & 0.47 & 1.60 & 0.70 to 3.64 & 0.27 \\
\hline
\end{tabular}

* The analyses were adjusted for age

In table 2 the results are presented of the bivariate associations between the risk factors and upper limb disorders. Both pain catastrophizing (PCS) and lower physical fitness were significantly associated with non-specific work-related upper limb disorders.

Table 3. Results of the multivariable logistic regression analyses on risk factors of WRULD*

\begin{tabular}{lcccc}
\hline Risk factor & B & OR & 95\% Cl & p-value \\
\hline Pain Catastrophizing Scale (0-52) & 0.31 & 1.37 & 1.17 to 1.59 & 0.00 \\
State Anxiety Inventory (20-80) & -0.10 & 0.91 & 0.81 to 1.02 & 0.11 \\
Trait Anxiety Inventory (20-80) & 0.08 & 1.08 & 0.97 to 1.20 & 0.16 \\
Multidimensional Perfectionism Scale (29-145) & -0.18 & 0.98 & 0.94 to1.03 & 0.46 \\
Self-reported physical fitness (9-45) & -0.44 & 0.65 & 0.48 to 0.87 & 0.01 \\
Education (high/low) & -0.39 & 0.68 & 0.12 to 3.95 & 0.67 \\
Sex (male/female) & 0.96 & 2.60 & 0.48 to 14.01 & 0.27 \\
\hline
\end{tabular}

*The analyses were adjusted for age 
Table 3 presents the results of the multivariable logistic regression model on the measured risk factors. None of the interactions between the continuous predictors and the log of it self were significant (i.e. all p-values were higher than 0.10) which indicates that assumption of the linearity of the logit was not violated. The case group was significantly more likely to have a higher PCS score ( $\mathrm{OR}=1.37 ; 95 \% \mathrm{Cl} 1.17$ to $1.59 ; \mathrm{p}=0.00$ ) and a lower physical fitness score $(\mathrm{OR}=0.65 ; 95 \% \mathrm{Cl} 0.48$ to $0.87 ; \mathrm{p}=0.01)$ than the control group. No significant associations were found between non-specific upper limb disorders and state and trait anxiety, and neurotic perfectionism. Nagelkerke's $R^{2}$ of the multivariable model was .74.

\section{Discussion}

The results of this cross-section case-control study show that pain catastrophizing and lower physical fitness are associated with non-specific work-related upper limb disorders. Contrary to the results of other studies, which addressed the role of pain catastrophizing as a prognostic factor of long-term symptoms, ${ }^{20}$ the present study revealed an association of pain catastrophizing with non-specific work-related upper limb disorders of relatively recent onset (i.e. $<12$ weeks). This may suggest a role of pain catastrophizing in the etiology of non-specific work-related upper limb disorders. Conversely, it may also reflect symptom burden among cases. However, the low average pain scores on the VAS (10 cm visual analogous scale) at baseline (mean score 2.8) seem to contradict this phenomenon. In several other studies, amongst other prospective cohort studies, it has been shown that pain catastrophizing acts as a predictor of chronic pain symptoms. In most of these studies pain catastrophizing predicted chronic states of widespread pain in general ${ }^{21}$ or low back pain ${ }^{22}$ and in some studies also upper limb disorders. ${ }^{20}$

What is remarkable in our study is the fact that 47 out of 78 computer workers who initially volunteered to participate in the control group had to be excluded because of suffering or having suffered from non-specific work-related upper limb disorders. However, they were not aware of it until they had filled out the questionnaire although they were told on beforehand that they were not allowed to have any upper limb symptoms in the past or present. We also calculated the PCS score of the control group as a whole including these 47 participants and still found a significant difference between the "controls" and cases ( $p=0.00)$, the "controls" showing significantly less catastrophizing behavior as compared to the cases. Possibly this is the stimulus as to why computer workers with non-specific upper limb disorders and showing pain catastrophizing behavior, not only develop, but are "painfully" aware of their upper limb disorders. In our study the role of pain catastrophizing overruled the impact of neurotic perfectionism and anxiety, found in earlier studies as risk factors. ${ }^{9,10}$ Contrary to the study of Hamberg-van Reenen et al ${ }^{5}$ which showed inconclusive evidence for the relationship between low physical capacity and future musculoskeletal pain in a large prospective 
cohort study, we found an association between lower physical fitness and early nonspecific WRULD.

The participants of our intervention study from which the cases in this case-control study were taken, were recruited by means of advertisements in local newspapers, through personal contact with occupational physicians of large companies, and by mailing to general practitioners. ${ }^{12}$ This may have resulted in a selection of participants who differ from an actual health care population in the extent to which they are preoccupied with their disorder. ${ }^{23}$ To increase the validity of this case-control study, the controls were recruited by means of advertisements at the different departments among all levels of university employees who performed similar types of computer screen work as the case group. However, in a case-control study controls should ideally be recruited from the same study base as cases arise. Of the socio-demographic characteristics only age was significantly different between the case and control group. We therefore adjusted for age in the multivariable analysis.

We made use of validated questionnaires. A question that may arise is whether it is possible to measure pain catastrophizing in people without pain as was the case in our control group. Therefore it should be stated that the Pain Catastrophizing Scale has been validated in people without pain. ${ }^{15}$ The Groningen Fitness Questionnaire has been validated by Lemmink et al in $2001^{24}$ for the elderly.

As our study has a cross-sectional design, an etiological role of pain catastrophizing or low physical fitness cannot be confirmed. The potential role of pain catastrophizing or lower physical fitness as a risk factor needs to be confirmed in a prospective study with participants who are preferably free of pain at the beginning of the study.

The associations found in this study, in contrast, suggest that both reassurance and proper education on the subject of the risk of (chronic) non-specific upper limb symptoms in computer screen work and stimulation of physical fitness and activity might be valuable strategies to prevent the burden of non-specific upper limb disorders.

\section{References}

1. Brandt LP, Andersen JH, Lassen CF, Kryger Al, Overgaard E, Vilstrup et al. (2004) Neck and shoulder symptoms and disorders among Danish computer workers. Scandinavian Journal of Work, Environment and Health. 30 (5): 399-409.

2. Lassen CF, Mikkelsen S, Kryger Al, Brandt LP, Overgaard E, Thomsen J et al. (2004) Elbow and wrist / hand symptoms among 6,943 computer operators: an 1-year follow-up study (the NUDATA study). American Journal of Industrial Medicine 46 (5): 521-533.

3. IJmker S, Blatter BM, van der Beek AJ, van Mechelen W, Bongers PM. (2006) Prospective research on musculoskeletal disorders in office workers (PROMO): study protocol. BMC Musculoskeletal disorders 7: 55.

4. IJmker S. (2008) Risk factors for arm-wrist-hand and neck-shoulder symptoms among office workers. A longitudinal perspective.PhD Thesis. Body@Work, Amsterdam, the Netherlands.

5. Hamberg- van Reenen HH. (2008) Physical Capacity and work-related musculoskeletal symptoms. PhD Thesis. Body@Work, Amsterdam, the Netherlands. 
6. Ariëns GA, Bongers PM, Hoogendoorn WE, Houtman IL,Van der Wal G, Van Mechelen W. (2001) High quantitative job demands and low coworker support as risk factors for neck pain: results of a prospective cohort study. Spine 26 (17): 1896-1901 (discussion 1902-1903).

7. Van den Heuvel SG. (2006) Work-related neck and upper limb symptoms. PhD Thesis. TNO, Amsterdam, the Netherlands.

8. Koenders PG, Dijkstra L, Bouwman-Brouwer KM, Konijnenberg HS. (2006) Een worsteling met de muis (A wrestling with the Mouse). Tijdschrift voor Bedrijfs- en Verzekeringsgeneeskunde (Journal of Occupational and Insurance Medicine). 14, 2: 57-61.

9. Van Eijsden-Besseling MD, Peeters FP, Reijnen JA\& de Bie RA. (2004) Perfectionism and coping strategies as risk factors for the development of non- specific work- related upper limb disorders (WRULD). Occupational Medicine 54 (2): 122-127.

10. Roelofs PD. (2002) RSI en persoonsgebonden factoren: een oriënterende studie (RSI, personal and personality factors: an explorative study) University Maastricht (Thesis). http://www.unimaas.nl/bestand.asp?id=2275 Accessed June 23, 2009

11. Feuerstein M, Nicholas RA. (2006) Development of a short form of the Workstyle measure. Occupational Medicine 56 (2): 94-99.

12. Van Eijsden-Besseling MD, Staal JB, Attekum van A, de Bie RA, Van den Heuvel WJA. (2008) No difference between postural exercises and strength and fitness exercises for early, non-specific, work-related upper limb disorders in visual display unit workers: a randomized trial. Australian Journal of Physiotherapy 54 (2): 95-101.

13. Sullivan MJ, Thorn B, Haythornthwaite JA, Keefe F, Martin M, Bradley LA et al. (2001) Theoretical perspectives on the relation between catastrophizing and pain. Clin J Pain 17 (1):65-71

14. Vlaeyen JWS and Linton SJ. (2000) Fear avoidance and its consequences in chronic musculoskeletal pain: a state of the art. Pain 85: 317-332.

15. Van Damme S. (2002) Pain Catastrophizing Scale - Dutch version (PCS-DV) Gent: University Gent. http:// www.lo-bsw.ugent.be/VVGP/fichePCS.pdf Accessed March 31, 2009.

16. Van der Ploeg HM, Defares PB\& Spielberger CD. (1980) Handleiding bij de zelfbeoordelingsvragenlijst ZBV. Een Nederlandse bewerking van de Spielberger state-trait anxiety inventory STAI-DY. (A Dutch version of the Spielberger state-trait anxiety inventory) Lisse: Swets \& Zeitlinger BV, The Netherlands

17. Flos CHGM. (1998) Validity and reliability of the Frost Multidimensional perfectionism Scale (Thesis); Maastricht: Faculty of Health Sciences, University Maastricht, The Netherlands.

18. Van Heuvelen MJG, Kempen GIJM, Ormel J, Greef de MHG. (1997) Self- reported Physical Fitness of Older Persons: A substitute for Performance-Based Measures of Physical Fitness? Journal of Ageing and Physical Activity 5: 298-310.

19. Hosmer DW and Lemeshow S. (1989) Applied logistic regression. New York: Wiley .

20. Karels CH, Bierma-Zeinstra SM, Burdorf A, Verhagen AP, Nauta AP, Koes BW. (2007) Social and psychological factors influenced the course of arm, neck and shoulder complaints. J Clinical Epidemiology 60 (8): 839-48.

21. Keefe FJ, Rumble ME, Scipio CD, Giordano LA, Perri LCM. (2004) Psychological aspects of persistent pain: current state of the science. The Journal of Pain 5, (4):195-211.

22. Picavet HS, Vlaeyen JW, Schouten JS. (2002) Pain catastrophizing and kinesiophobia: predictors of chronic low back pain. Am J Epidemiology 156 (11): 1028-34.

23. Feleus A, Bierma-Zeinstra SMA, Miedema HS, Verhagen AP, Nauta AP, Burdorf (2007) A et al. Prognostic indicators for non-recovery of non-traumatic complaints at arm, neck and shoulder in general practice6 months follow-up. Rheumatology 46: 169-176.

24. Lemmink K, Kemper H, Greef de M, Rispens P, Stevens M. (2001) Reliability of the Groningen Fitness Test for the Elderly. Journal of Aging and Physical Activity 9: 194-212. 



\section{[6]}

No difference between postural exercises

and strength and fitness exercises for

early, non-specific, work-related upper

limb disorders in visual display unit

workers: a randomised trial

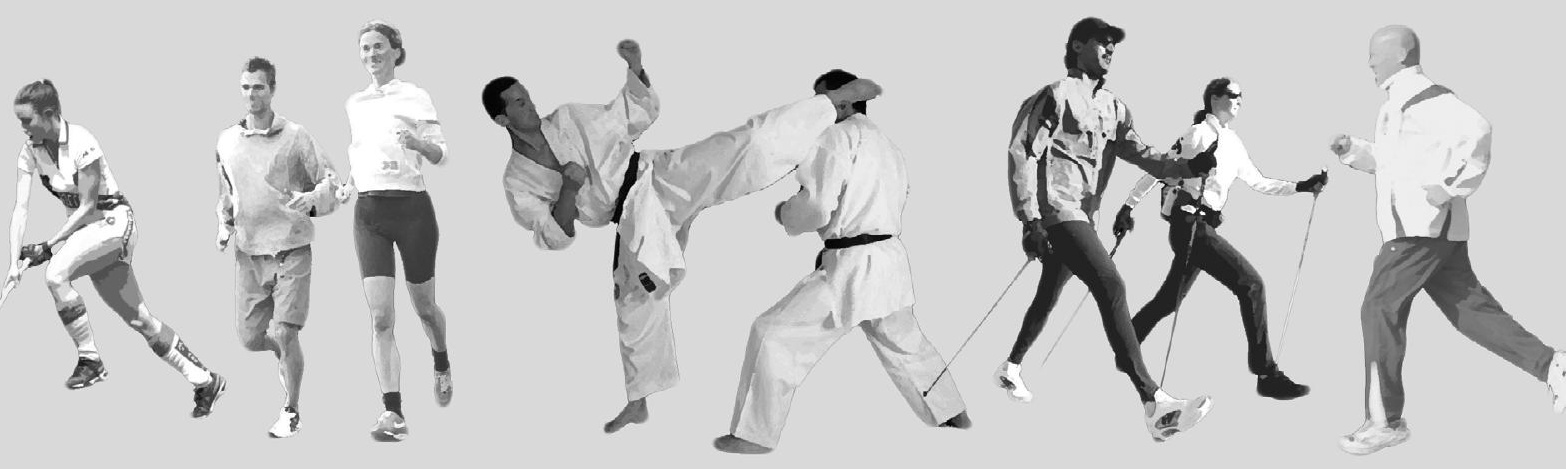

Marjon D. van Eijsden-Besseling, J. Bart Staal, Antonius van Attekum, Rob A. de Bie and Wim J. van den Heuvel

Published: Australian Journal of Physiotherapy 2008; 54 (2): 95-101. 


\begin{abstract}
Question: Are postural exercises delivered by Mensendieck/Cesar therapists more effective in decreasing pain, reducing disability and improving health-related quality of life in visual display unit workers with early non-specific work-related upper limb disorders than strength and fitness exercises delivered by physiotherapists?
\end{abstract}

Design: Randomised trial with concealed allocation and intention-to-treat analysis. Participants: Eighty-eight ( 6 drop-outs) visual display unit workers with early non- specific work-related upper limb disorders.

Intervention: One group received 10 weeks of postural exercises while the other group received 10 weeks of strength and fitness exercises.

Outcome measures: Pain was measured with a $10-\mathrm{cm}$ visual analogue scale, disability was measured with the Disabilities of Arm, Shoulder and Hand questionnaire, and health-related quality of life was measured with the Short Form-36. Number of participants experiencing upper limb complaints was also collected. Outcome measures were collected at baseline and again at 3, 6, and 12 months.

Results: There was no significant difference in decrease in pain between the groups at 3 months $(0.6 \mathrm{~cm}, 95 \% \mathrm{Cl} 0.0$ to 1.2$), 6$ months $(0.2,95 \% \mathrm{Cl}-0.3$ to 0.7$)$, or at 12 months $(0.1,95 \% \mathrm{Cl}-0.6$ to 0.8$)$. Differences between the groups in upper limb complaints, disability, and health- related quality of life were also small and not significant at any measurement occasion.

Conclusion: Postural exercises did not result in a better outcome than strength and fitness exercises. However, $55 \%$ of visual display unit workers with early non-specific work-related upper limb disorders reported being free of complaints one year after both interventions were commenced.

Trial registration: ISRCTN15872455. [van Eijsden-Besseling MD, Staal JB, van Attekum $A$, de Bie RA, van den Heuvel WJA (2008) No difference between postural exercises and strength and fitness exercises for early, non-specific, work-related upper limb disorders in visual display unit workers: a randomised trial. Australian Journal of Physiotherapy 54: 95-101] 


\section{Introduction}

In the last decade a number of authors have addressed the multicausal origins of ${ }^{1,29,33}$ and risk factors for the development of non-specific work-related upper limb disorders in visual display unit workers. ${ }^{10,18,35,41}$ However, research on the effectiveness of (multidisciplinary) therapies, especially in patients with early work-related upper limb disorders, is scarce. ${ }^{14,15,38}$ A recently-published systematic review of randomised and nonrandomised studies investigating the effect of conservative interventions in patients with mainly chronic non-specific work-related upper limb disorders shows that there is ample room for improvement in the methodological quality of the majority of the studies. ${ }^{39}$ Results are not conclusive and the evidence is conflicting when exercises are compared to no intervention. ${ }^{23,39}$ Limited evidence, however, was found for the effectiveness of exercises when compared to massage, implementing breaks during computer work sessions, massage as supplemental intervention to manual therapy, and manual therapy as supplemental intervention to exercise. ${ }^{39}$ Outcomes were measured mainly at the level of impairment, but rarely at the level of disability or quality of life. ${ }^{15,19,39}$ One randomised controlled trial showed that patients with chronic nonspecific work-related upper limb complaints benefited from multidisciplinary intervention consisting of psychological and physical sessions. ${ }^{16}$ However, no difference was found between the cost-effectiveness of multidisciplinary treatment and usual care. It can therefore be concluded that randomised studies with sound methodology are needed and that exercise therapy may be considered as a promising intervention. Moreover, we expect effective therapy in early non-specific work-related upper limb disorders to prevent impairments and disability becoming chronic.

This study was designed to compare the effectiveness of two exercise programs in visual display unit workers with early non-specific work-related upper limb disorderspostural exercises delivered by Mensendieck/Cesar therapists and strength and fitness exercises delivered by physiotherapists. The Mensendieck/Cesar approach is in use in the Netherlands, in Scandinavian countries, and in France. The approach combines exercise and education in order to improve posture and movement habits in relation to everyday activities. ${ }^{11,25,26,40}$ Visual display unit workers were chosen because they represent a relevant (and homogeneous) group at risk of developing non- specific workrelated upper limb disorders. ${ }^{18,33}$

The research question for this study was:

Are postural exercises delivered by Mensendieck/Cesar therapists more effective in decreasing pain, reducing disability, and improving health related quality of life in visual display unit workers with early non-specific work- related upper limb disorders than strength and fitness exercises delivered by physiotherapists? 
Clinical observation led to the hypothesis that postural exercises according to the Mensendieck/Cesar approach would be more effective than strength and fitness exercises.

\section{Method}

\section{Design}

A prospective randomised clinical trial was conducted. Patients were recruited by advertisement in local newspapers, through personal contact with occupational physicians of large companies, and by mailing to general practitioners. An occupational physician who was blinded to allocation sequence was involved in the selection of eligible participants. Within two weeks after selection and invitation of eligible patients to participate, baseline data were collected at one of two research locations, either the Maastricht University Hospital or the Institute for Rehabilitation Research in Hoensbroek. Participants were randomised to the postural exercise group or the strength and fitness exercise group in strata depending on the duration of the complaints (with a cut-off point at 6 weeks). Blocks of four were generated for each stratum by means of a computer generated random sequence table. Randomisation was concealed because a research assistant, who was not involved in the selection of the participants, allocated participants to groups using a list of random numbers which was generated before commencement of the study. Because both interventions were active, blinding of participants or therapists was not possible. In both groups, the 10-week intervention started within one week after baseline measures were collected. Outcome measures were collected at baseline and at 3, 6, and 12 months where the same questionnaires were completed using a computer under supervision of a research assistant. The research assistant instructed participants about the questionnaires, which had to be completed by using a computer in the participant's usual manner. The computer workstation was custom-made for this purpose for each participant. Only the pain outcome measure was assessed by the participants filling in the forms by pen during four sequential working days. Although the research assistant was blinded to group allocation, all outcome measures were self-reports so they were not blind. The completion of the questionnaires by the participants took approximately one hour each time.

\section{Participants}

Visual display unit workers were included if they: had been visual display unit workers for more than 3 months; were experiencing their first non-specific work-related upper limb disorder; had symptoms lasting more than two weeks but less than three months; and were between 20 and 45 years of age. 
Visual display unit workers were defined as employees performing computer work, with or without the use of a mouse, for at least 20 hours per week and for at least four hours continuously per day. Non-specific work-related upper limb disorders were described as pains and tingles in the upper back, neck, shoulders, arms or hands, related and restricted to visual display unit work, ie, not yet present during other everyday activities. ${ }^{22}$ Each worker completed the SALTSA questionnaire ${ }^{22}$ which is designed to diagnose 'early stage non- specific work-related upper limb disorder' and to exclude other kinds of specific work-related upper limb disorders.

Participants were excluded if they had: non-specific upper limb complaints during other daily activities (eg, brushing teeth and driving the car); specific work-related upper limb disorders (eg, carpal tunnel syndrome, tennis elbow, golfers elbow, tendonitis, de Quervain's tenosynovitis); other musculoskeletal conditions (eg, fibromyalgia, hypermobility syndromes); or were pregnant or partly or fully on sick leave; or had previously received therapy, or postural exercise therapy within the last five years.

Demographic data such as sex, age, number of working hours, and level of education were obtained at baseline. Participants were labeled as 'highly educated' if they had at least a bachelor's degree. Because the onset and course of non-specific, work-related, upper limb disorders are influenced by physical, psychosocial, and personal factors, these were measured at baseline..$^{8,18,21,33,35,41}$ Perfectionism (neurotic) was measured by the Multidimensional Perfectionism Scale, ${ }^{5,6,20}$ state and trait anxiety were measured by the State-Trait Anxiety Inventory, ${ }^{7,27}$ self-reported physical fitness level was measured by the Groningen Fitness Questionnaire, ${ }^{36}$ experienced job stress at the workplace was measured by the Job Stress Survey, ${ }^{3,28}$ and pain catastrophising thoughts by the Pain Catastrophizing Scale. ${ }^{30,31,32}$

\section{Intervention}

One group of participants received postural exercises according to the Mensendieck/Cesar approach in The Netherlands. Postural exercises according to Bess Mensendieck on the one hand and Maria Cesar on the other do not differ basically and both therapies and their training programs have been assimilated since the fusion of both societies in $2004 .^{40}$ The Mensendieck/ Cesar approach promotes a method of body posture and movement education by exercises in which integration of body and mind takes place in order to consciously improve 'poor' body posture and 'bad' movement habits in relation to everyday activities. The core of the approach is to make use of feedback from muscle, joint, tendon, and ligaments by means of audiovisual and proprioceptive signals. It is hypothesised that this feedback, repeatedly offered to and transformed in the central nervous system, will lead in the long term to automatic improvement of spinal and peripheral postural and movement habits with generalisation to daily activi- 
ties, aiming at decreasing complaints. Verbal instructions and demonstration by the therapist, as well as the use of mirrors, are essential. Video taping the participant for feedback is also valuable. ${ }^{40}$ Training in patient-specific everyday activities such as computer work forms a part of this approach ${ }^{26}$ so it can be categorised as functional. Patients are expected to do their postural exercises at home in front of a mirror and at their work place. Therapists are not allowed to touch their patients. The accredited training to become a Mensendieck/ Cesar therapist takes three years fulltime; it differs from the accredited training by the Royal Dutch Physiotherapy Association to become a physiotherapist, where training takes four years fulltime. The four Mensendieck/Cesar therapists involved in this study attended workshops and were trained practically in treating patients with non-specific work-related upper limb disorders according to the clinical practice guidelines issued by their professional organisation. ${ }^{2}$ They were not physiotherapists.

Table 1. Intervention schedules for the postural exercise and strength and fitness exercise groups.

\begin{tabular}{lcccc}
\hline Weeks & Postural exercise group & Sessions & $\begin{array}{c}\text { Strength and fitness } \\
\text { exercise group }\end{array}$ & Sessions \\
\hline $1-3$ & $2 \times 1 \mathrm{hr} / \mathrm{wk}$ & 6 & $3 \times 0.5 \mathrm{hr} / \mathrm{wk}$ & 9 \\
$4-6$ & $1 \times 1 \mathrm{hr} / \mathrm{wk}$ & 3 & $2 \times 0.5 \mathrm{hr} / \mathrm{wk}$ & 6 \\
$7-8$ & $1 \times 0.5 \mathrm{hr} / \mathrm{wk}$ & 2 & $1 \times 0.5 \mathrm{hr} / \mathrm{wk}$ & 2 \\
9 Exercises at home & $0.5 \mathrm{hr}$ & 0 & $0.5 \mathrm{hr}$ & 0 \\
10 Final session & 10.5 & 12 & 9 & 1 \\
Total & & & & 18 \\
\hline
\end{tabular}

The other group of participants received strength and fitness exercises delivered by four physiotherapists who attended a course for work-related upper limb disorders based on the latest evidence. They did not use electrotherapy or massage. Apart from local exercises to address painful areas, active spinal and peripheral muscle training and fitness exercises were part of the intervention. The focus was on improvement of muscle condition for long-lasting static postures.

Participants in both arms of the trial received 10 weeks of intervention because, based on our clinical experience, this dosage is needed to prevent early non-specific workrelated upper limb disorders become chronic. ${ }^{16}$ The postural exercise group received 12 sessions as compared to 18 for the strength and fitness exercise group (Table 1). However, the postural exercise group received 1.5 hours more intervention than the strength and fitness exercise group. The week before the final session, all participants did their exercises at home. Intervention was paid for by health insurance. Appendix 1 provides more detail of the trial method (see eAddenda for Appendix 1). 


\section{Outcome measures}

Pain was measured at the location with the highest intensity using the $10-\mathrm{cm}$ horizontal numerical visual analogue scale according to Jensen and Mc Farland. ${ }^{12}$ Pain was noted by the participants over four sequential working days at four fixed times per day (1100, 1400, 1700, and 2000 hours) to get a clear impression of the pain experienced throughout the whole working week. Therefore, this outcome measure consisted of the average of 16 visual analogue scale scores over four days, with a higher rating indicating a higher intensity of pain. According to Jensen $\&$ Mc Farland ${ }^{12}$ this instrument has a good test-retest reliability, internal consistency, and validity.

Disability was measured with the Disabilities of the Arm, Shoulder and Hand. ${ }^{24,37}$ At least 27 of the 30 items must be completed to calculate a score ranging from 0 to 100 . A lower score indicates less disability. Veehof ${ }^{37}$ showed that the Dutch language version of this measure has excellent internal consistency (Cronbach's alpha 0.95) while test-retest reliability and concurrent validity are satisfactory.

Health-related quality of life was measured with the generic Short Form-36 questionnaire. ${ }^{9,19,34}$ The Short Form-36 consists of 36 questions divided over 8 subscales, and one question about change in health experienced during the past year. The total sum score of the Short Form-36 was used which ranges from 0 to 100. The higher the total score, the higher the quality of life. The subscales can be used to compare persons with different chronic conditions. The reliability of most of the subscales in chronic populations is higher than 0.80 , while the homogeneity is higher than 0.50 , indicating a strong unidimensional hierarchical scale. ${ }^{17}$

The number of participants experiencing upper limb complaints was measured by asking participants to answer YES/NO to the question 'Do you still experience non-specific work-related upper limb complaints?'

\section{Data analysis}

The expected improvement in pain in the postural exercise group was set at $60 \%$, and for the strength and fitness exercise group at $40 \%$, implying a minimal clinically relevant difference of $20 \%$, correlating with $20 \mathrm{~mm}$ difference on the horizontal visual analogue scale. These expected improvements in pain were based on past clinical experience. With an alpha of 0.05 and a 1-beta of $80 \%$ in total, 94 visual display unit workers were needed to provide sufficient power to answer the research questions.

Data were analysed by a blinded statistician. Data were checked for missing values and normality. Each follow-up time point was analysed separately and the analyses were 
carried out according to the intention-to-treat principle. Missing values were replaced by the last observation carried forward method. Differences in baseline characteristics and baseline values of the outcome measures between the postural exercise group and the strength and fitness exercise group were tested with an independent samples t-test $(\alpha=0.05)$. The three outcome measures pain, functional disability, and quality of life were analysed by means of linear regression analysis. In the event of significant differences between baseline characteristics and baseline values of the outcome measures between the two groups, adjustments were made in the linear regression analyses.

\section{Results}

\section{Flow of participants through the trial}

Flow of participants through the trial is presented in Figure 1. Participants were selected from the 313 potential participants who contacted us and were diagnosed between May 2003 and February 2005. Many potential participants had to be excluded for various and in some cases multiple reasons: 133 had complaints for more than three months, 77 had already received therapy, 46 were older than 45 years, 38 lived too far away, two refused randomisation, four refused to participate due to private circumstances, and 70 due to other reasons consistent with the predefined exclusion criteria. As 88 participants (28\%) met the inclusion criteria and were willing to participate. 44 participants were randomised to each arm of the trial. The groups were comparable at baseline for nearly all variables. The only significant difference between the postural exercise and the strength and fitness exercise group concerned the score on the Pain Catastrophizing Scale $(p=0.04)$ in that the strength and fitness exercise group demonstrated more catastrophising thoughts (Table 2) which was adjusted for in the analyses.

Between baseline and three months there were six drop outs. There were four dropouts from the postural exercise group: stress from losing job and increase in complaints $(n=1)$, recruited participant too late for the first session $(n=1)$, time pressure of job ( $n$ $=2$ ). There were two dropouts from the strength and fitness exercise group: participant wanted alternative intervention after 3 sessions $(n=1)$, participant did not want to comply with study requirements $(n=1)$. 
Table 2. Baseline characteristics of the postural exercise and strength and fitness exercise groups.

\begin{tabular}{|c|c|c|c|}
\hline & $\begin{array}{l}\text { Postural exercise } \\
\text { group }(n=44)\end{array}$ & $\begin{array}{l}\text { Strength and fitness } \\
\text { exercise group }(n=44)\end{array}$ & $p$ value \\
\hline Gender, M:F & $19: 25$ & $19: 25$ & - \\
\hline Education, High:Low & 29:15 & $30: 14$ & - \\
\hline Age (yr), mean (SD) & $33.3(7.7)$ & $34.8(7.7)$ & 0.38 \\
\hline $\begin{array}{l}\text { Multidimensional Perfectionism Scale* ( } 29 \text { to } \\
\text { 145), mean (SD) }\end{array}$ & $62.7(16.4)$ & $63.2(18.7)$ & 0.89 \\
\hline State Anxiety Inventory* (20 to 80 ), mean (SD) & $32.9(8.9)$ & $33.1(10.6)$ & 0.93 \\
\hline Trait Anxiety Inventory* (20 to 80 ), mean (SD) & 34.5 (9.9) & $35.3(9.8)$ & 0.69 \\
\hline Self-reported fitness (9 to 45), mean (SD) & $26.9(2.8)$ & $26.7(2.1)$ & 0.64 \\
\hline Fitness mark (1 to 10$)$, mean (SD) & $7.0(1.1)$ & $7.2(1.5)$ & 0.38 \\
\hline Job Stress Survey* (0 to 81), mean (SD) & $16.2(10.7)$ & $15.6(10.0)$ & 0.82 \\
\hline Pain Catastrophizing Scale (0 to 52), mean (SD) & $22.5(6.6)$ & $25.5(6.3)$ & 0.04 \\
\hline \multicolumn{4}{|l|}{ Duration of complaints } \\
\hline$<6$ weeks $(n=16)$ & 8 & 8 & \\
\hline$>6$ weeks $(n=72)$ & 36 & 36 & \\
\hline Working hours per week, mean (SD) & $37.2(10.7)$ & $38.5(6.3)$ & 0.5 \\
\hline
\end{tabular}

*The higher the score, the more the attribute applies

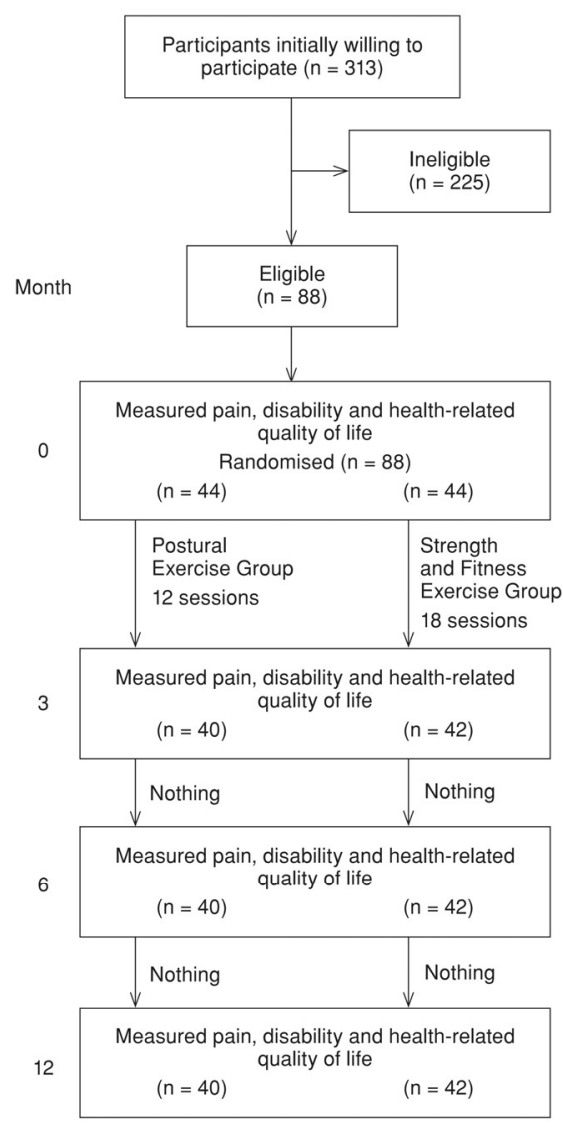

Figure 1. Design and flow of participants through the trial 


\section{Compliance with intervention}

To make both groups comparable, we converted the number of sessions to 30-min sessions. Mean number of 30-min sessions attended was 14.3 out of 18 (SD 4.2) for the strength and fitness exercise group and 17 out of 21 (SD 3.6) for the postural exercise group. One participant in each group never attended, one participant in the strength and fitness exercise group stopped attending after three sessions, and three participants in the postural exercise group stopped attending after 5, 9, and 14 sessions respectively. All other participants only stopped when they were free of complaints. After accounting for participants who stopped attending because they were free of complaints, compliance was $96 \%$ in the strength and fitness exercise group and $94 \%$ in the postural exercise group.

\section{Effect of intervention}

Group data for pain, disability, and quality of life are presented in Table 3; data for number of participants experiencing upper limb complaints appear in Table 4.

Table 4. Number of participants (\%) with complaints in both groups and relative risk $(95 \% \mathrm{Cl})$ between groups.

\begin{tabular}{lccccccccc}
\hline Outcome & & \multicolumn{4}{c}{ Groups } & \multicolumn{4}{c}{ Relative risk between groups } \\
& Month 3 & Month 6 & Month 12 & Month 3 & Month 6 & Month 12 \\
\hline \multirow{4}{*}{ Complaints } & PE & SFE & PE & SFE & PE & SFE & PE relative to & PE relative to & PE relative to \\
& & & & & & & SFE & SFE & SFE \\
& $(68)$ & 28 & 21 & 21 & 19 & 20 & 1.07 & 1.00 & 0.95 \\
& $(64)$ & $(48)$ & $(48)$ & $(43)$ & $(46)$ & $(0.79$ to 1.45$)$ & $(0.65$ to 1.55) & (0.59 to 1.52) \\
\hline
\end{tabular}

$\mathrm{PE}=$ postural exercise group, $\mathrm{SFE}=$ strength and fitness exercise group

At 3 months, the strength and fitness exercise group had decreased their pain $0.6 \mathrm{~cm}$ (95\% $\mathrm{Cl} 0.0$ to $1.2, p=0.05$ ) more than the postural exercise group on the $10-\mathrm{cm}$ visual analogue scale. However, this difference was not maintained at 6 and 12 months. Otherwise no significant differences between the groups were observed. Overall, there were only small improvements from baseline to one year. 


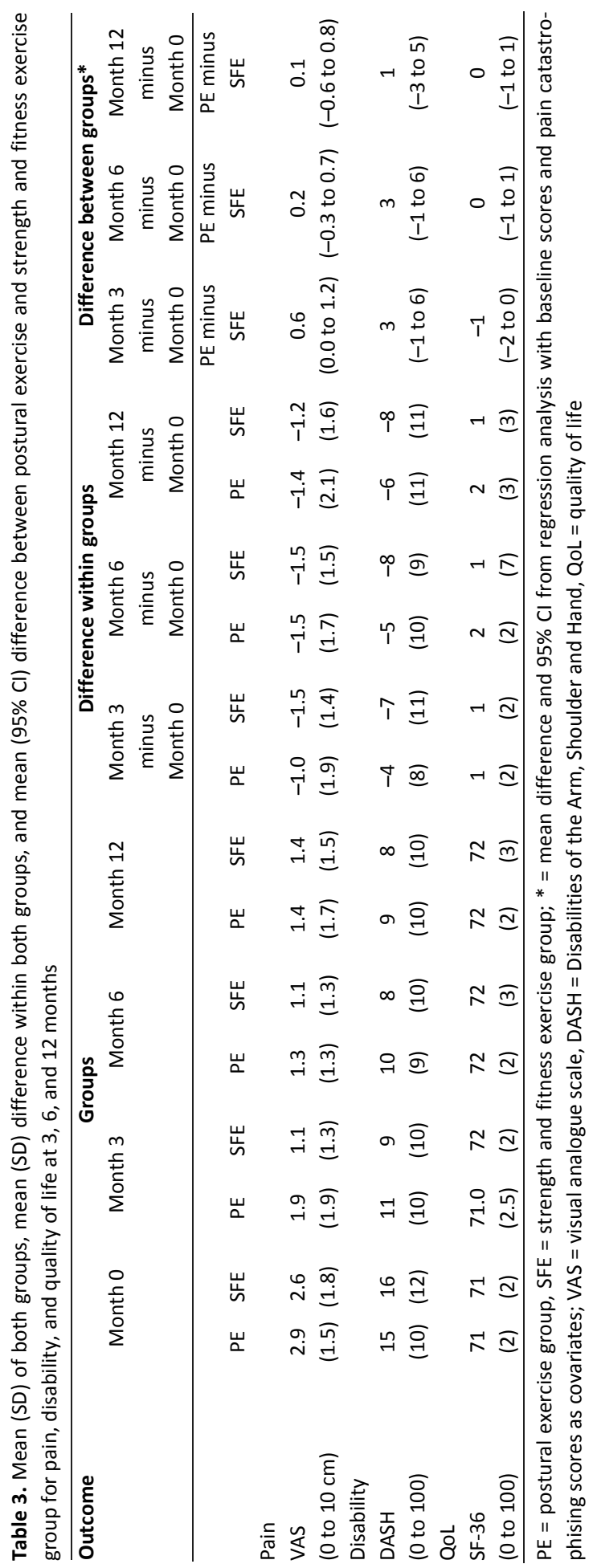


Answers to 'Do you still experience non-specific work- related upper limb complaints?' showed that complaints decreased gradually over the year and that about $55 \%$ of both groups were free of pain at the end of one year (Table 4).

\section{Discussion}

The prevalence of non-specific work-related upper limb disorders among visual display unit workers in The Netherlands, and also worldwide, is high. Non-specific work- related upper limb disorders tend-if untreated-to become chronic very easily. ${ }^{16}$ Daily practice in our tertiary referral centre for non-specific work-related upper limb disorders shows this. Almost no research has been done on early intervention with respect to early non-specific work-related upper limb disorders. Two types of therapy were compared in this study, postural exercises delivered by Mensendieck/Cesar therapists and strength and fitness exercises delivered by physiotherapists. Although clinical observations in our centre gave the impression that patients benefited more from postural exercises than from strength and fitness exercises, this was not substantiated.

Earlier research in Norway ${ }^{25}$ in low back pain patients showed that postural exercises according to the Mensendieck approach reduced the occurrence of recurrent episodes of low back pain. Intervention delivered by Cesar therapists has been shown to be as effective for low back pain as intervention delivered by physiotherapists. ${ }^{11}$ Together with our favorable clinical observations this supported our choice to study the effects of postural exercises in patients with work-related upper limb disorders.

Almost no significant difference was found between the postural exercises and the strength and fitness exercises in outcome at either the impairment level or the disability level, or regarding health-related quality of life. About $55 \%$ of visual display unit workers with early non-specific work-related upper limb disorders reported being free of complaints one year after having started early intervention. We are not sure whether these improvements are caused by the interventions since we did not include a waiting-list control group. In two Dutch cohort studies on the prognosis of nonspecific upper limb complaints similar results were found. Feleus ${ }^{4}$ reported a recovery rate of $54 \%$ in a general practice, and Karels ${ }^{13}$ and reported a recovery rate of $60 \%$ after six months in a physiotherapy practice; but in both cases no information about the actual content of the intervention was provided. Therefore, patient preferences may play an important role in the decision of which intervention to choose. Both therapies were about equal in terms of therapist cost. The outcomes were reached with 1.5 hours less strength and fitness exercises than postural exercises. On the other hand, there were fewer sessions delivered by the Mensendieck/Cesar therapists compared with the physiotherapists (12 compared to 18 ). 
This randomised trial is the first of its kind in early non- specific work-related upper limb disorders. Our centre for non-specific work-related upper limb disorders hosts more than 1500 patients, while each week new patients are being admitted. We had therefore expected that there would be an overwhelming number of patients applying to participate in this research project. However, many efforts had to be made to find potential participants. Finally, after extension of the original inclusion period by three months, 313 patients applied and only 88 persons (28\%) were included. The most likely explanation for the low inclusion rate is that patients with early non-specific workrelated upper limb disorders, who met the inclusion criteria, were very interested in our study but could not find the time, due to constraints at work and were hoping that their complaints would disappear without professional help. On the other hand there were many patients with chronic complaints lasting longer than three months $(n=133)$ who strongly desired to participate but did not meet the inclusion criteria. These observations convinced us that it would not be feasible for ethical reasons to select and follow another control group with early non- specific work-related upper limb complaints without giving any type of therapy (ie, a waiting-list control group).

Possibly, both therapies resemble each other too much to find significant differences in outcomes. At baseline there was only a moderate intensity of pain (ie, less than $3 \mathrm{~cm}$ on a $10-\mathrm{cm}$ visual analogue scale), and a small amount of disability (about 15\%) which may have elicited floor effects, while the scores for health-related quality of life (about $70 \%$ ) are rather good. This is understandable because we were dealing with early nonspecific work-related upper limb disorders. Remarkable on the other hand is the high score at baseline on the Pain Catastrophizing Scale in these visual display unit workers with early complaints. Scores on the State and Trait Anxiety Inventories, the Multidimensional Perfectionism Scale, and the Job Stress Survey at baseline suggested that participants were not particularly anxious, perfectionist, or stressed (Table 2).

Randomised trials of larger groups of visual display unit workers are recommended to arrive at more conclusive results. In future, personality and psychosocial work-related risk factors ${ }^{8,33,35}$ and inter-related coping mechanisms should be the focus of intervention since both physically- oriented exercise programs led to the same outcome in this study.

eAddenda: Appendix 1 available at www.physiotherapy. asn.au

Ethics: This research project was approved by the Medical Ethical Committee of the University Hospital of Maastricht.

Sources of support: Research Stimulation Fund of University Hospital Maastricht, Institute for Rehabilitation Research, Hoensbroek, The Netherlands. 


\section{References}

1. Bongers PM (2003) Oration: Maak werk van RSI. (Take pains over WRULD) Amsterdam: Bout \& Zonen.

2. Bredero AB, Jans MP, Vos GE (2000) Richtlijn oefentherapie Mensendieck bij patiënten met RSI-klachten: Nederlandse Vereniging voor oefentherapie Mensendieck/Nederlands Paramedisch Instituut (Guideline for postural exercise therapy according to Mensendieck for patients with repetitive strain injuries.) Dutch Society for Postural Exercise Therapists/ Dutch Paramedical Institute.

3. de Wolff B, Swinnen L, de Fruyt F, de Wolff C, Spielberger CD (2002) JSS Job Stress Survey. Handleiding/Manual. Swets Test Publishers.

4. Feleus A, Bierma-Zeinstra SM, Miedema HS, Verhagen AP, Nauta AP, Burdorf A, Verhaar JA, Koes BW (2006) Prognostic indicators for recovery of non-traumatic complaints at arm, neck and shoulder: 6 months follow-up. Rheumatology 46: 169-176.

5. Flos CH (1998) Validity and reliability of the Frost Multidimensional Perfectionism Scale (Thesis). Maastricht: Faculty of Health Sciences, University Maastricht.

6. Frost RO, Marten PA (1990) Perfectionism and evaluative threat. Cognitive Therapy Research 14: 559572.

7. Furer JW, König-Zahn C, Tax B (1995) 14 State-Trait Anxiety Inventory (STAI) Het meten van de gezondheidstoestand. Beschrijving en evaluatie van vragenlijsten Deel 3 Psychische gezondheid (Measuring the health status. Description and evaluation of questionnaires. Part 3 Mental health). Assen: Van Gorcum, pp. 136-146.

8. Gerhards SAH (2006) Cost-effectiveness of specific Mensendieck/Cesar therapy for screen workers with non- specific WRULD phase one. Thesis. Faculty of Health Sciences. University of Maastricht, The Netherlands.

9. Hays RD, Sherbourne CD, Mazel R (1993) The RAND 36-item health survey 1.0. Health Economics 2: 217227.

10. Health Council of the Netherlands (2000) RSI, Publication No. 2000/22. The Hague: Health Council of the Netherlands.

11. Hildebrandt VH, Proper KI, van den Berg R, Douwes M, van den Heuvel SG, van Buuren S (2000) Cesar therapy is temporarily more effective in patients with chronic low back pain than the standard treatment by family practitioner: randomized, controlled and blinded clinical trial with 1 year follow-up (article in Dutch). Ned Tijdschr Geneeskd 144: 2258-2264.

12. Jensen MP, McFarland CA (1993) Increasing the reliability and validity of pain intensity measurement in chronic pain patients. Pain 55: 195-203.

13. Karels CH, Bierma-Zeinstra SM, Burdorf A, Verhagen AP, Nauta AP, Koes BW (2007) Social and psychological factors influenced the course of arm, neck and shoulder complaints Journal of Clinical Epidemiology 60: 839-848.

14. Karjalainen KA, Malmivaara AO, van Tulder MW, Roine RP, Jauhiainen S, Hurri HO, Koes BW (2000) Biopsychosocial rehabilitation for upper limb repetitive strain injuries in working age adults. Cochrane Database of Systematic Reviews: (3) CD002269.

15. Konijnenberg HS, de Wilde NS, Gerritsen AA, van Tulder MW, de Vet HC (2001) Conservative treatment for repetitive strain injury. Scandinavian Journal of Work, Environment and Health 27: 299-310.

16. Meijer EM, Sluiter JK, Heyma A, Sadiraj K, Frings-Dresen MH (2006) Cost- effectiveness of multidisciplinary treatment in sick-listed patients with upper extremity musculoskeletal disorders: a randomized, controlled trial with one-year follow- up. International Archives of Occupational and Environmental Health 79: 654-664.

17. Moorer P, Suurmeije ThP, Foets M, Molenaar IW (2001) Psychometric properties of the RAND-36 among three chronic diseases (multiple sclerosis, rheumatic diseases and COPD) in the Netherlands. Quality of Life Research 10: 637-645.

18. Peereboom KJ c.s. (2005/2006) RSI Handboek (RSI Handbook) 4th Edition. The Hague: Sdu Editors.

19. Picavet HSJ, Hoeymans N (2004) Health related quality of life in multiple musculoskeletal diseases: SF-36 and EQ-5D in the DMC3 study. Annals of the Rheumatic Diseases 63: 723-729. 
20. Purdon C, Antony MM, Swinson RP (1999) Psychometric properties of the Frost Multidimensional Perfectionism Scale in a clinical anxiety disorder sample. Journal of Clinical Psychology 55: 1271-1286.

21. Roelofs PD (2002) RSI en persoonsgebonden factoren: een oriënterende studie. (RSI, personal and personality factors: an explorative study). Maastricht: University (Thesis). From http://www.unimaas.nl/bestand.asp?id $=2275$

22. Sluiter JK, Rest KM, Frings-Dresen MH (2001) Criteria document for evaluation of the work-relatedness of upper extremity musculoskeletal disorders. Scandinavian Journal of Work, Environment and Health 27 Suppl 1: 1-102.

23. Smidt N, de Vet HC, Bouter LM, Dekker J (2005) Effectiveness of exercise therapy: a best-evidence summary of systematic reviews. Australian Journal of Physiotherapy 51: 71-85.

24. SooHoo NF, McDonald AP, Seiler JG 3rd, McGillivary GR (2002) Evaluation of the construct validity of the DASH questionnaire by correlation to the SF-36. Journal of Hand Surgery 27: 537-541.

25. Soukup MG, Glomsröd B, Lönn JH, Bö K, Larsen S (1999) The effect of a Mensendieck exercise program as secondary prophylaxis for recurrent low back pain. A randomized controlled trial with $12-$ months follow-up. Spine 24: 1585-1591.

26. Soukup MG, Lönn J, Glomsröd B, Bö K, Larsen S (2001) Exercises and education as secondary prevention for recurrent low back pain. Physiotherapy Research International 6: 27-39.

27. Spielberger CD (1983) Manual for the State-Trait Anxiety Inventory (Form Y). Pao Alto: Consulting Psychologists Press.

28. Spielberger CD, Reheiser EC, Vagg PR (1998) Measuring stress in the work place: The Job Stress Survey. In Kenny D, Carlson DS, McGuigan FJ, Sheppard W (Eds) Stress and health: research and clinical applications. Ryde: Gordon \& Breach.

29. Staal JB, de Bie RA, Hendriks EJ (2007) Aetiology and management of work-related upper limb disorders. Best Practice \& Research Clinical Rheumatology 21: 123-133.

30. Sullivan MJ, Stanish W, Waite H, Sullivan M, Tripp DA (1998) Catastrophizing, pain and disability in patients with soft- tissue injuries. Pain 77: 253-260.

31. Van Damme S, Crombez G, Vlaeyen JW, Goubert L, van den Broeck A, van Houdenhove B (2000) De Pain Catastrophizing Scale: Psychometrische karakteristieken en normering (The Pain Catastrophizing Scale: Psychometric Characteristics and Norms). Gedragstherapie 33: 209-220.

32. Van Damme S, Crombez G, Bijttebier P, Goubert L, van Houdenhove B (2002) A confirmatory factor analysis of the Pain Catatrophizing Scale: invariant factor structure across clinical and non-clinical populations. Pain 96: 319-324.

33. Van den Heuvel S (2006) Work-related neck and upper limb symptoms. (PhD Thesis) Amsterdam TNO.

34. Van der Zee KL, Sanderman R (1993) Het meten van de algemene gezondheidstoestand met de RAND36. Een handleiding. (Measurement of the general state of health with the RAND-36. A manual). Groningen: Noordelijk Centrum voor Gezondheidsvraagstukken.

35. Van Eijsden-Besseling MD, Peeters FP, Reijnen JA, de Bie RA (2004) Perfectionism and coping strategies as risk factors for the development of non-specific work-related upper limb disorders (WRULD). Occupational Medicine 54: 122-127.

36. Van Heuvelen MJ, Kempen GI, Ormel J, de Greef MH (1997) Self-reported physical fitness of older persons: a substitute for performance-based measures of physical fitness? Journal of Aging and Physical Activity 5: 298-310.

37. Veehof MM, Sleegers EJ, van Veldhoven NH, Schuurman AH, van Meeteren NL (2002) Psychometric qualities of the Dutch language version of the disabilities of the arm, shoulder and hand questionnaire (DASH-DLV). Journal of Hand Therapy 15: 347-354.

38. Verhagen AP, Bierma-Zeinstra SM, Feleus A, Karels C, Dahaghin S, Burdorf L, de Vet HC, Koes BW (2004) Ergonomic and physiotherapeutic interventions for treating upper extremity work related disorders in adults. Cochrane Database Systematic Reviews (1): CD003471.

39. Verhagen AP, Karels C, Bierma-Zeinstra SM, Feleus A, Dahaghin S, Burdorf A, Koes BW (2007) Exercise proves effective in a systematic review of work-related complaints of the arm, neck, or shoulder. Journal of Clinical Epidemiology 60: 110.e1-.e14. 
40. VvOCM, Vereniging voor oefentherapie Cesar en Mensendieck (2005) (Society for Exercise Therapy Cesar and Mensendieck). www.vvocm.nl

41. IJmker S, Huysmans M, Blatter BM, van der Beek AJ, van Mechelen W, Bongers PM (2007) Should office workers spend fewer hours at their computer? A systematic review of the literature. Occupational and Environmental Medicine 64: 211-222. 


\section{[7]}

Cost-effectiveness of postural exercise therapy versus physiotherapy in computer screen-workers with early non-specific work-related upper limb disorders (WRULD): a randomized controlled trial

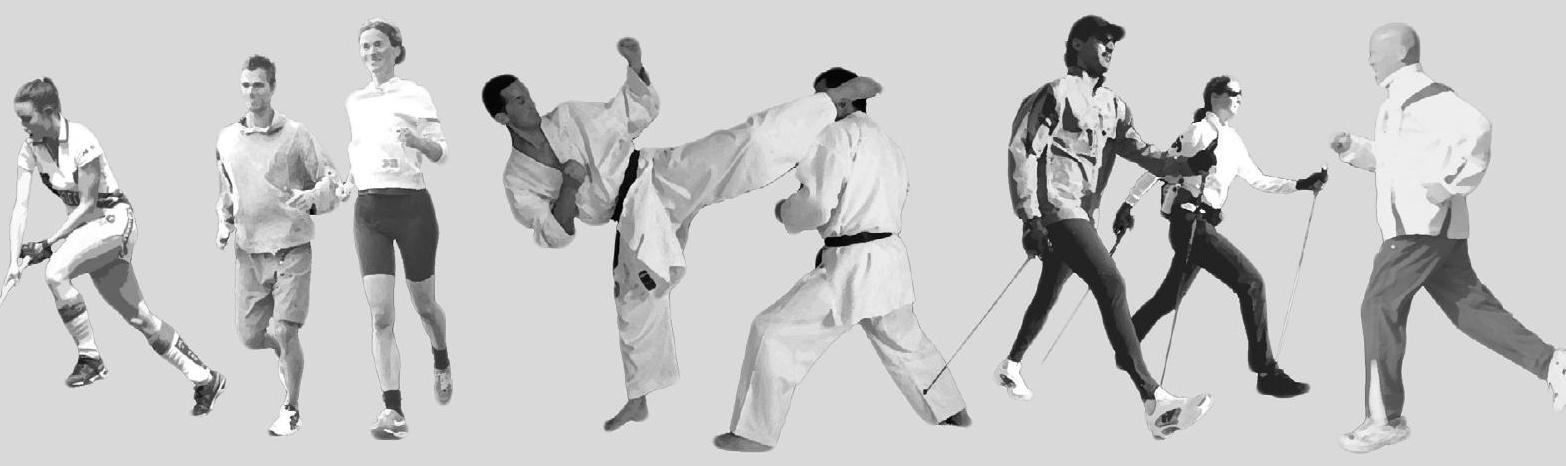




\begin{abstract}
Background: Exercise therapies generate substantial costs in computer workers with non-specific work-related upper limb disorders (WRULD).

Aims: To study if postural exercise therapy is cost-effective compared to regular physiotherapy in screen-workers with early complaints, both from health care and societal perspective.
\end{abstract}

Methods: Prospective randomized trial including cost-effectiveness analysis; one year follow-up. Participants: Eighty-eight screen-workers with early non-specific WRULD; six drop-outs. Interventions: A ten week postural exercise program versus regular physiotherapy. Outcome measures: Effectiveness measures: Pain: visual analogous scale (VAS), self-perceived WRULD (yes/no). Functional outcome: Disabilities of Arm, Shoulder and Hand- Dutch Language Version (DASH-DLV). Quality of life outcome: EQ-5D. Economic measures: health care costs including patient and family costs and productivity costs resulting in societal costs. Cost-effectiveness measures: health care costs and societal costs related to the effectiveness measures. Outcome measures were assessed at baseline; three, six and twelve months after baseline.

Results: At baseline both groups were comparable for baseline characteristics except scores on the Pain Catastrophizing Scale and comparable for costs. No significant differences between the groups concerning effectiveness at one year follow-up were found. Effectiveness scores slightly improved over time. After one year $55 \%$ of participants were free of complaints. After one year the postural exercise group had higher mean total health care costs, but lower productivity costs compared to the physiotherapy group. Mean societal costs after one year (therefore) were in favor of postural exercise therapy [- €622; 95\% Cl $-2087 ;+590)]$. After one year, only self- perceived WRULD seemed to result in acceptable cost-effectiveness of the postural exercise strategy over physiotherapy; however the probability of acceptable cost-effectiveness did not exceed $60 \%$.

Considering societal costs related to QALYs, postural exercise therapy had a probability of over $80 \%$ to be cost-effective over a wide range of cost-effectiveness ceiling ratios; however based on a marginal QALY-difference of 0.1 over a 12 month time frame.

Conclusion: Although our trial failed to find significant differences in VAS, QALYs and ICERs based on VAS and QALYs at one-year follow-up, CEACs suggest that postural exercise therapy according to Mensendieck/Cesar has a higher probability of being cost-effective compared to regular physiotherapy; however further research is required. 


\section{Background}

The prevalence of Work-Related Upper Limb Disorders (WRULD) in the Dutch working population is estimated about $19-30 \% .{ }^{1}$. Due to expectations of increasing intensity of computer screen-work, the prevalence of WRULD among screen-workers is expected to increase even more. ${ }^{2,3}$

WRULD can result in decreased productivity, increased medical consumption and consequently increased costs. A recent study estimates the total yearly costs due to specific and non-specific WRULD in the Netherlands at about 2.1 billion Euros, consisting of medical costs, costs due to decreased productivity, absenteeism related to WRULD and disability pensions. ${ }^{4}$

It can be assumed that WRULD is associated with a decreased quality of life. ${ }^{5}$

Of all WRULD complaints, it is estimated that specific disorders are responsible for about $13-37 \%$ of them. The majority concerns non-specific WRULD. ${ }^{1,2}$

In the Netherlands non-specific WRULD is treated within various medical and paramedical disciplines. ${ }^{1}$ Postural exercise (PE) therapy according to Mensendieck/Cesar ${ }^{6}$ and regular physiotherapy (RP) are two treatments in the Netherlands used for patients suffering from WRULD. ${ }^{7}$

Very little reliable research is available regarding the effectiveness of exercise and other treatments in non-specific WRULD. ${ }^{8-11}$

The same goes for cost-effectiveness studies ${ }^{12,13}$ in which the quality of life rarely was used as an outcome measure in musculoskeletal disorders. ${ }^{14}$

The high prevalence, costs and decreased quality of life signify a large impact of nonspecific WRULD.

Beyond effectiveness studies, cost-effectiveness studies in relation with quality of life are needed in patients with non-specific WRULD to be able to improve health care and to lower the costs.

As the department of rehabilitation of the Maastricht University Hospital acts as a tertiary referral centre for non-specific WRULD complaints a cost-effectiveness study among computer screen-workers with early stages of non-specific WRULD was set up. 
In the current study we tested if postural exercise therapy according to Mensendieck/Cesar is cost-effective with respect to pain, disability and quality of life as when compared to regular physiotherapy in computer screen-workers with early stages of non-specific WRULD, both from a health care and societal perspective.

\section{Methods}

\section{Design}

A prospective randomized clinical trial was set up among computer screen-workers with early non-specific work-related upper limb disorders. ${ }^{11}$ Recruitment took place by advertisement in local newspapers, by personal contact with occupational physicians of large industries and by mailing to general practitioners in South Limburg. Screenworkers fulfilling the inclusion criteria were invited to take part in this study. Selection and diagnosis were performed by an independent occupational physician familiar with the diagnosis of "non-specific WRULD" who was blinded to allocation sequence.

Within two weeks after eligible patients were selected and invited to participate by the occupational physician, baseline assessments were performed at one of two locations, either the Maastricht University Hospital or the Institute for Rehabilitation Research in Hoensbroek, a small town in the south-eastern region of the Netherlands.

Participants were randomized to the PE group or the RP group in strata depending on the duration of the complaints (cut-off point six weeks). Blocks of four were generated for each stratum by means of a computer generated random sequence table.

Randomization was concealed because a research assistant, who was not involved in the selection of the participants, allocated participants to groups using a list of random numbers which was generated before commencement of the trial. Because both interventions were active, blinding of participants and therapists was not possible. In both groups, the ten week intervention started within one week after baseline measures were completed. Outcome measures were collected at baseline and at three, six and twelve months where the same questionnaires were completed using a computer under the supervision of a research assistant. The research assistant instructed participants about the questionnaires, which had to be completed by using a computer in the participant's usual manner. The computer workstation was custom-made for this purpose for each participant. Only the pain outcome measure was assessed by the participants filling in the forms by pen during four sequential working days. ${ }^{15}$ Although the research assistant was blinded to group allocation, all outcome measures were self- 
reports so they were not blind. The completion of the questionnaires by the participants took approximately one hour each time.

This research project was approved by the Medical Ethical Committee of the University Hospital of Maastricht.

\section{Participants}

Computer screen-workers with early non-specific WRULD. ${ }^{11}$ Early non-specific WRULD were defined as pains and tingles in upper back, neck, shoulders, arms or hands related and restricted to computer screen-work, not yet present during other daily activities and not labelled as a specific diagnosis such as tennis elbow. Computer screen-workers were defined as those employees performing computer work, with or without the use of a mouse, for at least twenty hours per week and at least four hours continuously per day. Computer screen-workers were chosen because they represent a homogeneous group who are at risk for developing non-specific WRULD ${ }^{2,16}$

To be eligible for this study, participants had to fulfil the following inclusion criteria:

- were computer screen-worker at the time of first complaints and being employed in present job for at least three months

- had non-specific WRULD with symptoms existing longer than two weeks but shorter than three months

- $\quad$ aged between 20 and 45 years

Excluded were patients not fulfilling the inclusion criteria and patients with non-specific WRULD during other daily activities such as teeth brushing and car driving, patients with specific WRULD (e.g. carpal tunnel syndrome, tennis elbow, golfers elbow, tendonitis de Quervain), patients with other diseases of musculoskeletal system (e.g. fibromyalgia, hyper mobility syndromes), pregnant patients, patients who were on sick leave and patients who already had received therapy for their complaints or who had received postural exercise therapy during the last five years.

\section{Interventions}

One group of participants received PE therapy, in the Netherlands known as Mensendieck and Cesar. PE therapy according to Bess Mensendieck and Maria Cesar do not differ basically and both therapies and their training programs have been assimilated since the fusion of both societies in 2004. ${ }^{6,11}$ PE therapy according to Mensendieck/Cesar is in use in the Netherlands, the Scandinavian countries and France. PE therapy promotes a method of body posture- and movement education by exercises in which the integration of body and mind takes place in order to improve 
consciously poor body posture and bad movement habits in relation to daily life activities. The core of the therapy is to make use of feedback from muscle-, joint-, tendonand ligament positions by means of audio- (verbal instructions), visual (mirrors and video records) and proprioceptive registered signals. ${ }^{6}$ It is hypothesized that this feedback, repeatedly offered to and transformed in the central nervous system, will lead in the long term to automatic improvement of postural and movement habits with generalization to daily activities aiming at decrease of complaints. Training in patient specific daily life activities such as computer work forms a part of this therapy. The four therapists involved in this study were trained in treating patients with non-specific WRULD.

The other group of participants received RP and was treated by four physiotherapists who attended a WRULD-course. They did not make use of applications or massage techniques. Active muscle training and fitness exercises were part of the therapy. The focus was on improvement of muscle condition for long-lasting static postures.

All participants in both treatment arms received ten weeks of therapy according to protocol. $^{11}$

The PE group received in total one and a half hours more therapy compared to the RP group, although the last group received six more sessions (Table 1).

Table 1. Therapy schedules

\begin{tabular}{lll}
\hline Weeks & $\begin{array}{l}\text { Postural Exercise therapy (PE) } \\
\text { Per week }\end{array}$ & $\begin{array}{l}\text { Regular Physiotherapy (RP) } \\
\text { Per week }\end{array}$ \\
\hline $1-3$ & $2 \times 1$ hour & $3 \times 1 / 2$ hour \\
$4-6$ & $1 \times 1$ hour & $2 \times 1 / 2$ hour \\
$7-8$ & $1 \times 1 / 2$ hour & $1 \times 1 / 2$ hour \\
9 & Exercises at home & Exercises at home \\
10 & Final session $1 / 2$ hour & Final session $1 / 2$ hour \\
Total hours treatment & $101 / 2$ hours & 9 hours \\
\hline
\end{tabular}

Treatments were paid for by health care insurance companies.

\section{Outcome measures}

\section{Baseline characteristics}

At baseline, besides the effectiveness measures (see further) sex, age, number of working hours and level of education were assessed.

Participants were labeled as "highly educated" if they had at least a bachelor's degree. 
As this syndrome is related to work, the number of working hours was registered. Because onset and course of non-specific WRULD are influenced by physical, psychosocial and personal risk factors, ${ }^{2,16-18}$ variables assessing these risk factors were measured at baseline.

The following variables were assessed:

1. The validated Groningen Fitness Questionnaire ${ }^{19}$ was used to measure individual self-reported fitness level.

2. The Dutch version of the Job Stress Survey (JSS) ${ }^{20}$ was used to measure job stress experienced at the work place.

3. The Dutch version of the Multidimensional Perfectionism Scale of Frost (MPS-F) measures (neurotic) perfectionism. ${ }^{17,21}$

4. The Dutch version of the State-Trait Anxiety Inventory (STAI) measures staterespectively trait anxiety ${ }^{22}$

5. The Dutch version of the Pain Catastrophizing Scale (PCS) has been used to measure to which extend people who suffer from pain experience catastrophizing thoughts. ${ }^{23}$

\section{Effectiveness measures}

As a primary outcome measure we used the horizontal numerical visual analogous ten $\mathrm{cm}$ scale (VAS) according to Jensen ${ }^{15}$ to measure pain at baseline and pain in course of time at the location with the highest pain intensity. In our research project pain was measured at each measurement moment by the participants themselves by hand during four sequential working days/four fixed times a day (at 11, 14, 17 and 20 o' clock) to get a relevant impression about the existence of pain during the whole working week. The final VAS outcome measure was recalculated as the average of sixteen ratings over the four days. In addition, self-perceived WRULD at each follow-up moment was assessed by a dichotomous variable which was the answer to the question: "do you still perceive non-specific WRULD complaints, yes or no?"

As a secondary outcome measure we used the Disabilities of the Arm, Shoulder and Hand- Dutch Language Version (DASH-DLV) questionnaire ${ }^{24}$ to measure physical function and symptoms and the disabilities to fulfil daily life activities. At least 27 out of 30 items must be completed to calculate a score from 0 till 100. A lower score indicates a lower disability rate.

To measure the generic quality of life we made use of the EQ-5D of the EuroQol Group. ${ }^{5,25}$ This questionnaire is in use in cost-effectiveness studies. ${ }^{13}$ The questionnaire consists of five questions regarding the dimensions mobility, self-care, usual activity, pain/discomfort and anxiety/depression. Each question has three response categories 
ranging from no problem, some problems and many problems. Using a standardised algorithm, the end score of the EQ-5D is a utility, falling within a value scale of zero (dead) to one (perfect health). ${ }^{5,13,26}$ The EQ-5D is used to calculate the quality adjusted life year (QALY). ${ }^{13,26}$ The QALY was corrected for differences in baseline utility using regression-correction. A regression analysis was performed with the utility-score during the follow-up measurement as the dependent variable and the baseline utility-score as independent variable. For correction, the Beta of this equation is multiplied with the individual baseline utility-score.

All scales are commonly used internationally and are reliable and validated.

\section{Economic outcome measures}

Costs are defined from the societal perspective. These are subdivided into health care costs (including out of pocket costs for the patient and family) and productivity costs. Only costs related to WRULD are included in the analyses. Costs are determined by multiplying the volume reported on each cost item by the estimated costs per unit (Table 2). Out of pocket costs for patient and family were directly measured in the payment. A questionnaire measuring health care costs and costs for patient and family has been used. Missing items in this questionnaire are interpreted as being zero if there simultaneously were markings in cost items elsewhere in the cost questionnaire. The health care costs comprise items like GP visits, home care, medication etc. The costs for the patient and family consist of the reported devices and domestic home care.

Table 2. Standard cost prices

\begin{tabular}{|c|c|c|}
\hline Unit & Standard cost price (euro), index 2005 & References \\
\hline Productivity loss per hour & 36.00 per hour & Oostenbrink et al., 2004 \\
\hline \multicolumn{3}{|l|}{ General Practitioner } \\
\hline - Consultation * & 30.14 per consultation & Oostenbrink et al., 2004 \\
\hline - Visit at home $*$ & 60.29 per consultation & Oostenbrink et al., 2004 \\
\hline - Contact by phone $*$ & 15.07 per consultation & Oostenbrink et al., 2004 \\
\hline - Repeat prescription * & 15.07 per consultation & Oostenbrink et al., 2004 \\
\hline - Assistant $*$ & 15.07 per consultation & $\begin{array}{l}\text { Proxy: } 1 / 2 \text { standard price } \\
\text { GP consultation }\end{array}$ \\
\hline $\begin{array}{l}\text { Cesar/Mensendieck treat- } \\
\text { ment }(\mathrm{PE})^{*}\end{array}$ & 34.32 per session & Oostenbrink et al., 2004 \\
\hline $\begin{array}{l}\text { Physiotherapy treatment } \\
(\mathrm{RP})^{*}\end{array}$ & 33.95 per session & Oostenbrink et al., 2004 \\
\hline Day treatment & 235.69 per session & Oostenbrink et al., 2004 \\
\hline $\begin{array}{l}\text { Home care (domestic and } \\
\text { alpha help) * }\end{array}$ & 32.38 per hour & Oostenbrink et al., 2004 \\
\hline \multirow[t]{2}{*}{ Ergo therapy * } & 38.48 per session ( $30 \mathrm{~min}$. in institution) & Dutch Department for \\
\hline & & $\begin{array}{l}\text { Ergo therapy, personal } \\
\text { communication (phone } \\
\text { call), 24.03.2006 }\end{array}$ \\
\hline
\end{tabular}




\begin{tabular}{|c|c|c|c|c|}
\hline \multirow[t]{2}{*}{ Unit } & \multicolumn{3}{|c|}{ Standard cost price (euro), index 2005} & \multirow[t]{2}{*}{ References } \\
\hline & Min. & Max. & Mean & \\
\hline $\begin{array}{l}\text { Polyclinic consultation (radi- } \\
\text { ology, orthopedics, specialist } \\
\text { in general) }\end{array}$ & 57.64 & 102.92 & $\begin{array}{l}80.28 \text { per consulta- } \\
\text { tion (min. } 10 \text { min in a } \\
\text { general hospital, } \\
\text { max. } 15 \text { min in an } \\
\text { academic hospital) }\end{array}$ & Oostenbrink et al., 2004 \\
\hline $\begin{array}{l}\text { Psychology in primary health } \\
\text { care }\end{array}$ & 64.36 & 88.12 & $\begin{array}{l}79.07 \text { per consulta- } \\
\text { tion ( } 45-50 \mathrm{~min} .)\end{array}$ & $\begin{array}{l}\text { Mean tariff of diverse } \\
\text { psychologist practices in } \\
\text { primary health care }\end{array}$ \\
\hline $\begin{array}{l}\text { Company (occupational) } \\
\text { doctor }\end{array}$ & 123.76 & 183.17 & $\begin{array}{l}153.47 \text { per consulta- } \\
\text { tion ( } 60 \mathrm{~min} .)\end{array}$ & $\begin{array}{l}\text { "Nederlandse Vereniging } \\
\text { voor Arbeids- en Bedrijfs- } \\
\text { geneeskunde", personal } \\
\text { communication (phone } \\
\text { call), } 2006\end{array}$ \\
\hline Medication & & & per box & CvZ, $2006^{30}$ \\
\hline $\begin{array}{l}\text { - Aleve (Naproxen, } 220 \text { mg, } \\
20 \text { tablets) }\end{array}$ & 2.71 & 4.26 & 3.48 & \\
\hline $\begin{array}{l}\text { - Ibuprofen (400 mg, } 20 \\
\text { tablets) }\end{array}$ & 1.65 & 8.43 & 5.04 & \\
\hline $\begin{array}{l}\text { - Ibuprofen (600 mg, } 20 \\
\text { tablets) }\end{array}$ & 8.32 & 8.8 & 8.56 & \\
\hline $\begin{array}{l}\text { - Ibuprofen ( } 400 \text { mg, } 50 \\
\text { pieces tablets/coated tab- } \\
\text { let) }\end{array}$ & $4.13 / 4.46$ & $11.34 / 12.54$ & 8.12 & \\
\hline $\begin{array}{l}\text { - Diclofenac (mean of differ- } \\
\text { ent mg, } 30 \text { tablets) }\end{array}$ & 6.76 & 15.47 & 10.7 & \\
\hline Devices & & & Per device & $\begin{array}{l}\text { Ansil company, personal } \\
\text { communication (mail), } \\
2006\end{array}$ \\
\hline - Optical mouse & 21.78 & 39.6 & 30.69 & \\
\hline - Ergonomic mouse & 44.55 & 54.46 & 49.51 & \\
\hline - Pen mouse tablet & 127.72 & 127.72 & 127.72 & \\
\hline - Ordinary/wireless mouse & 5.94 & 13.86 & 9.9 & \\
\hline - Document holder & 56.44 & 87.19 & 71.82 & \\
\hline - Desk chair & 445.54 & 990.1 & 717.82 & \\
\hline - Keyboard & 34.65 & 48.51 & 41.58 & \\
\hline $\begin{array}{l}\text { - Bureau adjustable in height } \\
\text { (electric) }\end{array}$ & 485.15 & 1188.19 & 836.67 & \\
\hline - Workplace screening & 282.18 & 475.25 & 378.72 & $\begin{array}{l}\text { University of Maastricht, } \\
\text { department "Arbo \& } \\
\text { Milieu", personal com- } \\
\text { munication: mail, } \\
\text { 29.05.2006 }\end{array}$ \\
\hline
\end{tabular}

\footnotetext{
* On the original cost price a surcharge of $45 \%$ overhead and accommodation costs is calculated.
}

The number of PE and RP sessions during the ten week intervention period registered by the therapists is used to calculate the health care costs of intervention sessions during this period. 
Costs concerning productivity loss are based on the reported sick leave from work due to non-specific WRULD. Data concerning absenteeism are collected in a questionnaire concerning employment and absence through illness. ${ }^{27}$ Productivity costs are calculated according to the friction-cost method, indicating that almost everyone is replaceable in the labour process. ${ }^{28}$ A friction cost period of 22 weeks or 154 days is adopted. ${ }^{28}$

In the cost calculation one general cost price per lost hour of productivity is used for all patients. The number of days absent from work is related to the number of working days and working hours reported by the individual patient. Economic data are gathered three times during the one year follow-up period by the questionnaires, each time measuring the last two months prior to the questionnaires. These assessments took place at the same time as the effectiveness measures. The costs are based on these questionnaires and extrapolated to the costs during the full one year follow-up period.

The handbook of Oostenbrink et $\mathrm{al}^{29}$ is used as a guideline for determining the cost prices.

Those cost prices of health care services not mentioned, being ergo therapy, psychology and care by occupational doctor are obtained from professional organizations. Prices of medication are obtained from the Dutch College of Health Insurance. ${ }^{30}$

Cost prices of devices are obtained from the reporting of patients. If the cost price of a relevant device is not reported by the patient, a suitable minimum, maximum and mean cost price is estimated. Cost price estimates of devices are obtained from an organization specialized in devices for ergonomic work places. For some of the cost items there was one mean cost price, for other items a mean cost price is calculated based on a minimum and maximum cost price. All cost prices are indexed to 2005 by using the price index numbers of the Dutch Central Bureau of Statistics ${ }^{31}$ (Table 2).

The costs prices of health care practitioners consist of all costs directly and indirectly attributable to the unit (these are the costs of personnel, medical staff, material, medical apparatus, medical supporting departments, accommodation and overhead).

\section{Cost-effectiveness measures}

In the cost-effectiveness analyses the VAS, self-perceived WRULD and DASH-DLV are related to the health care costs. The QALY is related to the societal costs including productivity costs, in a cost-utility analysis. 


\section{Data analysis}

The expected improvement in pain in the PE group was set at $60 \%$ and for the RP group at $40 \%$, implying a minimal clinical relevant difference of $20 \%$, correlating with $20 \mathrm{~mm}$ difference on the horizontal VAS-scale. These expected improvements in pain were based on past clinical experience in our department of rehabilitation of the Maastricht University Hospital. ${ }^{11}$ With an alpha of 0.05 and a 1-beta of $80 \%$ in total $n=94 \mathrm{com}$ puter screen-workers were needed to provide sufficient power to answer the research questions.

Data were analyzed by a blinded statistician using SPSS 13.0 for Windows (version 13.0; SPSS inc. Chicago, III.)

Data were checked for missing values and normality. Missing values have been replaced by mean imputation and by LOC-F (Last Observation Carried Forward) method. Each follow-up moment was analyzed separately and the analyses were carried out according to the intention to treat principle. Differences in baseline characteristics and baseline values of the outcome measures between PE and RP group were tested with an independent samples t-test $(\alpha=0.05)$. In the event of significant differences between the two groups in baseline characteristics, adjustments were made in the statistical analyses. ${ }^{11}$

The primary effectiveness measure, the horizontal VAS according to Jensen, has been analyzed at each follow-up moment by a t-test. Scores on DASH and EQ-5D questionnaires have been dealt with in the same way. The $\chi^{2}$-test has been used to analyze the answer on the question put dichotomously: "do you still experience non-specific WRULD complaints, yes or no".

The costs of both patient groups were compared by the bootstrapping method making use of confidence intervals in percentiles. By bootstrapping samples of the same size as the original data are drawn with replacement from the observed data. ${ }^{32}$ In our study thousand bootstrap samples/replications were drawn.

The economic evaluation concerns cost-effectiveness and cost-utility analyses. The incremental cost-effectiveness ratios (ICER) are calculated based on the measured costs and outcome parameters. Health care costs are related to the medical outcome parameters and societal costs, including productivity costs are related to the QALY. Bootstrapping is performed and the simulated ratios indicate the uncertainty of the ICERs of the observed data. The ICERs resulting from bootstrapping are plotted on a costeffectiveness acceptability curve (CEAC) indicating the probability for a range of ceiling 
ratios (society's maximum willingness to pay for one unit of effectiveness) that the cost-effectiveness of the PE treatment is acceptable. ${ }^{33}$

Table 2 presents all cost prices with some items having a minimum and maximum cost price. Due to uncertainty concerning the cost price estimates two deterministic sensitivity analyses are performed. ${ }^{26}$ These prices are varied simultaneously, once as minimum and once as maximum cost prices in the sensitivity analysis. In the sensitivity analysis with minimized cost prices, the productivity costs are based on 28.33 (28'20") contract hours divided over five working days a week. These contract hours are based on data of the CBS concerning the average working hours of the total working population in the Netherlands in $2004 .^{34}$ This minimizes the productivity costs.

\section{Results}

313 potential participants reacted or on the advertisements or were recruited by occupational physicians. Participants were selected and diagnosed between May 2003 and February 2005 and each participant had to complete a short questionnaire. The Saltsareport ${ }^{35}$ has been used as a guidebook to enable the correct diagnosis "early nonspecific WRULD" by excluding potential participants with all kinds of specific WRULD. ${ }^{11}$

Finally $28 \%$ of these potential participants (i.e. 88 participants) have been included in this study, meeting the inclusion criteria and willing to participate. Information about the routing of the participants through the trial is presented in Figure 1. 


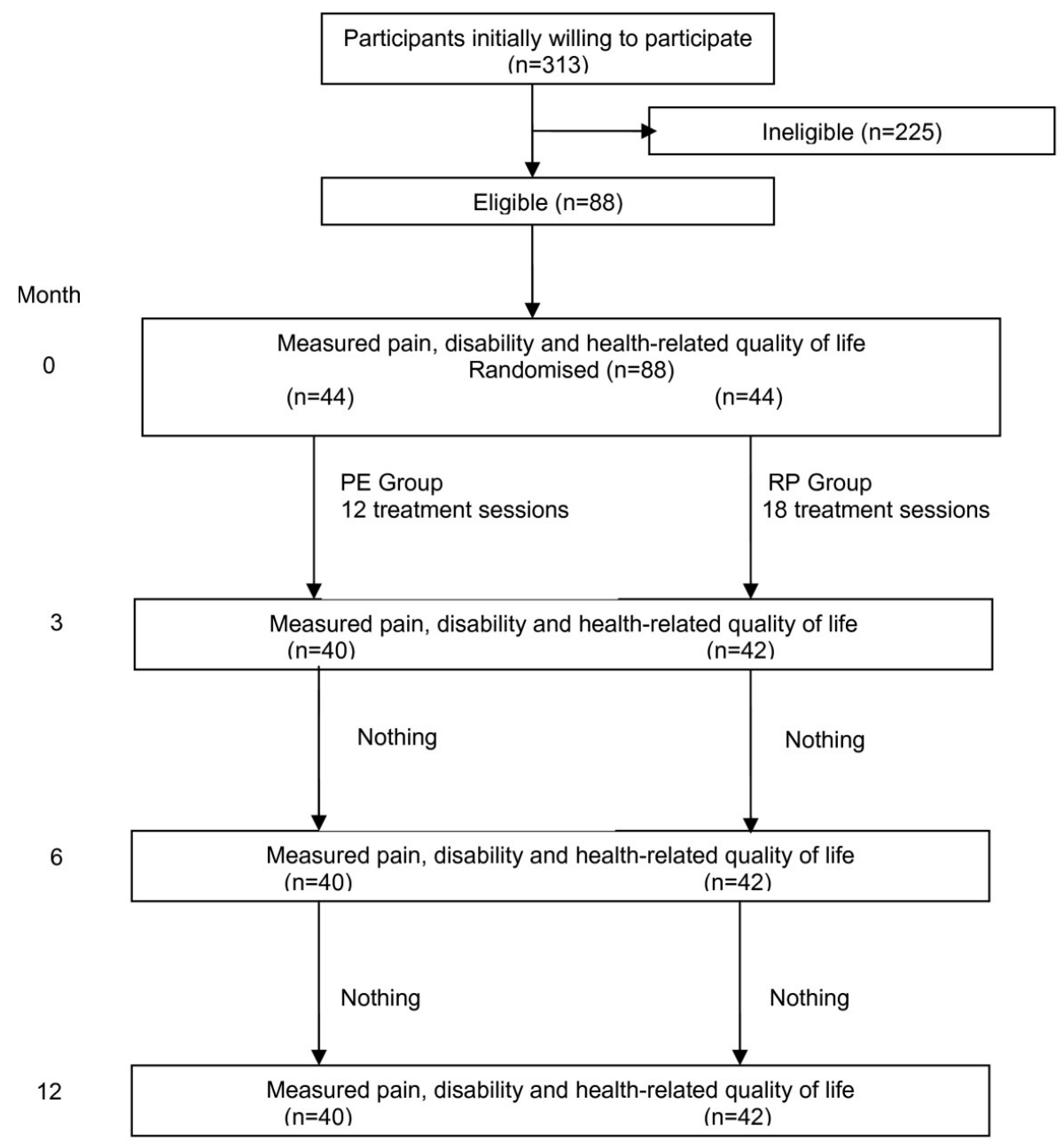

Figure 1. Flow chart describing the routing of the participants through the trial.

Many potential participants had to be excluded for more than one reason. ${ }^{11}$

Forty-four participants were randomized to each arm of the trial.

Both groups were comparable at baseline for nearly all variables except the score on the Pain Catastrophizing Scale (Table 3). 
Table 3. Baseline characteristics of the PE group and the RP group

\begin{tabular}{lccc}
\hline & $\begin{array}{c}\text { PE group } \\
\text { (n=44) }\end{array}$ & $\begin{array}{c}\text { RP group } \\
\text { (n= 44) }\end{array}$ & p-value \\
\hline Gender M:F & $19: 25$ & $19: 25$ & - \\
Education High:Low & $29: 15$ & $30: 14$ & - \\
Age (yr), mean (SD) & $33.3(7.7)$ & $34.8(7.7)$ & 0.38 \\
Pain (VAS, 0-10 cm), mean (SD) & $2.9(1.5)$ & $2.6(1.8)$ & 0.40 \\
Functional disability (Disabilities of Arm, Shoulder and Hand & $15.2(10.3)$ & $16.1(12.3)$ & 0.72 \\
questionnaire) (0-100), mean (SD) & & & 0.32 \\
Quality of life (EQ-5D) (0.00-1.00) & $0.83(0.11)$ & $0.86(0.10)$ & 0.89 \\
Multidimensional Perfectionism Scale (29-145), mean (SD) & $62.7(16.4)$ & $63.2(18.7)$ & 0.93 \\
State Anxiety Inventory (20-80), mean (SD) & $32.9(8.9)$ & $33.1(10.6)$ & 0.69 \\
Trait Anxiety Inventory (20-80), mean (SD) & $34.5(9.9)$ & $35.3(9.8)$ & 0.64 \\
Self-reported fitness (9-45),mean (SD) & $26.9(2.8)$ & $26.7(2.1)$ & 0.38 \\
Fitness mark (1-10), mean (SD) & $7.0(1.1)$ & $7.2(1.5)$ & 0.38 \\
Job Stress Survey (0-81), mean (SD) & $16.2(10.7)$ & $15.6(10.0)$ & 0.82 \\
Pain Catastrophising Scale (0-52), mean (SD) & $22.5(6.6)$ & $25.5(6.3)$ & 0.04 \\
Duration of complaints & & & 8 \\
<6 weeks N = 16 & 8 & 36 & \\
> 6 weeks N = 72 & $36.2(10.7)$ & $38.5(6.3)$ & 0.5 \\
Working hours per week, mean (SD) & & & \\
\hline
\end{tabular}

At baseline all data were available of the 88 participants. Between baseline assessment and three months assessment there were six drop outs for various reasons, four of the PE group and two of the RP group. Besides three non-compliant participants in the PE group, there was one participant who followed therapy, but resigned immediately after the therapy. One of the two non-compliants from the RP group wanted the other intervention after three treatment sessions, being the reason for his drop out.

After accounting for participants who stopped attending because they were free of complaints, compliance was $94 \%$ in the PE therapy group and $96 \%$ in the RP group. ${ }^{11}$

\section{Effectiveness outcomes}

Table 4 reports the mean scores of groups, group differences and $95 \%$ confidence intervals per outcome measure at baseline, three months, six months and one year after baseline. At three months, the RP group experienced significantly less pain as compared to the PE group, however this difference was not maintained at six and twelve months. ${ }^{11}$ Otherwise no significant differences between the groups were observed. Also the QALY shows no significant differences between both groups. 
Table 4. Mean scores (PE and RP) and group differences $(95 \% \mathrm{Cl})$ per outcome measure at baseline, 3 months, 6 months and 1 year after baseline

\begin{tabular}{|c|c|c|c|}
\hline & $\begin{array}{c}\mathrm{PE}(\mathrm{n}=44) \\
\text { Mean }(95 \% \mathrm{Cl})\end{array}$ & $\begin{array}{c}\mathrm{RP}(\mathrm{n}=44) \\
\text { Mean }(95 \% \mathrm{Cl})\end{array}$ & $\begin{array}{c}\text { Differences between groups } \\
\text { Mean }(95 \% \mathrm{CI})\end{array}$ \\
\hline \multicolumn{4}{|l|}{ VAS (10.0-0.0)* } \\
\hline Baseline score & $2.88(2.43 ; 3.33)$ & $2.59(2.07 ; 3.11)$ & $0.29(-0.40 ; 0.99)$ \\
\hline 3 months & $1.90(1.35 ; 2.45)$ & $1.13(0.76 ; 1.51)$ & $0.77(0.09 ; 1.44)$ \\
\hline 6 months & $1.32(0.93 ; 1.72)$ & $1.13(0.76 ; 1.50)$ & $0.19(-0.36 ; 0.75)$ \\
\hline 1 year & $1.41(0.91 ; 1.91)$ & $1.37(0.91 ; 1.82)$ & $0.04(-0.64 ; 0.73)$ \\
\hline \multicolumn{4}{|c|}{ Self-perceived WRULD† } \\
\hline Baseline & 100 & 100 & 0 \\
\hline 3 months & $68.18(54.4 ; 81.9)$ & $63.64(49.4 ; 77.9)$ & $4.5(-14.9 ; 23.4)$ \\
\hline 6 months & $47.73(33.0 ; 62.5)$ & $47.73(33.0 ; 62.5)$ & $0.00(-20.4 ; 20.4)$ \\
\hline 1 year & $43.18(28.5 ; 57.8)$ & $45.45(30.7 ; 60.2)$ & $-2.30(-22.5 ; 18.1)$ \\
\hline \multicolumn{4}{|l|}{ DASH $(0-100)^{*}$} \\
\hline Baseline score & $15.23(12.18 ; 18.27)$ & $16.12(12.47 ; 19.76)$ & $-0.89(-5.71 ; 3.93)$ \\
\hline 3 months & $10.98(8.06 ; 13.91)$ & $8.75(5.89 ; 11.62)$ & $2.23(-1.92 ; 6.38)$ \\
\hline 6 months & $9.94(7.27 ; 12.62)$ & $7.78(4.93 ; 10.64)$ & $2.16(-1.81 ; 6.13)$ \\
\hline 1 year & $9.33(6.51 ; 12.15)$ & $8.22(5.19 ; 11.25)$ & $1.11(-3.09 ; 5.31)$ \\
\hline \multicolumn{4}{|l|}{ EQ-5D (0.00-1.00)* } \\
\hline Baseline score & $0.83(0.80 ; 0.87)$ & $0.86(0.83 ; 0.89)$ & $-0.02(-0.07 ; 0.02)$ \\
\hline 3 months & $0.89(0.86 ; 0.92)$ & $0.92(0.88 ; 0.95)$ & $-0.03(-0.07 ; 0.02)$ \\
\hline 6 months & $0.92(0.90 ; 0.95)$ & $0.91(0.89 ; 0.94)$ & $0.01(-0.03 ; 0.05)$ \\
\hline 1 year & $0.91(0.88 ; 0.95)$ & $0.90(0.87 ; 0.94)$ & $0.01(-0.04 ; 0.06)$ \\
\hline QALY (0.00-1.00) & $0.88(0.86 ; 0.91)$ & $0.87(0.84 ; 0.90)$ & $0.02(-0.02 ; 0.06)$ \\
\hline
\end{tabular}

* T-test; + Expressed in \% of patients with complaints; $\chi^{2}$ test

\section{Health care utilization and sick leave}

Table 5 presents data on consumption volumes, out of pocket payments and the sick leave due to WRULD during the follow-up period. Only a few patients reported additional utilization of (non-)health care resources and/or work absenteeism represented by productivity costs. Most of the PE therapy and RP sessions took place during the ten weeks intervention period. 
Table 5. Mean and maximum consumption volume, out of pocket payments and sick leave per patient 1 year after baseline

\begin{tabular}{|c|c|c|c|c|}
\hline \multirow[t]{2}{*}{ Type of utilization [Unit of measurement] } & \multicolumn{2}{|c|}{ PE $(n=44)$} & \multicolumn{2}{|c|}{$\operatorname{RP}(n=44)$} \\
\hline & Mean & Max.* & Mean & Max.* \\
\hline \multicolumn{5}{|l|}{ Volumes of care } \\
\hline \multicolumn{5}{|l|}{ GP care } \\
\hline - Standard GP consult [no. visits] & 0.60 & 6.00 & 0.54 & 6.00 \\
\hline - GP consult by phone [no. contacts] & 0.08 & 1.75 & 0.18 & 6.00 \\
\hline - GP assistent [no. visits] & 0.09 & 4.00 & 0.08 & 3.50 \\
\hline - GP repeat prescription [no. contacts] & 0 & 0 & 0.04 & 1.75 \\
\hline Mensendieck/Cesar therapy (PE) [no. sessions] & 18.00 & 38.00 & 0.05 & 2.00 \\
\hline Physiotherapy (RP) [no. sessions] & 1.41 & 18.00 & 16.52 & 44.50 \\
\hline Ergo therapy [no. sessions] & 0 & 0 & 0.05 & 2.00 \\
\hline Company doctor [no. visits] & 0.05 & 2.00 & 0.09 & 4.00 \\
\hline Day treatment [no. sessions] & 0 & 0 & 0.04 & 1.75 \\
\hline Psychology of primary care [no. sessions] & 0 & 0 & 0.23 & 10.00 \\
\hline \multicolumn{5}{|l|}{ Policlinic consults } \\
\hline - Radiology & 0 & 0 & 0.05 & 2.00 \\
\hline - Orthopedics & 0 & 0 & 0.29 & 12.75 \\
\hline - Specialist in general & 0 & 0 & 0.12 & 5.25 \\
\hline Home care [no. hours a week] & 0.12 & 5.25 & $<0.01$ & 0.06 \\
\hline \multicolumn{5}{|l|}{ Out of pocket payments and sick leave } \\
\hline Devices hand/arm [costs $€$ ] & 84.11 & 900.00 & 57.71 & 1668.80 \\
\hline Devices transport [costs $€$ ] & 0.31 & 13.50 & 4.71 & 138.00 \\
\hline Other devices [costs $€$ ] & 47.13 & 1256.19 & 126.99 & 2846.04 \\
\hline Medication [costs $€$ ] & 1.10 & 20.88 & 0.40 & 17.12 \\
\hline Productivity costs [costs $€$ ] & 316.80 & 13478.40 & 919.64 & 20160.00 \\
\hline
\end{tabular}

* The minimum consumption and costs of all items is zero.

\section{Costs}

Table 6 shows the mean costs (health care costs comprising costs for patient and family and productivity costs as well as societal costs) per patient group at baseline and mean cumulative (societal) costs per patient group after 3 months and one year. The upper and lower confidence limits in the table are the 2.5 th and 97.5 th percentile based on bootstrap replications. 
Table 6. Mean costs per patient group at baseline and mean cumulative costs per patient group after 3 months and 1 year $(95 \% \mathrm{Cl})^{*}$

\begin{tabular}{|c|c|c|c|c|c|c|}
\hline \multirow[b]{4}{*}{ Time elapsed } & \multicolumn{3}{|c|}{ PE $(n=44)$} & \multicolumn{3}{|c|}{$\operatorname{RP}(n=44)$} \\
\hline & \multicolumn{3}{|c|}{ Mean costs } & \multirow{2}{*}{\multicolumn{3}{|c|}{ Mean costs }} \\
\hline & \multicolumn{3}{|c|}{ Bootstrapped mean costs $(95 \% \mathrm{Cl}) *$} & & & Bootstrapped mean costs $(95 \% \mathrm{CI})^{*}$ \\
\hline & baseline & 3 months & 1 year & baseline & 3 months & 1 year \\
\hline \multicolumn{7}{|l|}{ Health care costs } \\
\hline \multirow[t]{2}{*}{ - Treatment costs } & 0 & 583 & 666 & 0 & 486 & 563 \\
\hline & $0(0 ; 0)$ & $584(542 ; 615)$ & $666(600 ; 735)$ & $0(0 ; 0)$ & $486(441 ; 524)$ & $565(485 ; 651)$ \\
\hline \multirow[t]{2}{*}{ - Other costs } & 22 & 6 & 29 & 23 & 26 & 125 \\
\hline & $22(10 ; 39)$ & $6(2 ; 11)$ & $29(12 ; 49)$ & $23(11 ; 38)$ & $26(8 ; 52)$ & $124(48 ; 228)$ \\
\hline \multirow[t]{2}{*}{ Total health care costs } & 22 & 589 & 694 & 23 & 512 & 688 \\
\hline & $22(10 ; 41)$ & $589(547 ; 620)$ & $693(621 ; 764)$ & $23(10 ; 39)$ & $512(463 ; 559)$ & $684(550 ; 839)$ \\
\hline Costs for the patient & 36 & 104 & 164 & 8 & 107 & 190 \\
\hline and family & $35(6 ; 80)$ & $105(42 ; 188)$ & $166(83 ; 268)$ & $8(3 ; 14)$ & $106(1 ; 243)$ & $189(33 ; 398)$ \\
\hline \multirow[t]{2}{*}{ Productivity costs } & 0 & 0 & 317 & 0 & 106 & 920 \\
\hline & $0(0 ; 0)$ & $0(0 ; 0)$ & $323(0 ; 940)$ & $0(0 ; 0)$ & $109(0 ; 318)$ & $913(24 ; 2106)$ \\
\hline \multirow[t]{2}{*}{ Societal costs } & 58 & 693 & 1176 & 31 & 725 & 1797 \\
\hline & $59(21 ; 110)$ & $694(612 ; 786)$ & $1152(764 ; 1890)$ & $31(15 ; 50)$ & $722(528 ; 1017)$ & 1817 (830; 3099) \\
\hline
\end{tabular}

* The mean costs; the upper and lower confidence limits are the $2.5^{\text {th }}$ and $97.5^{\text {th }}$ percentile based on bootstrap replications

Table 7 shows the mean differences in costs between the two groups at baseline, after three months and one year. Also here the upper and the lower confidence limits are the 2.5th and 97.5 th percentile based on bootstrap replications.

Table 7. Mean differences in costs between groups at baseline, after 3 months and 1 year $(95 \% \mathrm{Cl})^{*}$

\begin{tabular}{lccc}
\hline & \multicolumn{3}{c}{$\begin{array}{c}\text { Mean difference } \\
\text { Bootstrapped mean difference }(\mathbf{9 5 \%} \mathbf{~ C l})^{*}\end{array}$} \\
\hline $\begin{array}{l}\text { Time elapsed } \\
\text { Health care costs }\end{array}$ & Baseline & $\mathbf{3}$ months & $\mathbf{1}$ year \\
- Treatment costs & 0 & 97 & 103 \\
& $0(0 ; 0)$ & $99(42 ; 156)$ & $101(-4 ; 205)$ \\
- Other costs & -1 & -20 & -97 \\
& $-1(-21 ; 19)$ & $-21(-47 ;-1)$ & $-96(-200 ;-19)$ \\
Total health care costs & -1 & 77 & 6 \\
& $-1(-20 ; 22)$ & $77(11 ; 135)$ & $9(-164 ; 168)$ \\
Costs for the patient and family & 28 & -2 & -25 \\
& $28(-2 ; 72)$ & $-1(-150 ; 126)$ & $-23(-252 ; 159)$ \\
Productivity costs & 0 & -106 & -603 \\
Societal costs & $0(0 ; 0)$ & $-109(-318 ; 0)$ & $-590(-1862,521)$ \\
& 28 & -31 & -622 \\
\hline
\end{tabular}

* The mean difference in costs between patient groups; the upper and lower confidence limits are the $2.5^{\text {th }}$ and $97.5^{\text {th }}$ percentile based on bootstrap replications 


\section{Baseline}

At baseline the health care costs and productivity costs are about the same. The costs for the patient and family and the societal costs have a rather small cost difference of $€ 28$ between the two patient groups $(95 \% \mathrm{Cl} ;-2,+72$ respectively $-13,+81$ ).

\section{Follow-up}

The PE group has higher treatment costs during the follow-up period compared to the RP group. Although other health care costs were lower in the PE group, the total health care costs indicate that the PE group has higher costs opposed to the RP group during the period after baseline. Concerning all other follow-up cost items the PE group is less costly than the RP group.

\section{Health care costs}

During the intervention period the total health care costs of the PE group are higher (mean costs $€ 589$ PE vs. RP $€ 512$; incremental cost $+€ 77 ; 95 \% \mathrm{Cl}+11,+135$ ). There were no differences between both groups in costs over 1-year follow-up (mean costs $€ 694$ PE versus RP €688; incremental cost + €6; 95\% Cl -164; +168). The health care costs mainly consist of the costs of the treatments for PE therapy or RP during the ten weeks intervention period. Concerning the other health care costs, the PE group is less costly than the RP group with $€ 29$ versus $€ 125$ at one year after baseline (incremental cost at one year - $€ 97,95 \% \mathrm{Cl} ;-200,-19)$ and $€ 6$ versus $€ 26$ just after the intervention period.

\section{Costs for the patient and family}

There were no differences between both groups in costs at three months respectively 1-year follow-up (incremental costs -€2; 95\% Cl; -150, +126 resp. -€25; 95\% Cl; -252, $+159)$.

\section{Productivity costs}

During the follow-up period only few patients (four patients in the RP group and two patients in the PE group) of both treatment groups had productivity loss due to their non-specific WRULD complaints. At one year after baseline the mean costs due to productivity loss were $€ 317$ in the PE group and $€ 920$ in the RP group (incremental cost at one year $-€ 603 ; 95 \% \mathrm{Cl} ;-1862,+521)$. At three months incremental cost was $-€ 106$; $95 \% \mathrm{Cl} ;-318,0$.

\section{Societal costs}

The mean societal costs one year after baseline are $€ 1797$ for the RP group, which is about $€ 622$ more $(95 \% \mathrm{Cl} ;-2087,+590)$ than the mean societal costs of $€ 1176$ of the PE therapy group. The difference between the mean health care and the mean societal costs per patient of the RP group in relation to the PE group is mainly attributable to the higher productivity costs in the RP group. 


\section{Cost-effectiveness analysis}

Because of a possible bias due to group differences at baseline (although not statistically different) in combination with small differences at follow-up regarding VAS-scores, DASH and EQ5D, the (Incremental Cost-Effectiveness Ratio) ICERs of the PE versus the RP treatment are calculated at three months and one year after baseline based on change scores of each group (see Table 8 ). Regarding all incremental costs and effects we calculated the upper and lower confidence limits of 2.5th and 97.5th percentile based on bootstrap replications.

Table 8. Mean differences in incremental effects/costs and incremental cost-effectiveness ratios of PE versus RP 3 months and 1 year after baseline $(95 \% \mathrm{Cl})^{*}$

\begin{tabular}{|c|c|c|c|c|c|c|}
\hline \multirow[t]{2}{*}{ Time elapsed } & \multicolumn{3}{|c|}{3 months } & \multicolumn{3}{|c|}{1 year } \\
\hline & Incremental effect & $\begin{array}{l}\text { Incremental } \\
\text { costs }\end{array}$ & ICER \# & $\begin{array}{c}\text { Incremental } \\
\text { effect }\end{array}$ & $\begin{array}{l}\text { Incremental } \\
\text { costs }\end{array}$ & ICER \# \\
\hline \multicolumn{7}{|c|}{ Health care costs in relation to } \\
\hline - VAS & $\begin{array}{c}0.48 \\
(-0.17 ; 1.12)\end{array}$ & $\begin{array}{c}77 \\
(11 ; 135)\end{array}$ & $\begin{array}{c}160.74 \\
(-1185,1924)\end{array}$ & $\begin{array}{c}-0.25 \\
(-0.99 ; 0.57)\end{array}$ & $\begin{array}{c}6 \\
(-164 ; 168)\end{array}$ & $\begin{array}{c}-26.38(I) \\
(-2186,2777)\end{array}$ \\
\hline $\begin{array}{l}\text { - Self-perceived } \\
\text { WRULD }\end{array}$ & $\begin{array}{c}-0.05 \\
(-0.25,0.16)\end{array}$ & $\begin{array}{c}77 \\
(11 ; 135)\end{array}$ & $\begin{array}{l}-1690.22(I) \\
(-4337, x x x)\end{array}$ & $\begin{array}{c}0.02 \\
(-0.18 ; 0.23)\end{array}$ & $\begin{array}{c}6 \\
(-164 ; 168)\end{array}$ & $\begin{array}{c}285.65 \\
(-4131, x x x)\end{array}$ \\
\hline - DASH & $\begin{array}{c}-3.14 \\
(-7.22,0.73)\end{array}$ & $\begin{array}{c}77 \\
(11 ; 135)\end{array}$ & $\begin{array}{c}-24.48(I) \\
(-204 ; 108)\end{array}$ & $\begin{array}{c}-1.99 \\
(-6.68 ; 2.20)\end{array}$ & $\begin{array}{c}6 \\
(-164 ; 168)\end{array}$ & $\begin{array}{c}-3.27(1) \\
(-399 ; 327)\end{array}$ \\
\hline \multicolumn{7}{|c|}{ Societal costs in relation to } \\
\hline - QALY & & & & $\begin{array}{c}0.02 \\
(-0.02,0.06)\end{array}$ & $\begin{array}{c}-622 \\
(-2087,590)\end{array}$ & $\begin{array}{c}-33772.60(D) \\
(-324027,240226)\end{array}$ \\
\hline
\end{tabular}

* The upper and lower confidence limits are the $2.5^{\text {th }}$ and $97.5^{\text {th }}$ percentile based on bootstrap replications; $x x x=$ non-existent; (I): PE strategy is inferior compared to RP treatment; (D): PE strategy dominates RP treatment; Note 1: the above presented incremental costs and effects are based on change scores instead of the absolute costs and effects as presented in Table 4; Note 2: \# negative ICERs should be interpreted with caution.

Negative ICERs should be interpreted with caution. These can indicate both dominance (higher effectiveness and lower costs) and inferiority (lower effectiveness and higher costs) of PE strategy over RP treatment; therefore we refer to Figures 2 and 3 for clarification (see further). 


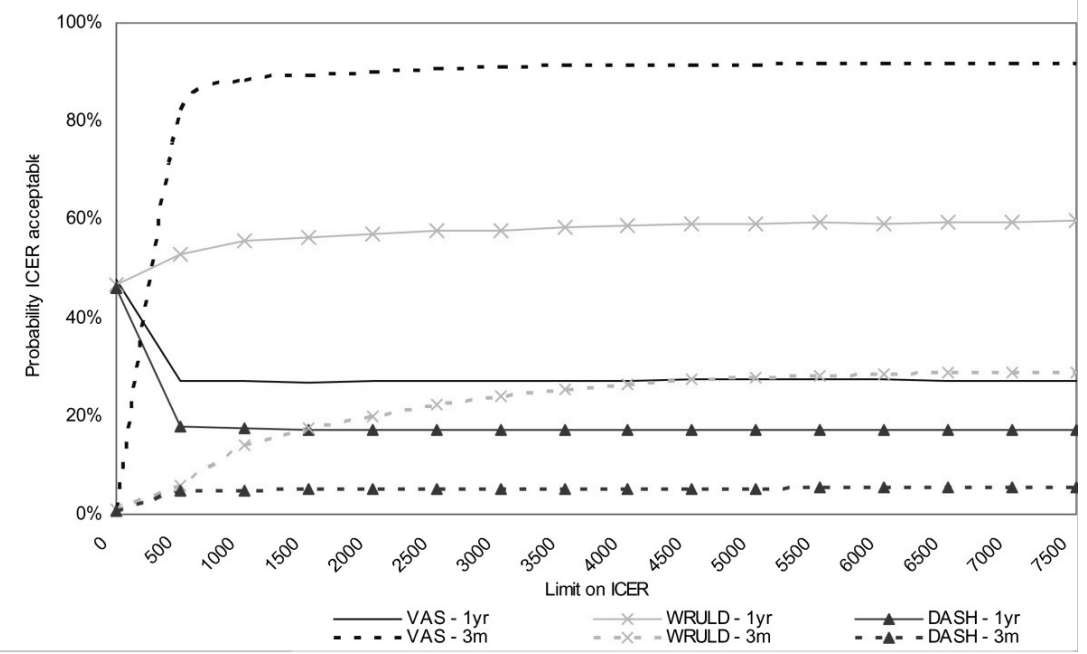

Figure 2. Cost-effectiveness acceptability curve with health care costs.

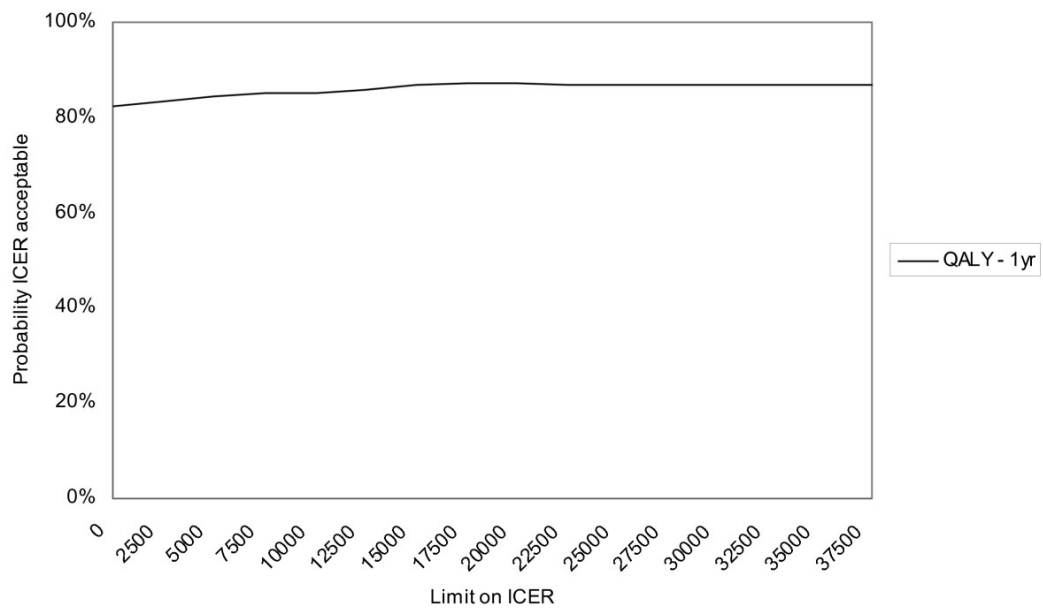

Figure 3. Cost-effectiveness acceptability curve with societal costs.

\section{Three months after baseline}

Using health care costs the ICER for the VAS pain intensity at three months after baseline is about $€ 161$ per unit of improvement. This means that an additional amount of $€ 161$ is needed to achieve an improvement of one point on the VAS scale through Mensendieck/Cesar therapy as opposed to regular physiotherapy. 
Concerning the three-month follow-up effectiveness measures self-perceived WRULD and DASH; the PE treatment is both more expensive and less effective as the RP. This indicates that the PE treatment is inferior opposed to the RP when evaluated from the self-perceived WRULD and DASH at a three-month follow-up period.

\section{One year after baseline}

At one-year follow-up, the PE treatment is both more expensive (health care costs) and less effective regarding pain (VAS) and disability (DASH), indicating that the PE treatment is inferior opposed to the RP.

The ICER for self-perceived WRULD one year after baseline is about $€ 286$, meaning that an additional $€ 286$ is needed to achieve one more complaint-free patient through PE therapy.

The societal costs of the PE therapy group are lower compared to the RP group, while the treatment is more effective in terms of QALYs during the one-year period. Consequently the PE treatment is considered dominant from this societal perspective. The gain of an additional QALY through PE treatment implicates a cost saving of about $€ 33,773 .=$

\section{Cost-effectiveness acceptability curve}

Figure 2 presents the cost-effectiveness acceptability curves (CEACs) with the health care costs related to the effectiveness outcomes on the VAS, the self-perceived WRULD and the DASH at three months and one year after baseline. When the willingness to pay for an additional unit of effect on one of these outcome parameters is zero, the PE treatment tends towards inferiority. At three months after baseline there is a probability of only $1 \%$ that the ICER is acceptable at a ceiling of zero. At one year after baseline the probability that the PE treatment is cost-effective is about 46 to $48 \%$ for these three parameters. When the limit on the ICER is increased the PE treatment tends towards dominance concerning the change in VAS pain intensity achieved after three months (probability increases to 92\%) and the number of patients with self-perceived WRULD-complaints after one year (probability increases to 60\%). The other CEACs in Figure 2 still tend towards inferiority of the PE treatment, even when the willingness to pay increases. The cost utility analysis concerns the incremental QALY compared to the incremental societal costs during the one year follow-up period. As shown by Figure 3 the probability that the PE treatment is cost-effective is about 82 to $87 \%$, depending on the ceiling ratio. From this perspective the PE treatment has a high probability to be cost-effective compared to RP treatment.

\section{Sensitivity analysis}

The sensitivity analysis with maximized costs resulted in mean health care costs of $€ 704$ and societal costs of $€ 1876$ per RP patient compared to $€ 697$ respectively $€ 1191$ per PE 
therapy patient. In the sensitivity analysis with minimum costs, the mean health care costs decreased to $€ 671$ and societal costs decreased to $€ 1507$ per RP patient compared to $€ 692$ respectively $€ 1073$ per PE therapy patient. These sensitivity analyses only lead to small changes in the cost differences between both patient groups. The shape of the CEACs of the sensitivity analyses is comparable to the CEACs of the baseline analyses.

\section{Discussion}

Little research has been done regarding cost-effectiveness in WRULD-patients.

One cost-effectiveness study ${ }^{12}$ has been done among WRULD-patients with chronic complaints and one study is still running. ${ }^{13}$ The study of Meijer (2006) shows that there is no difference in cost-effectiveness between two groups which were treated by multidisciplinary intervention respectively usual care.

This cost-effectiveness study, comprising WRULD-related health care costs including costs for the patient and family and productivity costs resulting in societal costs, is as a randomized controlled trial in computer screen-workers with early stages of nonspecific WRULD the first of its kind. There was only a small rate of missing values in this research making the chance of bias low. The low percentage of dropout (less than 10\%) was the reason to perform only an intention-to-treat analysis and no per-protocol analysis. Moreover this patient group concerns patients with early non-specific WRULD complaints of which is assumed that their dropout would not imply a significant impact on the results.

The results failed to show PE therapy according to Mensendieck/Cesar is more effective in computer screen-workers with early non-specific WRULD with respect to the effectiveness outcome measures (Table 4). In both groups there are small improvements over the one year follow-up period while after one year $55 \%$ of the participants reports to have no complaints any longer. The small effects on the outcome measures possibly can be explained by the fact that only patients with beginning complaints were included and therefore showed low scores on the scales. Despite the finding that there was no difference between groups we did not change the principle of conducting the cost-effectiveness analysis since our trial was based on the expectation of a difference in effectiveness between treatments. ${ }^{36}$ Our study shows wide confidence intervals on both effectiveness and cost differences between the two treatment arms. Due to uncertainty surrounding our estimate of treatment effects arising from the negative results and small size of our trial, interpretation of the ICERs should be undertaking with caution. $^{37}$ 
Moreover, Figure 4 shows the results of the bootstrap run on the incremental costs per VAS. Given the fact that the bootstrapped ICERs are scattered around the origin, the confidence intervals of the ICERs presented in Table 8 are difficult to interpret.

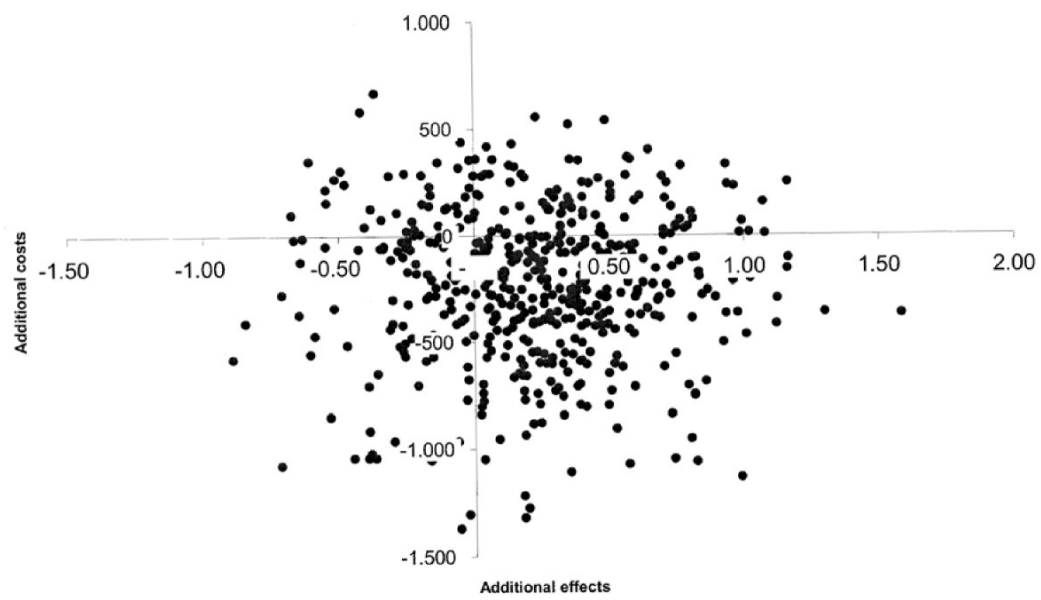

Figure 4. Result of the bootstrap run based on the incremental costs per VAS: Incremental cost-effectiveness plane.

Non-specific WRULD is 'work-related. ${ }^{16}$ However, this research did not include a workrelated effectiveness measure. Suffering from beginning complaints and according to the inclusion criteria, all participants were still at work at start of the treatment. Consequently "return-to-job" was not a useful effectiveness measure for this particular patient group.

Regarding cost-effectiveness, mean total health care costs including costs for the patient and family did not differ significantly between both groups at one year follow-up. This despite the fact that during the intervention period when most health care costs were made and mainly consisted of the costs of the treatments, these costs were higher in the PE group having one and a half hours more therapy compared to the RP group. On the other hand, productivity costs after one year were lower in the PE group. Productivity costs were based on 28.33 (28'20") contract hours divided over five working days a week ${ }^{38}$ However, our participants worked much more hours per week (ca. 38 hours per week). Productivity costs were calculated according to the friction cost approach, but this research did not take into account all of the possible productivity costs items from this approach. For example the productivity costs during the work due to decreased work performance called presenteeism ${ }^{27}$ were not questioned in this research. These observations probably reflect an underestimation of the productivity costs measured in this study with possibly consequences for the outcome. 
The mean societal costs one year after baseline were in favor of the PE therapy group, mainly attributable to the higher productivity costs in the RP group.

From the health care costs perspective at three months follow-up only with respect to the VAS the PE strategy had a high probability of acceptable cost-effectiveness. At one year follow-up the PE strategy had only regarding the self-perceived WRULD a- not the $60 \%$ exceeding- probability of acceptable cost-effectiveness.

Considering societal costs in relation to QALYs, the PE treatment had a probability of over $80 \%$ to be cost-effective over a wide range of cost-effectiveness ceiling ratios.

However, differences were marginal, possibly because this study only concerned computer screen-workers with early stages of non-specific WRULD and already no significant differences between the groups were found in the effectiveness of both therapies themselves.

As our preference concerns the societal perspective and the QALYs we tend to prescribe postural exercise therapy according to Mensendieck/Cesar for computer screenworkers with early stages of non-specific WRULD.

\section{Conclusion}

In conclusion, although our trial failed to find significant differences in VAS, QALYs and ICERs based on VAS and QALYs at one-year follow-up, CEACs suggest that the postural exercise therapy according to Mensendieck/Cesar has a higher probability of being cost-effective compared to regular physiotherapy; however further research is required.

\section{References}

1. RSI: The Hague: Health Council of the Netherlands; Publication No. 2000/22E. [http://neurologiadeItrabajo.sen.es/pdf/rsi_report_curso2000_nt.pdf]

2. Peereboom KJ: RSI Handboek (RSI Handbook). 4th edition. The Hague, the Netherlands: Sdu Editors; 2005.

3. Staal JB, de Bie RA, Hendriks EJM: Aetiology and management of work-related upper extremity disorders. Best Practice \& Research Clinical Rheumatology 2007, 21(1):123-133.

4. Gezondheidsschade en kosten als gevolg van RSI en psychosociale arbeidsbelasting in Nederland [http://docs.szw.nl/pdf/129/2006/129_2006_3_8656.pdf] (Health effects and costs as consequences of RSI and psychosocial work load in the Netherlands). TNO Kwaliteit van Leven/Ministerie van Sociale Zaken en Werkgelegenheid 2005. Retrieved October 28, 2005,

5. Picavet HSJ, Hoeymans N: Health related quality of life in multiple musculoskeletal diseases: SF- 36 and EQ-5D in the DMC3 study. Ann Rheum Dis 2004, 63:723-729. 
6. VvOCM, Vereniging voor oefentherapie Cesar en Mensendieck (Society of exercise therapy Cesar and Mensendieck). 2005.info@vvocm.nl

7. Oefentherapie (Exercise therapy). The Hague: Health Council of the Netherlands; publication No. 2003/22 [http://tno-arbeid.adlibsoft.com/adlib/docs/oefentherapie.pdf]

8. Verhagen AP, Karels C, Bierma-Zeinstra SM, Burdorf L, Feleus A, Dahaghin S, de Vet HC, Koes BW: Ergonomic and physiotherapeutic interventions for treating work-related complaints of the arm, neck or shoulder in adults. Cochrane Database Syst Rev 2006, 3:CD003471.

9. Verhagen AP, Karels C, Bierma-Zeinstra SM, Feleus A, Dahaghin S, Burdorf A, Koes BW: Exercise proves effective in a systematic review of work-related complaints of the arm, neck or shoulder. J Clin Epidemiol 2007, 60(2):e110.e1-e110.e14. 110.e14

10. Smidt N, de Vet HCW, Bouter LM, Dekker J: Effectiveness of exercise therapy: A best-evidence summary of systematic reviews. Australian Journal of Physiotherapy 2005, 51:71-85.

11. Van Eijsden-Besseling MD, Staal JB, Van Attekum A, De Bie RA, Heuvel WJA: No difference between postural exercises and strength and fitness exercises for early, non-specific, work-related upper limb disorders in visual display unit workers: a randomized trial. Australian Journal of Physiotherapy 2008, 54(2):95-101.

12. Meijer EM, Sluiter JK, Heyma A, Sadiray K, Frings-Dresen MH: Cost-effectiveness of multidisciplinary treatment in sick listed patients with upper extremity musculoskeletal disorders: a randomized, controlled trial with one-year follow-up. Int Arch Occup Environ Health. 2006, 79(8):654-664.

13. Bernaards $\mathrm{CM}$, Ariens GA, Hildebrandt VH: The (cost)-effectiveness of a lifestyle physical activity intervention in addition to a work style intervention on the recovery from neck and upper limb symptoms in computer workers. BMC Musculoskelet Disord 2006, 7:80.

14. Vitale MA, Vitale MG, Zivin JG, Braman JP, Bigliani LU, Flatow EL: Rotator cuff repair: an analysis of utility scores and cost-effectiveness. J Shoulder Elbow Surg 2007, 16(2):181-7.

15. Jensen MP, McFarland CA: Increasing the reliability and validity of pain intensity measurement in chronic pain patients. Pain 1993, 55:195-203.

16. Van den Heuvel S: Work-related neck and upper limb symptoms. In PhD Thesis. Amsterdam, TNO; 2006.

17. Van Eijsden-Besseling MD, Peeters FP, Reijnen JA, de Bie RA: Perfectionism and coping strategies as risk factors for the development of non- specific work-related upper limb disorders (WRULD). Occup Med (Lond). 2004, 54(2):122-127.

18. IJmker S, Huysmans M, Blatter BM, van der Beek AJ, van Mechelen W, Bongers PM: Should office workers spend fewer hours at their computer? A systematic review of the literature. J Occup Environ Med 2007, 64:211-222.

19. van Heuvelen MJ, Kempen GI, Ormel J, de Greef MH: Self-reported Physical Fitness of Older Persons: A substitute for Performance- Based Measures of Physical Fitness? Journal of Ageing and Physical Activity 1997, 5:298-310.

20. de Wolff B, Swinnen L, de Fruyt F, de Wolff C, Spielberger CD: JSS. Job stress Survey. Handleiding/Manual. Swets Test Publishers; 2002.

21. Frost RO, Marten PA: Perfectionism and evaluative threat. Cognitive Therapy Research 1990, 14:559-72.

22. Van der Ploeg HM, Defares PB, Spielberger CD: Handleiding bij de zelfbeoordelingvragenlijst ZBV. Een Nederlandse bewerking van de Spielberger state-trait anxiety inventory STAI-DY. (A Dutch version of the Spielberger state-trait anxiety inventory) 1980.

23. Van Damme S: Pain Catastrophizing Scale- Dutch version (PCS-DV). [http://www.lobsw.ugent.be/VVGP/fichePCS.pdf] Gent: Universiteit Gent 2002. Retrieved June 7, 2006

24. Veehof MM, Sleegers EJA, Van Veldhoven NHMJ, Schuurman AH, Van Meeteren NLU: Psychometric qualities of the Dutch language version of the disabilities of the arm, shoulder and hand questionnaire. (DASH-DLV). Journal of Hand Therapy 2002, 15:347-354.

25. Brooks R: EuroQol: the current state of play. Health Policy 1996, 37:53-72.

26. Drummond MF, Sculpher MJ, Torrance GW, O'Brien B, Stoddart GI: Methods for the Economic Evaluation of Health care Programmes. 3rd edition. Oxford: Oxford University Press; 1996. 
27. Koopmanschap M, Burdorf A, Jacob K, Meerding WJ, Brouwer W, Severens JL: Productivity and health in economic evaluation; setting the research agenda. Pharmacoeconomics 2005, 23:47-54.

28. Koopmanschap MA, Rutten FFH, van Ineveld BM, Van Roijen L: The friction cost method for estimating the indirect costs of disease. Journal of Health Economics 1995, 14:171-189.

29. Oostenbrink JB, Koopmanschap MA, Rutten FFH: Standardisation of costs: the Dutch Manual for Costing in economic evaluations. Pharmacoeconomics 2002, 20(7):443-54.

30. CvZ College voor Zorgverzekeringen. Medicijnkosten [http://www.medicijnkosten.nl] (Dutch College of Health Insurance. Costs of drugs) 2006. Retrieved April, 2006

31. CBS Centraal Bureau voor de Statistiek [http:/ / statline.cbs.nl/ StatWeb/ Table.asp?STB=G1\&LA=nl\&$\mathrm{DM}=S L N L \& P A=70145$ ned\&D1 $=0,4 \& D 2=01,61,70,87,102,131,135,162,166,212213,223,247,1 \& D$ $3=25,38,51,(I-5)-I \& H D R=T, G 2]$ (Dutch Central Bureau of Statistics) Voorburg/Heerlen. Consumentenprijsindices (CPI) alle huishoudens; Retrieved May 8, 2006

32. Briggs $A H$, Wonderling DE, Mooney CZ: Pulling cost-effectiveness analysis up by its bootstraps: a nonparametric approach to confidence interval estimation. Health-Econ 1997, 6(4):327-40.

33. Fenwick E, Claxton K, Sculpher M: Representing uncertainty: the role of cost- effectiveness acceptability curves. Health-Econ 2001, 10(8):779-87.

34. CBS Centraal Bureau voor de Statistiek Voorburg/Heerlen [http:/ / statline.cbs.nl/ StatWeb/ Table.asp?STB=G3\&LA=nI\&DM=SLNL\&PA=3 7169ewl\&D1=112-114\&D2=a\&D3=0\&D4=a\&L YR=G4:0,G2:0,G5:11\&HDR=T,G1] Enquete werkgelegenheid en lonen 2004. Retrieved May 29, 2006

35. Sluiter JK, Rest KM, Frings-Dresen MH: Criteria document for evaluation of the work-relatedness of upper extremity musculoskeletal disorders. Scandinavian Journal of Work, Environment and Health 2001, 27(Suppl 1):1-102.

36. Briggs AH, O'Brien BJ: The death of cost-minimization analysis? J Health Econ 2001, 10:179-184.

37. Claxton K: The irrelevance of inference: a decision making approach to stochastic evaluation of health care technologies. J Health Econ 1999, 18:341-364.

38. Oostenbrink JB, Maiwenn JA: The analysis of incomplete cost data due to dropout. Health Economics 2005, 14:763-776. 


\section{[8]}

General discussion

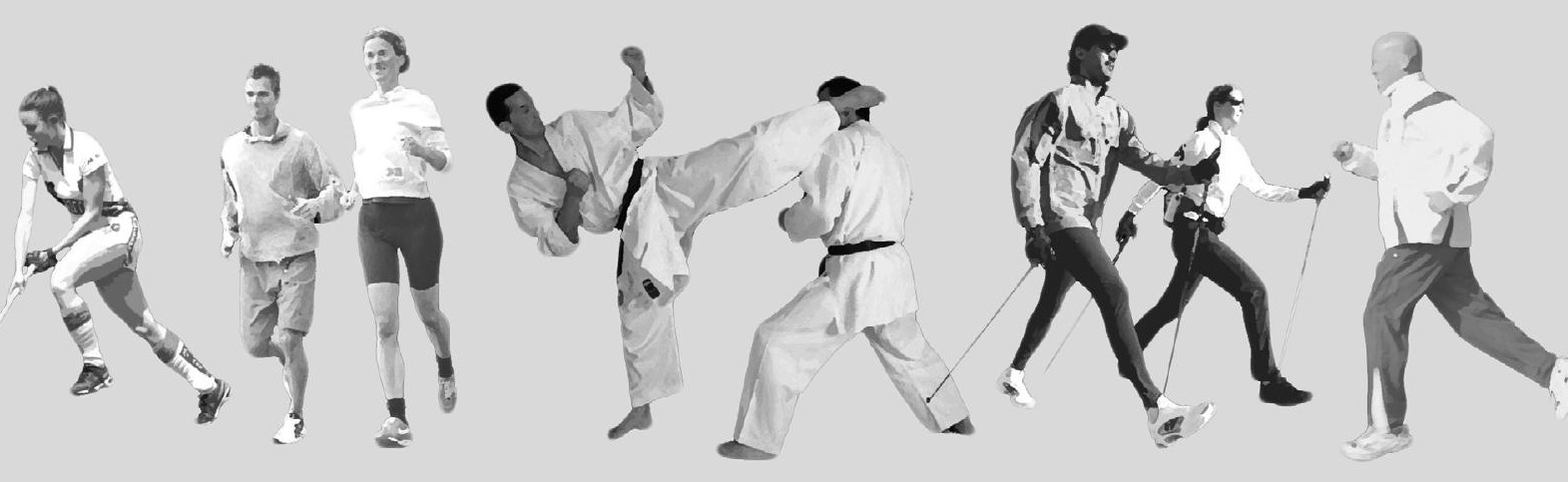




\section{Introduction}

Fifteen years of experience treating patients with non-specific WRULD complaints at a tertiary referral centre within the department of rehabilitation and physical medicine of the University Medical Centre Maastricht, have shown that, if left untreated, these complaints become chronic.

Furthermore, research and daily practice show that not only physical and psychosocial work-related factors but also socio-demographic and personality characteristics play an important role in the development and persistence of WRULD complaints. ${ }^{1-7}$ The consequences of WRULD with respect to experienced disability and decreased quality of life, as well as decreased productivity, work-related absenteeism, increased medical consumption and increased societal costs, are huge. ${ }^{8}$ This fact has motivated us to conduct our study on the course of non-specific WRULD, in general, and the role of above-mentioned factors on the development and course of the disease and functional disability.

Although clinical experience seemed to indicate that appropriate treatment consists of a combination of exercise therapy and education to improve posture and movement habits in everyday activities, firm evidence for this was absent. ${ }^{9}$ Therefore a randomized clinical trial was also performed.

This thesis project can thus be seen as the amalgam of a randomized controlled trial, a retrospective cohort study and two case-control studies, all with the purpose of shedding light on the phenomenon of WRULD and related research questions.

The following paragraphs present a summary of the main findings, the strengths and weaknesses of the performed studies, and a discussion of the overall results. Based on the findings and discussion, suggestions will be made for further work in improving the model for studying and treating non-specific WRULD. This chapter ends with conclusions, recommendations for further research and practical implications of the findings.

\section{Main findings}

First research question: what is the course of non-specific WRULD and do work- and treatment related factors, socio- demographic, psychological and physical factors predict clinical status and functional disability?

This question was answered by means of a retrospective cohort study. The outcome variables here were course of the disease and functional disability.

\section{Course of non-specific WRULD}

The computer screen workers visiting our referral centre with WRULD in our retrospective study showed a poor outcome at follow-up averaging 4.4 years. Only one in four 
computer screen workers had improved, while the rest had worsened slightly ${ }^{10,11}$ As little as $9 \%$ made a full recovery, while $14 \%$ developed a chronic pain syndrome and the remaining $77 \%$ worsening slightly (Chapters 2 and 3 ).

\section{Work- and treatment related factors}

With respect to work- related and treatment- related risk factors our retrospective study showed that "having worked more hours per day before diagnosis" was associated with lower functional disability, while "having undergone other therapies during the treatment period" (other than multidisciplinary rehabilitation and/or psychotherapy) resulted in more functional disability (high score on the DASH-Disabilities of Arm, Shoulder and Hand questionnaire). ${ }^{11}$ None of the selected work- and treatment related factors appeared to be significantly associated with clinical status (Chapter 2).

\section{Socio-demographic factors}

Computer workers having achieved a lower educational level were at risk for prolonged and severe non-specific WRULD and functional disability. ${ }^{10}$ Being elderly and female were also risk factors for further functional disability ${ }^{10}$ (Chapter 3 ).

\section{Psychological, personality and physical factors}

Psychological and personality factors (such as trait anxiety, neurotic perfectionism and pain catastrophising) measured after the on average 4.4 years follow up were not related to the course of clinical status and disability (Chapter 3 ).

Poorer self-reported physical fitness was associated with a more severe clinical status of non-specific WRULD and with more functional disability at 4.4 year follow-up ${ }^{10}$ (Chapter 3).

Second research question: do psychological factors play an important role in developing and persisting non-specific WRULD-complaints?

To answer this research question two case control studies were executed.

In the first one with two control groups (healthy controls and controls with chronic pain), both those with non-specific WRULD (cases) and those with chronic pain showed statistically higher scores than the healthy controls on psycho-neuroticism as measured by the SCL-90 (Symptom Check List). ${ }^{12}$ The impact of neurotic perfectionism measured by the MPS (Multidimensional Perfectionism Scale) ${ }^{13}$, however, was overruled by psycho-neuroticism. We therefore selected the second control group consisting of chronic pain patients whom we assumed had a high score on the SCL-90 to determine the im- 
pact of neurotic perfectionism. After controlling for psycho neuroticism, we could show that non-specific WRULD patients had significantly more neurotic perfectionist traits. Statistically significant differences in coping strategies (active coping, avoidance, passive reaction patterns etc) as measured by the UCL (Utrecht Coping List) ${ }^{14}$ were not found between computer screen workers with and without non-specific WRULD, although computer screen workers with non-specific WRULD showed a more active coping strategy than chronic pain patients (Chapter 4). ${ }^{15}$

In a second case-control study the cases from our randomized trial were compared with healthy controls, being a group of comparable computer screen workers without any non-specific WRULD. We found that pain catastrophising was associated with early non-specific WRULD: with significantly more catastrophising behaviour compared to the healthy controls (Chapter 5$)^{16}$

Third research question: are postural exercises delivered by postural exercise therapists according to the method of Mensendieck / Cesar more effective in decreasing beginning non-specific WRULD symptoms and in preventing disability and can this therapy be regarded as cost-effective when compared to usual care?

In our randomized trial ${ }^{17}$ among employed computer screen workers with beginning non-specific WRULD, postural exercise therapy according to Cesar/Mensendieck and regular physiotherapy were compared. The hypothesis was that postural exercise therapy according to the method Mensendieck/Cesar would be more effective in beginning non-specific WRULD than regular physiotherapy.

No statistically significant differences between the groups were found in the outcome measures pain (VAS / visual analogous scale), ${ }^{18}$ functional disability (DASH) ${ }^{19,20}$ and health related quality of life (Short Form-36) ${ }^{21}$ at 3 months, 6 months and at one year follow-up. Both groups improved only slightly, and after 1 year $45 \%$ of all patients still had complaints (Chapter 6).

A cost-effectiveness study was performed on the data from our randomized trial. CEACs (Cost-Effectiveness Acceptability Curves) suggested that from a societal perspective and in terms of QALYs (Quality Adjusted Life Year), postural exercise therapy according to Mensendieck / Cesar has a higher probability of being cost-effective in the long-term. Considering just a 12 month time frame however a marginal QALY- difference of 0.1 was found (Chapter 7$).^{22}$

\section{Strengths and weaknesses of the studies}

One of the strong points of this project has been the use of a variety of designs to unravel the mechanisms underlying non-specific WRULD. The introductory chapter dis- 
cusses the fact that it is still unknown which factors may cause non-specific WRULD and / or affect the course of the disease and /or influence the effectiveness of treatment. In our employment of a variety of study designs and populations we have increased the possibility of finding cues and explanations. The strengths and weaknesses of these varying studies will be discussed relative to research question and design.

Mainly validated instruments were used to assess "independent variables" as well as "outcome variables". The outcome measures used in our trial such as that for pain (VAS-visual analogous scale according to Jensen), ${ }^{18}$ functional disability (DASH) ${ }^{19,20}$ and the RAND (Short Form-36) for health related quality of life ${ }^{21}$ are internationally widely used and validated scales.

Most of the independent variables were also validated internationally, but not always on the same type of population, particularly with respect to age, as is the case with physical fitness (Groningen Fitness for the Elderly). ${ }^{23,24}$

No international classification exists to measure the course of non-specific WRULD.

First research question: what is the course of non-specific WRULD and do work- and treatment related factors, socio- demographic, psychological and physical factors predict clinical status and functional disability?

The retrospective study used data from the tertiary referral centre for non-specific WRULD patients of the University Medical Centre Maastricht. These data are registered in detail and the cohort is rather unique. The number of included cases provided sufficient statistical power. Non-response cases did not differ from the included cases regarding illness characteristics, socio-demographic characteristics and history of disease. The complete data set then represented the entire population of the tertiary referral centre. The fact, that we had to select the cohort from a tertiary referral centre might be seen as a disadvantage, since this meant inclusion of only "severe" or "difficult" cases. A weakness of the study was the wide range (1.9 to 5.8 years) in follow-up time (on average 4.4 years).

Another point, to consider when looking at the results, concerns the assessment of various variables at the end of the follow-up, variables which are potentially explaining the onset and course of the disease.

Second research question: do psychological factors play an important role in developing and persisting non-specific WRULD-complaints?

Generally, case-control studies are useful if longitudinal study designs are difficult to realise and / or answers to find "risk factors" related to (the onset of) a disease are needed on short term. Since a variety of such "risk factors" are reported in literature, we decided to use case-control designs to help trace possible important "risk factors". 
A strong point in the first case-control study is the selection of two different control groups, a healthy one and a group of patients with chronic pain: the latter was selected to include a group that would potentially score high on the SCL-90 to be able to find a better contrast with respect to the MPS. A weakness in the second case-control study is the fact that the controls have been selected at a later time point than the cases.

A problem in many case-control studies - as is in our own two - concerns the selection of the controls. "Healthy controls" are often based on self-report. This does not mean per se that controls do not have or have had conditions related to the disease which is the object of the study. As about half of the controls in the second case-control study indeed experienced or had experienced non-specific WRULD, we were able to analyse these subgroups ${ }^{16}$ (Chapter 5).

Third research question: are postural exercises delivered by postural exercise therapists according to the method of Mensendieck / Cesar more effective in decreasing beginning non-specific WRULD symptoms and in preventing disability and can this therapy be regarded as cost-effective when compared to usual care?

A randomized control design is the ideal for comparing two competing treatments. Since treatment here was related to the specific expertise of the professional caregiver, we had to select two groups of therapists, followed by a randomization of patients, who met the inclusion criteria.

All outcome measures used in this randomized trial are internationally widely used and validated scales ${ }^{17}$ (Chapter 6 ).

It took more time than expected to obtain the desired number of patients. Many persons, who wanted to be included in the study, appeared not to meet the inclusion criteria, i.e. they had suffered from non-specific WRULD symptoms before and/or these symptoms had already existed for a long period. Moreover, it seemed that there are personality characteristics which were a deterrent for entering the trial.

\section{Discussion}

First of all we would like to underline the seriousness of non-specific WRULD for a group of patients. Of the computer screen workers who visited our tertiary referral centre with WRULD complaints, as little as $9 \%$ made a full recovery, while $14 \%$ developed a chronic pain syndrome, the remaining $77 \%$ worsening slightly.

Our other studies showed that there is a large group of patients with (beginning) nonspecific WRULD complaints, demonstrating a somewhat different course of the disease. Over half of the patients in the randomised controlled trial reported the disappearance of their complaints after one year. These were patients with beginning non-specific 
WRULD. Unexpectedly, in the second case-control study we discovered through assessing the questionnaires that many 'healthy' controls reported having non-specific WRULD in the past or still, while not considering themselves as patients.

These different outcomes make clear, that while patients referred to our centre are 'more difficult cases', there is also a subgroup of persons with (beginning) non-specific WRULD at risk of developing chronic problems. So the poor prognosis of the cohort of computer screen workers may in part be explained by a selection effect as the study population was recruited from a tertiary referral centre. The potential risk factors found in this cohort study may therefore vary in magnitude from those found in studies which analyse patients with beginning non-specific WRULD.

The results of the cohort study (research question 1) have made clear, that workrelated factors are of less importance in explaining the worsening of the disease (at least for patients referred to a tertiary referral centre). Literature refers frequently to the influence of work- related factors on the onset of the disease. Our study shows, that these work-related factors do not play a role in the outcome of the disease. Furthermore psychological factors did not appear to influence clinical status and disability in this retrospective cohort study.

These results indicate, that a difference should be made between 'enabling' and 'sustaining' factors to understand the course of non-specific WRULD. The literature indicates that various factors may be seen as risk factors to develop non-specific WRULD complaints. ${ }^{1-6,25}$ These factors are important in the prevention of non-specific WRULD, but play a minor role in explaining the development into a chronic status or persistence course of the disease. For the latter, other factors may be important as will be discussed.

Sociodemographic factors play a role in non-specific WRULD as the results of research addressing questions 1 and 2 show. However, it remains unclear how to interpret the role of these factors. Women and older persons show worse functional disability after some years of the disease in spite of treatment, but did not appear to be at risk for developing a worse clinical status in the course of the disease. Obtained educational level appears to influence both the course of the disease and functional disability: lower education is associated with prolonged and severe non-specific WRULD and functional disability. ${ }^{10}$ This finding corresponds to the prognosis for patients with chronic low back pain. ${ }^{26}$ The influence of education on clinical status and disability may be caused by understanding and accepting the described therapies. It may be more difficult for persons with a lower education to adhere to our applied multidisciplinary approach which includes cognitive behavioural therapy, postural therapy, and graded exposure. 
Gender, age and education, however, did not appear to be statistically significant factors in the multivariable analysis of the second case-control study. The fact, that in all our studies the percentage of women was overrepresented, does not indicate a direct influence of sex on non-specific WRULD, since the sex difference may be an effect of referring (in the cohort study) or sampling. We did not control for sex in sampling the case-control study nor in the trial.

Perhaps there is an indirect effect of sex and education being related to stress exposure and coping styles.

In the randomised clinical trial we indicated after subgroup analyses small differences between men and women in experienced pain in the long term. Men seem to experience less pain in the long run than women. This might be related to different coping styles, but also to physical fitness. The trial study also showed that men had less disability than women when compared in the long term.

With respect to physical fitness our studies hinted at the importance of good (selfreported) physical fitness levels. Those with a poorer self-reported physical fitness had a poor clinical outcome and experienced disability in the long term. Moreover, computer screen workers without non-specific WRULD experienced a significantly better physical fitness level compared to the cases from our trial in spite of their significantly higher age. This finding indicates that physical fitness could be an important factor in preventing non-specific WURLD from becoming chronic. The design of our studies precluded the establishment of a causal direction of the relationship between WRULD and physical fitness.

Psychological factors were not identified as relevant in the cohort study. The special group of patients in the cohort study as well as the retrospective measurement may have limited the possibility of finding a relationship. Although psychological factors have been suggested in other studies as playing a role in the development and course of non-specific WRULD, they have not yet been studied in depth. ${ }^{27}$

Our case-control studies as well as our randomized trial looked specifically at psychological factors like neurotic perfectionism, psycho-neuroticism and coping styles, including pain catastrophising behaviour.

In the first case-control study, computer screen workers with non-specific WRULD showed a higher neurotic perfectionism score than the healthy controls.

In the randomized controlled trial in which two types of therapy were compared in computer screen workers with beginning non-specific WRULD, ${ }^{17}$ a surprising finding was that both groups at baseline showed high scores on the Pain Catastrophising Scale (PCS). ${ }^{17,28,29}$

This raised the specific question as to what the role of pain catastrophising could be in beginning non-specific WRULD. 
We executed the second case-control study to look more specifically into the role of pain catastrophising (psychological factors). Here we found a statistically significant higher score on pain catastrophising among cases with non-specific WURLD as compared to healthy controls.

The significantly higher score on pain catastrophising in computer screen workers with beginning non-specific WRULD than those without complaints could not be explained by symptom burden since the score on the VAS in computer screen workers with beginning non-specific WRULD was low. ${ }^{17}$ As mentioned above, through checking the questionnaires it was found that among the 'healthy controls' the majority suffered or had suffered from non-specific WRULD, but apparently was not aware of it. They were excluded from the study in the first instance, but when including this group in the analysis, we still found a low score on the Pain Catastrophising Scale, significantly lower as compared to the score of computer screen workers with beginning non-specific WRULD, selected as cases.

This finding gives rise to the hypothesis, that pain catastrophising is a powerful stimulus as to why computer workers with beginning non-specific WRULD experience their complaints as painful and worrying, become aware of their upper limb disorder and seek help. Together with other stress factors or risk factors this seems to create a mental burden for these patients. We could show that the role of pain catastrophising overruled the impact of neurotic perfectionism and anxiety, found in earlier studies as risk factors. ${ }^{5,15}$ The role of pain catastrophising in computer screen workers with nonspecific WRULD is in concordance with the model of Vlaeyen with respect to the development of chronic pain ${ }^{30}$.

The potential crucial role of pain catastrophising raises also a question about the Pain Catastrophising Scale (PCS) itself. According to the cut-off range for the PCS described by Sullivan et al ${ }^{31}$ we made use of a mean cut-off value of 20 points in our studies. The question is whether this cut-off point is appropriate for all type of populations and/or patients as another cut-off point may have been more appropriate in the cohort study to show the role of catastrophizing behaviour.

\section{From initial expectations to advancement in understanding}

In the nineties, daily clinical practice of patients with non-specific WRULD indicated that psychological factors such as neurotic perfectionism and coping style as well as work-related factors such as work organisation, heavy work load and experienced job stress were associated with the onset of non-specific WRULD besides frequent screen work. Physical condition was seen as a possible protective factor.

Clinical observations showed a high prevalence of non-specific WRULD in our tertiary referral centre among women, which might be related to the mentioned psychological factors. 
In the treatment of patients with non-specific WRULD it seemed that bad body posture and poor ergonomic circumstances at the work place at least partly were responsible for the development and / or persistence of non-specific WRULD. However, full adaptation of the body posture and ergonomic circumstances at the work place did not result in a significant reduction of complaints.

Clinical observations hinted at a somewhat larger benefit of specific postural exercise therapy according to Mensendieck / Cesar in computer workers with non-specific WRULD compared to regular physiotherapy.

Based on these observations we were interested in cooperating with other researchers interested in WRULD and health care professionals. This cooperation resulted in a more systematic measurement of work-related and personality factors. Also the number of health care professionals, confronted with WRULD complaints, increased and thus the search for answers. Therefore, the University Maastricht founded in 2003 an expertise centre to bring research, clinical practice and prevention together.

The expertise centre used an RSI (WRULD) model to study the relation between risk factors, WRULD, treatment and work (dis) ability as shown in Figure 1.

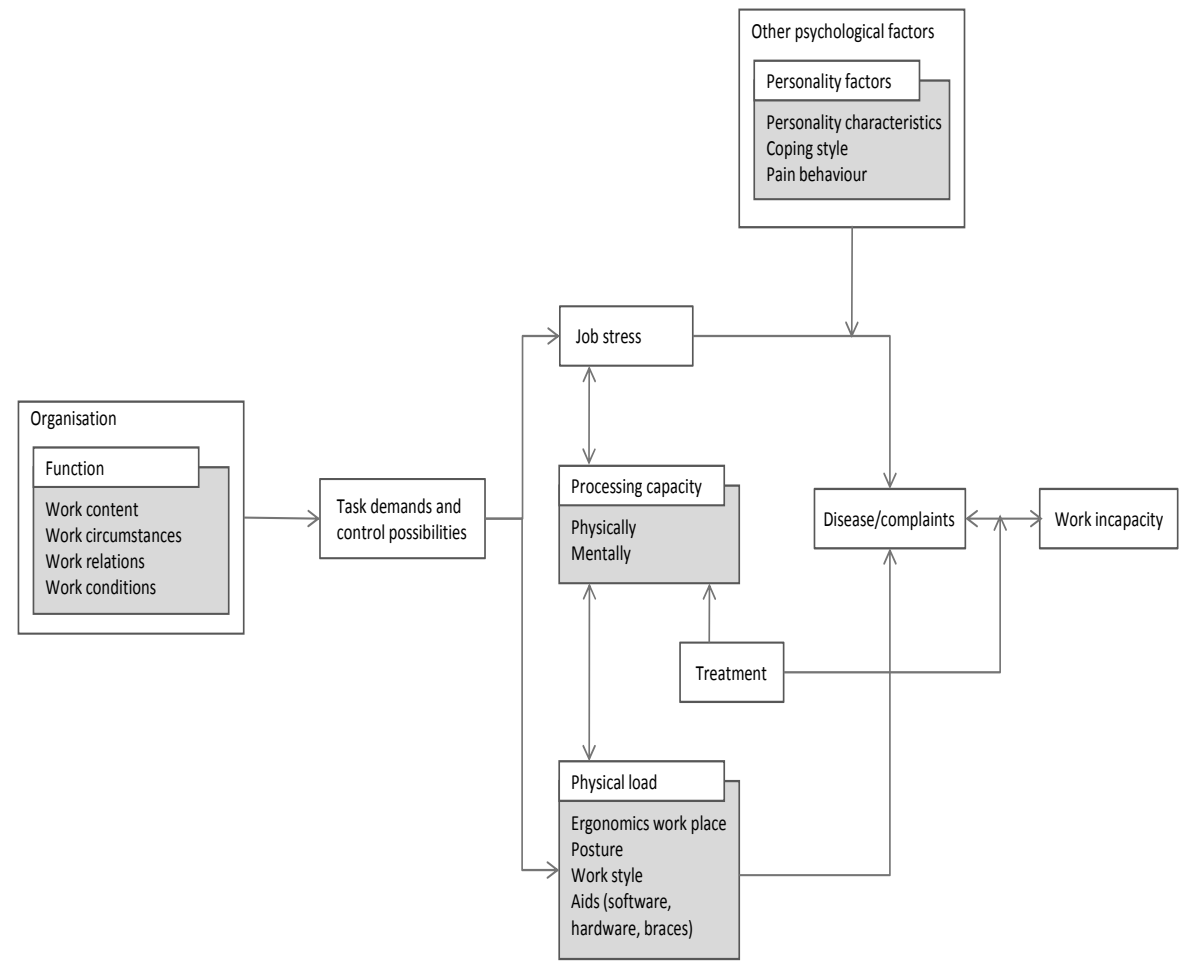

Figure 1. Model to study RSI (WRULD) at the expertise centre Maastricht University 2003 
Over the last decade, daily practice indicated more and more that psychological factors in interaction with work situation and socio-demographic variables played an important role in the onset as well as course of non-specific WRULD complaints, while physical fitness seemed to play an additional role.

In our studies we could show that it is important to make a difference between risk factors playing a role at the onset of the disease and factors, which influence the course of the disease (prognostic factors). While these factors may in part be the same, they interact differently during the disease process. The original model developed in 2003 is still useful as a starting point, but based on additional research one model to understand the onset and one model to understand the course of the disease should be specified. It is too early to design such models, but the following elements seem to be important, based on our studies.

In developing non-specific WRULD the 'key triggers' are a 'high task demanding work situation' (i.e. high workload, job stress) ${ }^{2,3,25}$ interacting with psychological factors (neurotic perfectionism) $)^{2,3,15}$ causing symptoms of non-specific WRULD. Sociodemographic factors (gender, age, education) and physical condition (physical fitness) may play an additional, interactive role at the onset, i.e. poor physical fitness, being female, being middle aged and having a low education increasing the chance of the onset of complaints.

High task demands leading to job stress in combination with neurotic perfectionism are especially risky for developing non-specific WRULD complaints. Employees in such circumstances seemed to have developed a specific work-style. ${ }^{25}$

When non-specific WRULD is present, it is particularly a negative attitude in the way the person understands and copes with pain and body image, which increases the chances for a chronic disease development versus cure. Persons with non-specific WRULD and pain catastrophising behaviour seem continuously aware of their complaints and do not have time or the ability to relax and participate in sports. In such a 'mental state', work conditions ${ }^{32}$ and socio-demographic factors have less influence on this process. The course of the disease then seems to follow the fear-avoidance model of Vlaeyen. ${ }^{30,33}$

\section{Conclusions}

In retrospect, we could show that computer screen workers with non-specific WRULD visiting our tertiary centre for this diagnosis have a poor prognosis; after 4.4 years of follow-up only one in four improved, while the remainder had worsened (slightly). This shows that relatively 'heavy cases' are referred to our academic centre.

Our studies show, that psychological factors, work conditions, socio-demographic factors and self-reported physical fitness all play a role in the onset and / or course of non- 
specific WRULD. However, the importance of this role varies depending on the process of the disease. None of these factors appear to have an important influence on there own. Interaction between various factors is the rule hindering prevention and treatment of the disease.

During the onset of the disease 'key triggers' are 'high task demanding work situation' (i.e. high workload, job stress) interacting with psychological factors (neurotic perfectionism) causing symptoms of non-specific WRULD.

The course of the disease is mainly influenced by psychological factors, especially the way the person copes with pain. Persons with non-specific WRULD and pain catastrophising behaviour seem continuously aware of their complaints, are unable to relax and lose any confidence that there will be a positive turn.

Early intervention in computer screen workers suffering from non-specific WRULD for less than 3 months does not appear to be effective when mainly physical aspects are addressed. Postural exercise therapy is not more effective than regular physiotherapy, although postural exercise therapy has a higher probability of being cost-effective from a societal perspective.

\section{Implications for daily practice}

Prevention of non-specific WRULD is indicated to occur in the work place. High task demanding work situations (i.e. high workload, job stress), being female, being of middle age, neurotic perfectionist, showing catastrophizing behaviour and having a lower education are the most important factors to pay attention to for occupational medicine.

Patients with beginning non-specific WRULD complaints, being female, having a low education, being older and not participating in sports are at risk for developing a next stage of the disease. For occupational medicine and general practice, these are important indicators to start a directed treatment. In such a case a "quick scan" including pain coping styles, neurotic perfectionism and physical fitness should be executed by the occupational doctor at the work place, combined with an analysis of the work conditions. $^{34}$

Depending on the results of the quick scan, a suitable individually directed therapy should be offered. At least, computer screen workers with non-specific WRULD need reassurance and proper education on the pitfalls of non-specific WRULD as well as encouragement to enter fitness programs rather than focussing on their impairments and disabilities. 
Postural exercise therapy and regular physiotherapy in itself will not be sufficiently effective for a relatively large part of the patients.

If patients with non-specific WRULD score high on neurotic perfectionism additional treatment is needed, i.e. multidisciplinary rehabilitation with the help of a psychologist. If patients score high on pain catastrophising - additionally to risk factors such as job stress and / or neurotic perfectionism, - referral to a specialized centre is recommended. Multidisciplinary therapy, including cognitive behavioural therapy, is indicated in such cases.

\section{Implications for research}

Clearly further research is needed. The suggested research should be part of a (national) research programme on WRULD related diseases and should address the following topics.

The set-up of a large prospective cohort study among computer screen workers free from non-specific WRULD is strongly recommended. Such a study should ensure a careful description regarding what is meant by "non-specific WRULD", and include at least a five years follow-up. Independent variables in such a study should include PCS (Pain Catastrophizing Scale), ${ }^{28,29}$ MPS (Multidimensional Perfectionism Scale), ${ }^{13}$ TSK (Tampa Kinesiophobia Scale), ${ }^{35}$ STAI 1 \& 2 (state \& trait anxiety), ${ }^{36}$ JSS (Job Stress Survey), ${ }^{37}$ selfreported physical fitness (GFE), ${ }^{23,24}$ socio-demographic factors (age, sex, education). Outcome measures such as functional disability, health related quality of life, clinical status and working status need to be included as well. In particular, the effect of interactions between job stress, catastrophising behaviour and neurotic perfectionism on the disease outcomes needs to be unravelled. ${ }^{15,16,25}$

A prospective trial based cost-effectiveness study has no surplus value as long as the above mentioned associations are not clear. A large prospective cohort study however would give the opportunity to collect valuable economic and quality of life data in a standardised way. These data could be used to set up cost-effectiveness modelling studies predicting cost-effectiveness of future interventions for treating WRULD.

Several methodological questions must be addressed.

The cut-off value of the Pain Catastrophising Scale, useful for specific group of patients, has to be validated.

The physical fitness scale was developed for and tested on an older population. The validation has to be extended to other age groups with adjustment for gender. 
The role of sex and education on the onset and course of the disease has to be studied. Some psychological or work-related factors may interact with $\operatorname{sex}^{38}$ as may physical fitness.

In future studies, males and females should be analysed separately. ${ }^{38}$

Level of education may be an important factor to understand therapy acceptance and compliance.

In general, more clinical interventions should be evaluated. As example may serve a recent started randomized intervention trial "CANS (Complaints Arm, Neck, Shoulder); stop or continue" taking into account the influence of personality factors. ${ }^{39}$ Treatments must be evidence-based. If such is lacking, treatments should not be executed.

As mentioned above, a comprehensive model might be developed to understand the onset and course of non-specific WRULD. This thesis offers important building stones for such a model.

\section{References}

1. IJmker S. Risk factors for arm-wrist-hand and neck-shoulder symptoms among office workers. A longitudinal perspective. PhD Thesis. Body@Work, Amsterdam, the Netherlands, 2008.

2. Van den Heuvel SG. (Work-related neck and upper limb symptoms. PhD Thesis Amsterdam. TNO; the Netherlands, 2006.

3. Van den Heuvel SG, Van der Beek AJ, Blatter BM, Bongers PM. Workstyle and overcommitment in relation to neck and upper limb symptoms. International Journal of Behavioural Medicine 2007; 14 (1): 12 20.

4. Cabecas JM Occupational Musculoskeletal Disorders in Europe: Impact, Risk factors and Preventive Regulations, Enterprise and Work Innovation Studies, 2, IET: 95-104; 2006.

5. Roelofs PDDM RSI en persoonsgebonden factoren: een oriënterende studie (RSI, personal and personality factors: an explorative study). Thesis. Maastricht University; Maastricht, the Netherlands, 2002. From: http://www.unimaas.nl/bestand.asp?id=2275.

6. MacFarlane GJ, Hunt IM, Silman AJ. Role of mechanical and psychosocial factors in the onset of forearm pain: prospective population based study. BMJ 2000; 321: 1-5.

7. Hamberg- van Reenen HH. Physical capacity and work-related musculoskeletal symptoms. PhD Thesis EMGO Institute. Amsterdam, the Netherlands, 2008.

8. Blatter B, Houtman I, van den Bossche S, Kraan K, van den Heuvel S. Gezondheidsschade en kosten als gevolg van RSI en psychosociale arbeidsbelasting in Nederland. (Health effects and costs as consequences of RSI and psychosocial work load in the Netherlands). TNO Kwaliteit van Leven / Ministerie van Sociale Zaken en Werkgelegenheid 2005. Retrieved January 27, 2009, from: http://docs.swz.nl/pdf/129/2006/129_2006_3_8656.pdf

9. Staal JB, de Bie RA, Hendriks EJM. Aetiology and management of work-related upper limb disorders. Best Practice \& Research Clinical Rheumatology 2007; Vol 21 (1): 123-133.

10. Van Eijsden-Besseling MD, Van den Bergh KA, Staal JA, de Bie RA, Van den Heuvel WJA. The course of non-specific work-related upper limb disorders and the influence of demographic factors, psychologic factors, and physical fitness on clinical status and disability. Archives of Physical Medicine and Rehabilitation 2010; 91: 862-67. 
11. Van Eijsden-Besseling MDF, Van den Bergh KA, Staal JB, de Bie RA, Van den Heuvel WJA. The influence of work- and treatment- related factors on clinical status and disability in patients with non-specific workrelated upper limb disorders. Accepted by journal WORK May 2010; in press.

12. Arrindell WA, Ettema JHM. Klachtenlijst Symptom Check List (SCL-90). Lisse : Swets \& Zeitlinger BV, the Netherlands, 1986

13. Frost RO, Marten P, Lahart C, Rosenblate R. The dimensions of perfectionism. Cognit Ther Res 1990;14: 449-468

14. Schreurs PJG, Van de Willige G Dealing with Problems and Events (UCL, Utrecht Coping List). Lisse: Swets \& Zeitlinger BV, the Netherlands, 1988.

15. Van Eijsden-Besseling MD, Peeters FP, Reijnen JA, De Bie RA. Perfectionism and coping strategies as risk factors for the development of non-specific work-related upper limb disorders (WRULD). Occupational Medicine 2004; 54 (2): 122-127

16. Van Eijsden-Besseling MD, Van Attekum A, de Bie RA, Staal JB. Pain Catastrophizing and lower physical fitness in a sample of computer screen workers with early non-specific upper limb disorders; a casecontrol study. Accepted by Industrial Health Jan. 2010; in press.

17. Van Eijsden-Besseling MD, Staal JB, Van Attekum A, De Bie RA, Van den Heuvel WJA. No difference between postural exercises and strength and fitness exercises for early, non-specific, work-related upper limb disorders in visual display unit workers: a randomized trial. Australian Journal of Physiotherapy 2008; 54 (2): 95-101

18. Jensen MP, McFarland CA Increasing the reliability and validity of pain intensity measurement in chronic pain patients. Pain 1993; 55: 195-203

19. Veehof MM, Sleegers EJ, van Veldhoven NH, Schuurman AH, van Meeteren NL Psychometric qualities of the Dutch language version of the disabilities of the arm, shoulder and hand questionnaire (DASH-DLV). Journal of Hand Therapy 2002; 15: 347-354.

20. Huisstede BMA, Feleus A, Bierma-Zeinstra SM, Verhaar JA, Koes BW. Is the disability of arm, shoulder, and hand questionnaire (DASH) also valid and responsive. Spine 2009; 43 (4), E 130-8.

21. Hays RD, Sherbourne CD, Mazel R. The Rand 36-item health survey 1.0 Health Economics 1993; 2: 217 227.

22. Van Eijsden-Besseling MD, Gerhards SA, De Bie RA, Severens JL. Cost - effectiveness of postural exercise therapy versus physiotherapy in screen workers with early non-specific work-related upper limb disorders; a randomized controlled trial. Trialsjournal 2009; 10; 103

23. Van Heuvelen MJG, Kempen GIJM,Ormel J, De Greef MHG Self-reported physical fitness of older persons: a substitute for performance-based measures of physical fitness? J Aging Phys Health 1997; 5: 298310.

24. Lemmink K, Kemper H, Greef de M, Rispens $P$, Stevens $M$. Reliability of the Groningen Fitness test for the Elderly. Journal of Aging and Physical Activity 2001; 9: 194- 212.

25. Harrington $C B$, Siddiqui $A$, Feuerstein $M$. Workstyle as a predictor of pain and restricted work associated with upper extremity disorders: a prospective study. J Hand Surg Am 2009; 34 (4): 724-31

26. Menezes Costa Luciola da C, Maher CG, McAuley JH, Hancock MJ, Herbert RD, Refshauge KM, Henschke N. Prognosis for patients with chronic low back pain: inception cohort study. BMJ 2009; 339:b3829

27. Karels CH, Bierma-Zeinstra SMA, Burdorf A, Verhagen AP, Nauta AP, Koes BW. Social and psychological factors influenced the course of arm, neck and shoulder complaints. Journal of Clinical Epidemiology 2007; 60 (8): 839-848.

28. Osman A, Barrios FX, Kopper BA, Hauptmann W, Jones J, O’Neill E. Factor Structure, Reliability and Validity of the Pain Catastrophizing Scale. Journal of Behavioral Medicine 1997; Vol 20 (6): 589-605

29. Van Damme S. Pain Catastrophizing Scale-Dutch version (PCS-DV) Gent: University Gent. http://www.lobsw.ugent.be/VVGP/fichePCS.pdf Accessed March 31, 2009

30. Vlaeyen JWS and Linton SJ Fear avoidance and its consequences in chronic musculoskeletal pain: a state of the art. Pain 2000; 85: 317-332.

31. Sullivan MJL, Bishop SR, Pivik J. The Pain Catastrophizing Scale: Development and Validation. Psychological Assessment 1995; 7: 524-533 
32. Feuerstein M, Nicholas RA, Huang GD, Dimberg L, Ali D, Rogers H. Job stress management and ergonomic intervention for work-related upper extremity symptoms. Applied Ergonomics 2004; 35 (6); 565-574.

33. Severijns R, Vlaeyen JW, Van den Hout MA, Picavet HS. Pain catastrophizing and consequences of musculoskeletal pain: a prospective study in the Dutch community. J Pain 2005; 6 (2): 125-32.

34. Feuerstein M, Nicholas RA. Development of a short form of the Workstyle measure. Occupational Medicine 2006; 56 (2): 94-99.

35. Clark, M.E., Kori, S.H., \& Brockel, J. Kinesiophobia and chronic pain: Psychometric characteristics and factor analysis of the Tampa Scale. American Pain Society 1996; Abstract 77.

36. Van der Ploeg HM, Defares PB \& Spielberger CD. Handleiding bij de zelfbeoordelingsvragenlijst ZBV. Een Nederlandse bewerking van de Spielberger state-trait anxiety inventory STAI-DY. ( A Dutch version of the Spielberger state-trait anxiety inventory) Lisse: Swets \& Zeitlinger BV, the Netherlands, 1980.

37. De Wolff B, Swinnen L, de fruyt F, de Wolff C, Spielberger CD JSS Job Stress Survey. Handleiding / Manual. Swets test Publishers, the Netherlands, 2002.

38. Hooftman WE, van Poppel MN, van der Beek AJ et al. Gender differences in the relations between workrelated physical and psychosocial risk factors and musculoskeletal complaints. Scandinavian Journal of Work, Environment and Health 2004; 30 (4): 261-78.

39. De Jong J, Vlaeyen JWS. Protocol “KANS: Stoppen of doorgaan?” (CANS; Stop or continue) Department of Rehabilitation University Hospital Maastricht and Clinical Psychological Science Maastricht University, Maastricht, the Netherlands, 2009. 


\section{[9]}

Summary

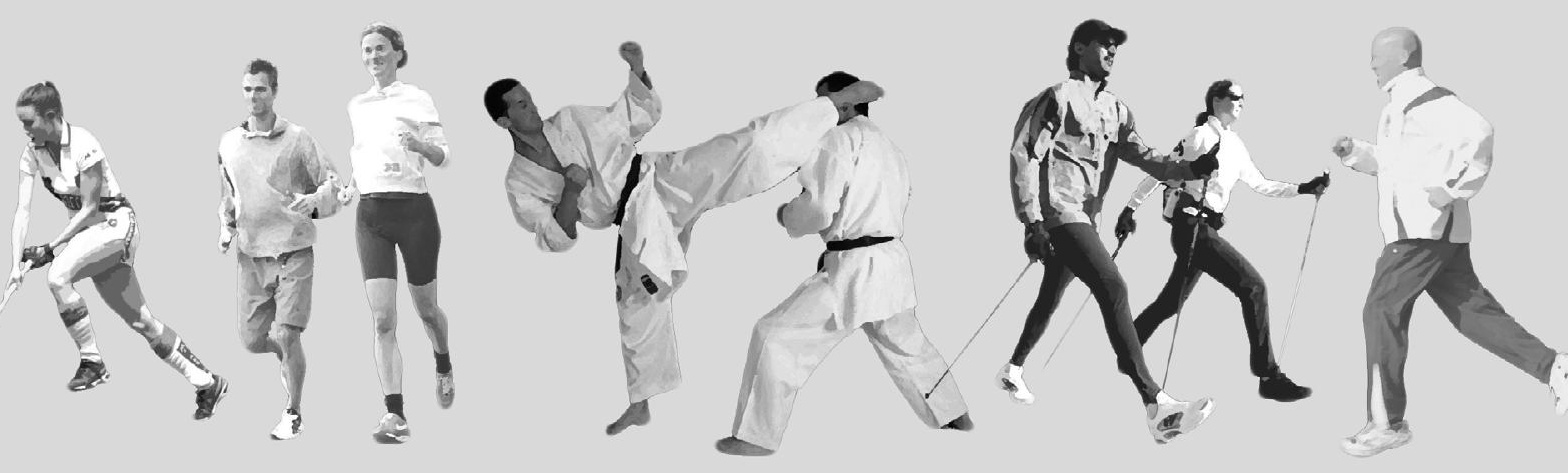


In Chapter1 an outline, background information and the main objectives of the studies are presented.

Personal experience in having treated patients with non-specific work-related upper limb disorders (WRULD) in the past 15 years in a tertiary referral centre, i.e. within the department of rehabilitation and physical medicine of the University Medical Centre Maastricht, showed that these complaints - if untreated - tend to become chronic.

Research and daily practice show that physical and psychosocial work-related factors as well as socio-demographic and personality factors may play a role in the development and persistence of WRULD complaints. The consequences of WRULD with respect to experienced disability and decreased quality of life, as well as decreased productivity, work-related absenteeism, increased medical consumption and increased societal costs, are huge.

This thesis project aimed to study risk factors evoking non-specific WRULD and those playing an important role in the development of persisting complaints resulting in a chronic condition. Therefore the course of non-specific WRULD complaints in a cohort of screen workers was studied.

Moreover we attempted to determine which therapy would be most (cost)-effective in patients with beginning complaints which tend to become chronic if left untreated.

The following research questions were answered.

1. what is the course of non-specific WRULD and do work- and treatment related factors, socio- demographic, psychological and physical factors predict clinical status and functional disability?

2. do psychological factors play an important role in developing and persisting nonspecific WRULD- complaints?

3. are postural exercises delivered by postural exercise therapists according to the method of Mensendieck / Cesar more effective in decreasing beginning nonspecific WRULD symptoms and in preventing disability and can this therapy be regarded as cost-effective when compared to usual care?

In Chapter 2 the influence of work- and treatment-related factors on clinical status (stage of WRULD) and disability (measured by the DASH - Disabilities of the Arm, Shoulder and Hand questionnaire) was addressed in a retrospective study among a cohort of 182 computer screen workers with non-specific WRULD.

Besides medical records and inventory of work- and treatment-related factors, before, at time of diagnosis and during the treatment period, a follow-up questionnaire regarding clinical status of WRULD and disability level at follow-up moment was used.

About $57 \%$ ( $N=107$ ) of this cohort returned the follow-up questionnaire and data of 103 screen workers could be analyzed.

None of the selected work-and treatment-related factors was significantly associated with clinical status. "Number of working hours per week before diagnosis" was negatively and "other therapies during treatment (not being multidisciplinary rehabilitation or psychotherapy)" was positively associated with DASH. 
Working more hours before WRULD diagnosis was not predictive for disability while having undergone other therapies during the treatment period was.

Limitations of this study are the poor quantification of the work-related factors and the reliance on self-report questionnaire information. This may have hampered finding associations between work- and treatment-related factors and the course of nonspecific WRULD. Furthermore these associations might not have been found because there are other important risk factors which were not studied here.

Nevertheless we are able to recommend that physical, psychosocial as well as personality factors be taken into account in the decision to treat computer screen workers with non-specific WRULD.

In Chapter 3 the course of non-specific WRULD and the influence of demographic factors, psychological factors and physical fitness on clinical status and disability is addressed with the same cohort of 182 computer screen workers with several stages of non-specific WRULD.

A cross-sectional analysis was conducted using a follow-up questionnaire assessing psychological and physical fitness characteristics whereby the follow-up period was on average 4 years.

Socio-demographic and medical characteristics were assessed based on medical records at onset and diagnosis.

Data of 104 screen workers could be analysed. Of the responders, 14\% developed a chronic pain syndrome and $9 \%$ recovered. The remaining (77\%) worsened slightly.

A higher DASH score was associated with being older, being female, having a lower educational achievement and poorer self-reported physical fitness level.

Lower educational achievement and poorer self-reported physical fitness were associated with a more severe clinical status.

Psychological factors did not appear to influence disability or clinical status in this study.

The prognosis of computer workers with non-specific WRULD is not favourable.

Those with a lower educational achievement and poorer self-reported physical fitness are at risk for a more severe clinical status and functional disability.

Limitations of this study are that the poor prognosis of this cohort of computer screen workers with non-specific WRULD may in part be explained by a selection effect, because the study population was selected at a tertiary rehabilitation clinic and may consist of patients at the more severe end of the disease spectrum.

A notable finding concerned the role of psychological factors. Some of these, such as neurotic perfectionism, overcommitment, trait anxiety are considered important triggers for the onset of non-specific WRULD. As the effect of psychological factors on the course of the disease or disability has not yet been fully addressed, their influence remains unclear. 
The associations found in this study, however, suggest that computer screen workers with non-specific WRULD should be encouraged to enter fitness programs. Moreover, special attention needs to be given to computer workers having a lower educational achievement, being female and being older.

In Chapter 4 personality factors were studied as possible risk factors for developing non-specific WRULD.

We studied neurotic perfectionism and coping strategies as potential risk factors through a case-control study with two control groups. The sample of cases ( $N=45$ ) was taken from computer screen workers with non-specific WRULD from our tertiary referral centre and the control groups were composed of respectively computer screen workers free from non-specific WRULD $(N=45)$ and chronic pain patients with generalized pain above and below trunk level $(\mathrm{N}=42)$.

Neurotic perfectionism was assessed by the MPS (Multidimensional Perfectionism Scale).

Because of its high correlation with neurotic perfectionism, the SCL (Symptom Check List)-90 was employed which measures general physical and psychological complaints (psycho neuroticism).

Logistic regression analysis revealed significant differences in SCL-90 scores between cases and those free from non-specific WRULD, thereby potentially negating the significance of the higher neurotic perfectionism in the case group.

Therefore, the second control group was composed of chronic pain patients with prospective high scores on the SCL-90. Logistic regression showed that, after controlling for psycho- neuroticism, non-specific WRULD patients had significantly more neurotic perfectionist traits.

Coping strategies, measured by the UCL (Utrecht Coping List), did not show significant differences in mean UCL scores. However, cases seemed to cope more actively as compared to chronic pain patients.

We concluded that psycho-neuroticism and neurotic perfectionism are important risk factors with respect to non-specific WRULD. Therefore, special attention needs to be given to those computer workers with non-specific WRULD showing psychoneurotic and neurotic perfectionist personalities.

Building on the results of (our) earlier studies in Chapter 5, we studied the role of personality factors, such as pain catastrophising, perfectionism and anxiety and the role of (self-reported) physical fitness in computer screen workers with beginning non-specific WRULD. We made use of validated questionnaires.

In our case-control study with cross-sectional analysis, the cases were retrieved from our randomised trial $(N=88)$ and the controls $(N=31)$ were recruited among healthy computer workers, working under the same circumstances as the cases. 
The influence of personality factors and physical fitness on non-specific WRULD was investigated with logistic regression.

Of the various potential predictor variables investigated, pain catastrophising (measured by the PCS-Pain Catastrophising Scale) and self-reported lower physical fitness (measured by the GFE-Groningen Fitness questionnaire for the Elderly) appeared to be statistically significantly related toWRULD. According to this study, pain catastrophising and lower physical fitness seem to be associated with early non-specific WRULD in computer screen workers.

A remarkable finding in this study was that through checking the questionnaires we found that of the 78 employees who originally volunteered as controls, 47 suffered or had suffered from non-specific WRULD. They were excluded from the analyses. However, when including this subgroup ( $N=47)$, it appeared that the "controls" still showed significantly less catastrophising behaviour than the cases.

Perhaps here lies the key as to why computer workers with non-specific WRULD and showing pain catastrophising behaviour, not only develop, but are "painfully" aware even those with low VAS (visual analogous scale) scores for pain - of their upper limb disorders.

In this study we found an association between lower physical fitness and early nonspecific WRULD. A limitation of this study is that controls were recruited at a later time point than the cases.

Nevertheless, we suggest that both reassurance and proper education on the pitfalls of WRULD and stimulation of physical fitness instead of emphasizing disability might be valuable strategies to prevent the burden of non-specific WRULD.

In Chapter 6 two therapies for non-specific WRULD were compared in computer screen workers with beginning complaints by means of a randomized controlled trial, in which postural exercise therapy according to the method Mensendieck / Cesar was compared to regular physiotherapy.

In total 88 computer screen workers were included and after randomization each group contained $\mathrm{N}=44$ computer workers. The intervention consisted of 10 weeks postural exercises or 10 weeks strength and fitness exercises according to protocol. Outcome measures were pain, measured by the VAS score of Jensen, quality of life measured by the Short Form-36 and functional disability measured by the DASH. At each measurement time point the number of participants experiencing non-specific WRULD was noted. Outcome measures were collected at baseline and 3, 6 and 12 months.

At baseline, analyses were based on 88 participants. There were 6 drop-outs at 3 months follow-up, so that further analyses were conducted on 82 participants ( 40 in the postural exercise group and 42 in the regular physiotherapy group). We made use of the intention-to-treat principle. Outcome measures were analysed by means of linear regression analyses, controlling for baseline characteristics. Results showed that there was no significant difference in decrease in pain between the groups at 3 months, 
6 months or at 12 months. Differences between the groups in upper limb complaints, disability and health-related quality of life were also small and not significant at each measurement moment. Overall, there were only small improvements from baseline to one year on all outcome measures. We could conclude that postural exercises did not result in a better outcome than regular physiotherapy.

However, 55\% of all participants with early non-specific WRULD were free of complaints one year after treatment commenced regardless of which treatment was followed.

A limitation of this study is that it is not clear whether the improvements were a result of the interventions since including a waiting-list control group was not warranted for ethical reasons.

Since both physically-oriented exercise programs led to the same outcome in this study, it is our suggestion that a randomized trial be performed among larger groups of computer screen workers with the intervention focus on personality, psychosocial work-related risk factors and inter-related coping mechanisms.

Since exercise therapies generate substantial costs in computer screen workers with non-specific WRULD, we conducted a cost-effectiveness study which is presented in Chapter 7. We investigated whether postural exercise therapy is more cost-effective than regular physiotherapy in computer screen workers with early complaints, both from a health care and societal perspective.

We conducted the study among the participants from the above-mentioned randomized controlled trial i.e. the 88 screen workers with early non-specific WRULD.

Besides the effectiveness measures from the original trial, economic outcome measures were used. In addition, quality of life was measured by the generic measure EQ-5D of the EuroQol Group. This EQ-5D was used to calculate the quality adjusted life years (QALYs) during follow-up.

Costs are subdivided into health care costs (including out of pocket costs for the patient and family) and productivity costs. Only costs related to WRULD were included in the analyses.

A questionnaire measuring health care costs and costs for patient and family was administered.

Costs concerning productivity loss were based on the reported sick leave from work due to non-specific WRULD, making use of a questionnaire concerning employment and absence through illness. Productivity costs were calculated according to the friction-cost method.

Assessments took place at the same time as the effectiveness measures.

In the cost-effectiveness analyses the effectiveness measures VAS, self-perceived WRULD and DASH were related to the health care costs. The QALY was related to the societal costs including productivity costs, in a cost-utility analysis. Incremental costeffectiveness ratios (ICERs) were calculated based on differences between the groups 
in measured average costs and outcome parameters. The bootstrapping method, making use of confidence intervals in percentiles, was applied to explore the statistical uncertainty surrounding the ICERs. The ICER uncertainty was used for plotting a costeffectiveness acceptability curve (CEAC), whereby increasing cost-effectiveness ceiling ratio values were used (society's maximum willingness to pay for one unit of effectiveness), enabling to show the probability that one of the therapies is most cost-effective. The results showed that at baseline both groups were comparable for costs. After one year the postural exercise group had higher mean total health care costs, but lower productivity costs compared to the regular physiotherapy group. Mean societal costs after one year (therefore) were in favour of postural exercise therapy. After one year, only self-perceived WRULD seemed to result in acceptable cost-effectiveness of the postural exercise strategy over regular physiotherapy; however, the probability of acceptable cost-effectiveness did not exceed $60 \%$.

Considering societal costs related to QALYs, postural exercise therapy had a probability of over $80 \%$ of being cost-effective over a wide range of cost-effectiveness ceiling ratios; however, based on a marginal QALY-difference of 0.1 over a 12 month time frame. We could conclude that, although our trial failed to find significant differences in VAS, QALYs and ICERs based on VAS and QALYs at one-year follow-up, CEACs suggested that postural exercise therapy has a higher probability of being cost-effective than regular physiotherapy. Further research is recommended.

In Chapter 8 the general discussion and conclusions are presented as well as the implications for daily practice and further research.

Conclusion: Computer screen workers with non-specific WRULD, visiting our tertiary referral centre for this diagnosis have a poor prognosis.

Risk factors of importance for the onset of non-specific WRULD are not necessarily the same as the prognostic factors contributing to the persistence of complaints.

The importance of their role varies depending on the course of the disease.

Interaction between various risk factors seems to be the rule, forming barriers to successful prevention and treatment of the disease.

Key triggers in the onset of the disease are a "high task demanding work situation (high work load, job stress)" interacting with psychological factors (neurotic perfectionism), while the course of the disease seems to be mainly influenced by the way a person copes with pain and experiences mental burden. The role of catastrophising in computer workers with non-specific WRULD is in concordance with the model of Vlaeyen with respect to the development of chronic pain. Self-reported physical fitness could be an important factor in the prevention of the chronicity of complaints.

Implications for daily practice: Prevention of non-specific WRULD needs to occur at the work place. High task demanding work situations (i.e. high workload, job stress), being female, being of middle age, neurotic perfectionist and having a lower educational 
achievement are the most important factors to pay attention to in occupational medicine.

Patients with beginning complaints, being female, having a low education, being older, not participating in sports and start catastrophising are at risk for chronic complaints. For occupational medicine and general practice, the use of a "quick scan" should be encouraged including pain coping styles, neurotic perfectionism and self-reported physical fitness; in case of occupational medicine combined with an analysis of the work conditions.

Depending on the results, a suitable individually directed therapy should be offered. Computer workers with non-specific WRULD need reassurance and proper education on the pitfalls of their disease and encouragement to enter fitness programs rather than dwelling on their impairments and disabilities.

If patients with non-specific WRULD score high on neurotic perfectionism, multidisciplinary treatment is needed with the help of a psychologist.

If patients score high on pain catastrophising, additionally to other risk factors such as job stress and / or neurotic perfectionism, referral to a specialized centre is recommended. In such cases multidisciplinary treatment, including cognitive behavioural therapy is indicated.

Implications for research: Research in this field should be part of a (national) research program. A large prospective cohort study among computer screen workers actually free from non-specific WRULD with a follow-up of five years is strongly recommended. A careful description regarding what is meant by "non-specific WRULD" is a condition sine qua non.

Independent variables should include: PCS, MPS, TSK (TAMPA scale for kinesiophobia), STAI (State / Trait Anxiety Inventory) 1 \& 2, JSS (Job Stress Survey), self-reported physical fitness (GFE) as well as socio-demographic factors. Outcome measures should include: DASH, health related QoL, clinical status and working status.

In particular, the interactions between job stress, catastrophising behaviour and neurotic perfectionism and their effect on disease outcomes need to be unravelled.

We suggest, to analyse males and females separately.

A large prospective study would be useful in establishing a validated cut-off value for the PCS for this specific group of patients and to extend the validation of the selfreported physical fitness scale to other age groups.

Moreover, such a prospective study would give the opportunity to collect valuable economic and related quality of life data in a standardized way, to populate costeffectiveness modelling studies predicting cost-effectiveness of future interventions for treating non-specific WRULD.

More clinical interventions should be evaluated by randomized trials to provide evidence-based treatments for this category of patients. 


\section{[10]}

Samenvatting

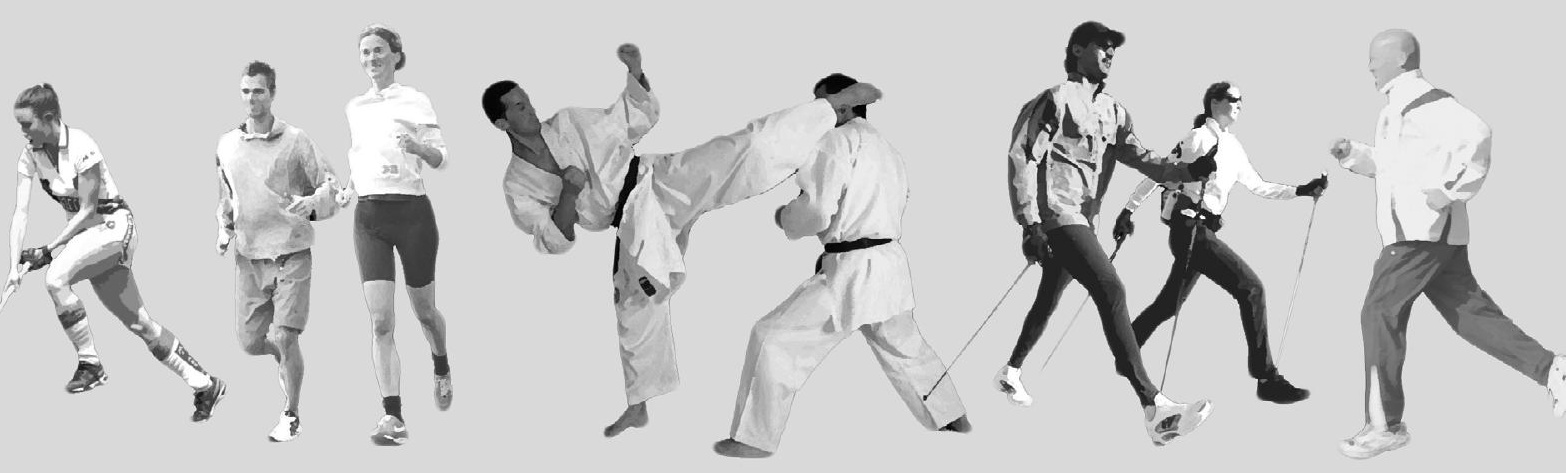


In Hoofdstuk 1 worden achtergrond en belangrijkste doelstellingen van de studies in dit proefschrift beschreven.

Persoonlijke ervaring met de behandeling van patiënten met aspecifieke werkgerelateerde klachten van arm, nek en schouder (KANS) in de afgelopen 15 jaar op de revalidatieafdeling van het Maastrichts Universitair Medisch Centrum die gespecialiseerd is in deze groep patiënten, maakte duidelijk dat deze klachten, wanneer onbehandeld, chronisch worden.

Onderzoek en dagelijkse praktijk laten zien dat fysieke en psychosociale werkgerelateerde factoren, alsook sociodemografische en persoonlijkheidsfactoren een rol kunnen spelen bij het ontstaan en blijven bestaan van KANS.

De gevolgen van KANS met betrekking tot ervaren beperkingen en verminderde kwaliteit van leven, alsook met betrekking tot verminderde arbeidsproductiviteit, ziekteverzuim, stijging in medische en maatschappelijke kosten, zijn groot.

Dit proefschrift is bedoeld om enerzijds de risicofactoren te bestuderen die aspecifieke KANS uitlokken, anderzijds de risicofactoren te bestuderen die aspecifieke KANS in stand houden, leidend tot chronische klachten.

Daarom waren we geïnteresseerd in het beloop van aspecifieke KANS in een cohort van beeldschermwerkers.

Bovendien probeerden we een antwoord te geven op de vraag welke therapie het meest (kosten)effectief zou zijn bij patiënten met beginnende aspecifieke KANS, klachten die chronisch worden indien ze onbehandeld blijven.

De volgende onderzoeksvragen werden beantwoord:

1. wat is het beloop van aspecifieke KANS en voorspellen werken behandelingsgerelateerde factoren, sociodemografische, psychologische en fysieke factoren klinische status en beperkingenniveau?

2. spelen psychologische factoren een belangrijke rol bij de ontwikkeling en het blijven bestaan van aspecifieke KANS?

3. is oefentherapie Mensendieck of Cesar (kosten) effectiever bij de behandeling van beginnende aspecifieke KANS met betrekking tot afname van klachten en voorkomen van beperkingen dan reguliere zorg?

In Hoofdstuk 2 is de invloed van werk-en behandelingsgerelateerde factoren op de klinische status (fase van KANS) en het beperkingenniveau (gemeten met de DASH Disabilities of the Arm, Shoulder and Hand questionnaire) retrospectief bestudeerd door middel van een cohort van 182 beeldschermwerkers met aspecifieke KANS.

Naast gebruik van medische gegevens en een inventarisatie van werk-en behandelingsgerelateerde factoren vóór, tijdens de diagnose en gedurende de behandelperiode, werd gebruik gemaakt van een follow-up vragenlijst met vragen over de klinische status en het beperkingenniveau ten tijde van het follow-up moment.

Ca. $57 \%(\mathrm{~N}=107)$ van dit cohort stuurde de vragenlijst terug en gegevens van 103 beeldschermwerkers konden worden gebruikt voor de analyses. 
Geen van de geselecteerde werk-en behandelingsgerelateerde factoren was significant geassocieerd met de klinische status. "Het aantal werkuren per week vóór de diagnose" was negatief en "andere therapieën gedurende de behandeling (anders dan multidisciplinaire revalidatie of psychotherapie)" positief geassocieerd met DASH.

Ofwel, het maken van meer werkuren per week vóór de diagnose aspecifieke KANS was niet voorspellend voor het ervaren van beperkingen, maar het hebben ondergaan van "andere therapieën gedurende de behandeling" wel.

Beperkingen van deze studie zijn allereerst het feit, dat het niet vinden van associaties tussen werk- en behandelingsgerelateerde factoren en het beloop van aspecifieke KANS mogelijk kan worden verklaard door de slechte kwantificering van de werkgerelateerde factoren en het vertrouwen in vragenlijsten waarbij gebruik wordt gemaakt van informatie via zelfrapportage.

Mogelijk spelen daarnaast andere risicofactoren (psychosociale en persoonlijke) een rol, die in dit onderzoek niet werden meegenomen.

Ondanks de beperkingen van deze studie adviseren we om in de beslissing beeldschermwerkers met aspecifieke KANS te behandelen zowel fysieke, psychosociale als persoonlijkheidsfactoren mee te nemen.

In Hoofdstuk $\mathbf{3}$ is het beloop van aspecifieke KANS en de invloed van sociodemografische en psychologische factoren, alsook van fysieke fitheid op de klinische status en het beperkingenniveau retrospectief bestudeerd. Hierbij is gebruik gemaakt van hetzelfde cohort van 182 beeldschermwerkers met verschillende fases van aspecifieke KANS.

Op het follow-up tijdstip werd een cross-sectionele analyse uitgevoerd, gebaseerd op gegevens van een follow-up vragenlijst met vragen over psychologische factoren en fysieke fitheid. De follow-up periode bedroeg gemiddeld 4 jaar.

Sociodemografische en medische kenmerken werden gemeten, gebaseerd op medische gegevens ten tijde van de eerste klachten en diagnose.

De gegevens van 104 beeldschermwerkers konden worden gebruikt voor de analyses. Van degenen die de vragenlijst terugstuurden, ontwikkelde $14 \%$ een chronisch pijnsyndroom en herstelde $9 \%$; bij de overigen (77\%) namen de klachten licht toe.

Een hoger beperkingenniveau was geassocieerd met een oudere leeftijd, vrouw-zijn, een lagere opleiding en een slechter -zelfgerapporteerd - fysiek fitheidsniveau.

Een lager opleidingsniveau en een slechter fysiek fitheidsniveau waren geassocieerd met een hogere fase van aspecifieke KANS.

In deze studie beïnvloedden psychologische factoren het beperkingenniveau of de klinische status niet.

De prognose van beeldschermwerkers met aspecifieke KANS is niet gunstig.

Degenen met een lagere opleiding en slechter fysiek fitheidsniveau lopen gevaar een hogere fase van aspecifieke KANS te ontwikkelen en uit te komen op een hoger beperkingenniveau. 
Beperkingen van deze studie zijn allereerst dat de slechte prognose van dit cohort beeldschermwerkers met aspecifieke KANS mogelijk deels te maken heeft met een selectie-effect, omdat de onderzoekspopulatie werd geselecteerd vanuit een in deze patiëntengroep gespecialiseerde revalidatieafdeling en deze patiënten mogelijk ernstigere klachten hadden.

Een opmerkelijke bevinding betrof de rol van psychologische factoren. Sommige van deze, zoals neurotisch perfectionisme, overdreven plichtsbesef en angstige aanleg worden beschouwd als triggers voor het ontstaan van aspecifieke KANS.

Omdat het effect van psychologische factoren op het beloop van aspecifieke KANS of het ontstaan van beperkingen niet duidelijk is uitgezocht, blijft hun invloed onduidelijk. De associaties die in deze studie werden gevonden, echter, suggereren dat beeldschermwerkers met aspecifieke KANS moeten worden aangemoedigd om aan fitness of sportprogramma's te gaan deelnemen.

Bovendien dient extra aandacht te worden besteed aan beeldschermwerkers met een lager opleidingsniveau, aan vrouwelijke en oudere beeldschermwerkers.

In Hoofdstuk 4 zijn persoonlijkheidsfactoren bestudeerd als mogelijke risicofactor voor de ontwikkeling van aspecifieke KANS.

We bestudeerden neurotisch perfectionisme en copingstrategieën als potentiële risicofactoren door middel van een case-control studie met 2 controlegroepen.

De beeldschermwerkers met aspecifieke KANS ( $\mathrm{N}=45$ ) kwamen van onze op deze patientengroep gespecialiseerde revalidatieafdeling en de controlegroepen waren respectievelijk beeldschermwerkers zonder aspecifieke KANS ( $N=45)$ en chronisch pijnpatiënten met gegeneraliseerde pijn boven en onder de gordel $(\mathrm{N}=42)$.

Neurotisch perfectionisme werd gemeten met behulp van de MPS (Multidimensional Perfectionism Scale).

We voegden de SCL (Symptom Check List) -90 toe die algemene lichamelijke en psychische klachten meet (psycho-neuroticisme) vanwege zijn hoge correlatie met neurotisch perfectionisme.

Logistische regressieanalyses lieten significante verschillen in SCL-90 scores zien tussen beeldschermwerkers met aspecifieke KANS en degenen die geen aspecifieke KANS hadden, daarbij het mogelijkerwijs significant hogere neurotisch perfectionisme in de groep beeldschermwerkers met aspecifieke KANS overrulend.

Daarom werd de tweede controlegroep samengesteld uit chronisch pijnpatiënten met te verwachten hoge scores op de SCL-90. Logistische regressie liet zien dat, wanneer gecontroleerd werd voor psychoneuroticisme, beeldschermwerkers met aspecifieke KANS significant neurotisch perfectionistischer waren.

Voor wat betreft copingstrategieën, gemeten met de UCL (Utrechtse Coping Lijst), waren er geen significante verschillen tussen de groepen voor wat betreft gemiddelde UCL scores. Echter, beeldschermwerkers met aspecifieke KANS hadden een actievere copingstijl dan chronisch pijnpatiënten. 
We concludeerden dat psychoneuroticisme en neurotisch perfectionisme belangrijke risico- factoren zijn voor het krijgen van aspecifieke KANS.

Daarom is het van belang speciale aandacht te geven aan beeldschermwerkers met aspecifieke KANS die psychoneurotische trekken hebben, of een neurotisch perfectionistische aanleg.

Voortbordurend op de resultaten van onze (eerdere) studies, bestudeerden we in Hoofdstuk 5 onder beeldschermwerkers met beginnende aspecifieke KANS aan de hand van gevalideerde vragenlijsten de rol van persoonlijkheidsfactoren zoals pijncatastroferend gedrag, neurotisch perfectionisme en angst alsook de rol van (subjectief ervaren) fysieke fitheid.

We voerden een case-control studie uit met een cross-sectionele analyse, waarbij we gebruik maakten van de beeldschermwerkers met beginnende aspecifieke KANS uit onze gerandomiseerde trial (zie verder) $(\mathrm{N}=88)$ en de controles $(\mathrm{N}=31)$ werden gerekruteerd onder gezonde beeldschermwerkers die onder dezelfde arbeidsomstandigheden werkten.

De invloed van persoonlijkheidsfactoren en fysieke fitheid op aspecifieke KANS werd bestudeerd door middel van logistische regressieanalyses.

Van alle onderzochte variabelen hadden "pijncatastroferend gedrag" (gemeten met de PCS-Pain Catastrophising Scale) en "laag subjectief ervaren niveau van fysieke fitheid" (gemeten met de GFE-Groningen Fitness questionnaire for the Elderly) een significante relatie met aspecifieke KANS.

In deze studie onder beeldschermwerkers lijken "pijncatastroferend gedrag" en een "laag subjectief ervaren niveau van fysieke fitheid" dus geassocieerd met beginnende aspecifieke KANS.

Een opmerkelijke bevinding in deze studie betrof het feit dat bij checken van de antwoorden uit de vragenlijsten, van de 78 beeldschermwerkers die zich hadden opgegeven als controlepersoon, er 47 aspecifieke KANS bleken te hebben gehad of nog steeds klachten hadden.

Zij werden uit de analyses gehaald. Echter, bij uitvoeren van de analyses inclusief deze subgroep van 47 personen, toonde de gehele controlegroep $(\mathrm{N}=78)$ nog steeds significant minder pijncatastroferend gedrag vergeleken met de proefpersonen die beginnende aspecifieke KANS hadden ( $\mathrm{N}=88$ ).

Mogelijkerwijs ligt hier de sleutel waarom beeldschermwerkers met aspecifieke KANS en pijncatastroferend gedrag niet alleen aspecifieke KANS krijgen, maar zich er ook pijnlijk van bewust zijn, zelfs ondanks een lage score op de VAS (visual analogous scale) voor pijnmeting.

In deze studie vonden we een associatie tussen "laag subjectief ervaren niveau van fysieke fitheid" en beginnende aspecifieke KANS.

Een beperking van deze studie was dat de controlepersonen werden gerekruteerd op een later tijdstip dan de proefpersonen. 
Desondanks adviseren we, opdat aspecifieke KANS niet tot een last wordt, geruststelling, een duidelijke uitleg betreffende de valkuilen van aspecifieke KANS alsook stimulering van

sport/ fitness in plaats van de nadruk te leggen op de bestaande beperkingen.

In Hoofdstuk 6 werden twee gangbare therapieën voor aspecifieke KANS met elkaar vergeleken bij beeldschermwerkers met beginnende aspecifieke KANS. Dit door middel van een gerandomiseerde trial, waarin houdingstherapie volgens de methode Mensendieck of Cesar werd vergeleken met reguliere fysiotherapie.

In totaal werden 88 beeldschermwerkers geïncludeerd en na randomisatie bestond elke groep uit 44 beeldschermwerkers.

De interventie bestond uit 10 weken houdingstherapie óf 10 weken fysiotherapie volgens protocol.

Uitkomstmaten waren pijn, gemeten met behulp van de VAS (visueel analoge pijnschaal) van Jensen; kwaliteit van leven, gemeten met de Short Form-36 en het beperkingenniveau, gemeten met de DASH.

Bovendien werd op elk meetmoment het aantal beeldschermwerkers dat nog klachten had bijgehouden. Uitkomstmaten werden vastgelegd vóór de interventie, na 3, 6 en 12 maanden.

Vóór de interventie waren de analyses gebaseerd op 88 proefpersonen; omdat er na 3 maanden follow-up 6 proefpersonen waren uitgevallen, werden de verdere analyses uitgevoerd op 82 proefpersonen ( 40 in de houdingstherapiegroep en 42 in de reguliere fysiotherapiegroep).Analyses vonden plaats volgens het intention-to-treat principe. Uitkomstmaten werden geanalyseerd met behulp van lineaire regressieanalyse, daarbij controlerend voor verschillen in variabelen bij de beginmeting.

De resultaten lieten zien dat er geen significant verschil was in pijnafname tussen de groepen bij 3 maanden, 6 maanden of 12 maanden. De verschillen tussen de groepen qua subjectief ervaren aspecifieke KANS, beperkingen en gezondheidgerelateerde kwaliteit van leven waren eveneens klein en niet significant op elk van de meetmomenten. Over het geheel genomen, waren er slechts kleine verbeteringen op alle uitkomstmaten vanaf de beginmeting tot het laatste meetmoment.

We concludeerden dat houdingstherapie geen beter resultaat te zien gaf dan reguliere fysiotherapie.

Echter, een jaar na start van de interventie was $55 \%$ van alle proefpersonen met beginnende aspecifieke KANS klachtenvrij.

Een beperking van deze studie is dat we er niet zeker van zijn of de verbeteringen het gevolg waren van de interventies omdat we om ethische redenen geen "wachtlijst controlegroep" aanlegden.

We geven de suggestie een grotere gerandomiseerde trial op te zetten onder beeldschermwerkers met aspecifieke KANS waarin de interventie niet alleen focust op fysieke oefenprogramma's, maar ook op persoonlijkheid, werkgerelateerde psychosociale 
risicofactoren en copingmechanismen, aangezien beide fysiek georiënteerde oefenprogramma's leiden tot hetzelfde resultaat.

Oefentherapieën genereren aanzienlijke kosten onder beeldschermwerkers met aspecifieke KANS.

Daarom voerden we een kosteneffectiviteitsstudie uit.

In Hoofdstuk 7 presenteren we een kosteneffectiviteitsstudie die als doel had te onderzoeken of houdingstherapie kosteneffectief is vergeleken met reguliere fysiotherapie bij beeldschermwerkers met beginnende aspecifieke KANS, zowel vanuit gezondheidszorg- als maatschappelijk perspectief.

De studie werd uitgevoerd onder de proefpersonen van de bovengenoemde gerandomiseerde trial i.e.de 88 beeldschermwerkers met beginnende aspecifieke KANS.

Naast de uitkomstmaten van de eigenlijke trial, maakten we gebruik van economische uitkomstmaten. Zo werd "kwaliteit van leven" gemeten met behulp van de generieke uitkomstmaat EQ-5D van de EuroQoL groep. Deze EQ-5D werd gebruikt om de QALY's (Quality Adjusted Life Year) tijdens de follow-up te meten.

De kosten werden onderverdeeld in kosten betreffende de gezondheidszorg (inclusief gebruikelijke dagelijkse kosten voor patiënt en gezin) en productiviteitskosten. Alleen kosten die betrekking hadden op aspecifieke KANS werden in de analyses meegenomen.

Er werd gebruik gemaakt van een vragenlijst die gezondheidskosten meet en gebruikelijke dagelijkse kosten voor patiënt en gezin.

Kosten met betrekking tot productiviteitsverlies werden gebaseerd op ziekmelding op het werk als gevolg van aspecifieke KANS; er werd gebruik gemaakt van een vragenlijst betreffende arbeid en ziekteverzuim.

Productiviteitskosten werden berekend in overeenstemming met de frictiekostenmethode.

De metingen vonden plaats op dezelfde tijdstippen als die van de trial.

In de kosteneffectiviteitsanalyses werden de effectmaten VAS, subjectief ervaren aspecifieke KANS, en DASH gerelateerd aan gezondheidszorgkosten. De QALY werd in een kostenutiliteitsanalyse gerelateerd aan de totale maatschappelijke kosten, dus inclusief productiviteitskosten.

ICER's (Incremental Cost-Effectiveness Ratio's) werden berekend op basis van verschillen tussen de groepen in gemeten kosten en uitkomstparameters. De statistische onzekerheid rond de ICER's werd vastgesteld met behulp van de "bootstrapping methode", gebruikmakend van betrouwbaarheidsintervallen in percentielen. De kans voor beide interventies om het meest kosteneffectief te zijn, werd weergegeven aan de hand van een "Cost-Effectiveness Acceptability Curve"(CEAC), waarbij oplopende drempelwaarden voor de maximale maatschappelijke bereidheid om te betalen voor één eenheid effectiviteit werden gehanteerd. 
De resultaten lieten zien dat, vóór de interventie, beide groepen vergelijkbaar waren qua kosten.

$\mathrm{Na}$ een jaar had de houdingstherapiegroep hogere gemiddelde totale gezondheidszorgkosten, maar lagere productiviteitskosten, vergeleken met de reguliere fysiotherapie. De gemiddelde maatschappelijke kosten na een jaar waren daarom in het voordeel van de houdingstherapie. Na een jaar was er alleen met betrekking tot "subjectief ervaren aspecifieke KANS" sprake van een acceptabele kosteneffectiviteit voor de houdingstherapie, vergeleken met de reguliere fysiotherapie. Echter, de kans op een acceptabele kosteneffectiviteit overschreed de $60 \%$ niet.

Wanneer men de maatschappelijke kosten beschouwt in relatie tot de QALY's, had de houdingstherapie een kans van meer dan $80 \%$ op kosteneffectiviteit over een brede range van plafondwaarden; echter, gebaseerd op een marginaal verschil in QALY's van 0.1 over een tijdsbestek van 12 maanden.

We concludeerden dat, hoewel onze trial geen significante verschillen vond in VAS, QALY's en ICER's gebaseerd op VAS-waarden en QALY's na een jaar follow-up, de CE$A C$ 's suggereren dat houdingstherapie een grotere kans heeft om kosteneffectief te zijn dan reguliere fysiotherapie. Verder onderzoek wordt wenselijk geacht.

In Hoofdstuk 8 worden de algemene discussie en conclusies gepresenteerd, alsook de implicaties voor dagelijks gebruik en adviezen voor verder onderzoek.

Conclusie: Beeldschermwerkers met aspecifieke KANS die onze, op deze patiëntengroep gespecialiseerde, revalidatieafdeling bezoeken, hebben een slechte prognose. Risicofactoren van belang bij het ontwikkelen van aspecifieke KANS zijn niet noodzakelijkerwijs hetzelfde als de prognostische factoren van belang bij het chronisch worden van de klachten.

Hun rol is verschillend, afhankelijk van het beloop van aspecifieke KANS.

Interactie tussen de verschillende risicofactoren lijkt usance. Dit belemmert een adequate preventie en behandeling van de aandoening.

Kernfactoren voor het ontstaan van aspecifieke KANS zijn "een werksituatie met hoge taakeisen (hoge workload, jobstress)" in combinatie met psychologische factoren (neurotisch perfectionisme), terwijl het beloop van de aandoening vooral lijkt te worden beïnvloed door de manier waarop iemand met pijn omgaat en de aandoening ervaart als een mentale last.

De rol van catastroferen bij beeldschermwerkers met aspecifieke KANS is in overeenstemming met het model van Vlaeyen met betrekking tot de ontwikkeling van een chronisch pijnsyndroom.

Zelfgerapporteerde fysieke fitheid kan een belangrijke factor zijn ter preventie van chronische klachten.

Implicaties voor de dagelijkse praktijk: Preventie van aspecifieke KANS dient plaats te vinden op de werkplek. 
Voor de bedrijfsgeneeskundige dienst zijn werksituaties met hoge taakeisen (i.e.hoge workload, jobstress), vrouw-zijn, middelbare leeftijd, neurotisch perfectionisme en lage opleiding de belangrijkste factoren om aandacht aan te besteden.

Patiënten met beginnende klachten, vrouwen, degenen die een lage opleiding hebben, zij die wat ouder zijn, degenen die niet deelnemen aan sport en degenen die de neiging hebben tot catastroferen lopen het risico chronische klachten te ontwikkelen.

Voor de bedrijfsgeneeskunde en de algemene dagelijkse praktijk zou het gebruik van een "quick scan" moeten worden aangemoedigd, waarin de wijze van omgaan met pijn, mate van neurotisch perfectionisme en zelfgerapporteerde fysieke fitheid kunnen worden vastgelegd. In geval van de bedrijfsgeneeskunde gecombineerd met een analyse van de werkomstandigheden.

Afhankelijk van de resultaten kan een individueel therapieplan worden opgesteld.

Beeldschermwerkers met aspecifieke KANS hebben geruststelling nodig, duidelijke uitleg betreffende de valkuilen van hun aandoening en dienen te worden aangemoedigd om aan sport te gaan doen. Dit in plaats van hun tekortkomingen en beperkingen te benadrukken.

Wanneer patiënten met aspecifieke KANS hoog scoren op neurotisch perfectionisme is multidisciplinaire behandeling nodig met het inschakelen van een psycholoog.

Wanneer patiënten hoog scoren op "pijncatastroferend gedrag", naast de aanwezigheid van andere risicofactoren zoals jobstress en /of neurotisch perfectionisme, dient verwijzing plaats te vinden naar een in deze diagnose gespecialiseerd centrum. In zulke gevallen is multidisciplinaire behandeling inclusief cognitieve gedragstherapie geïndiceerd.

Implicaties voor verder onderzoek: Onderzoek op dit gebied zou deel moeten uitmaken van een (nationaal) onderzoeksprogramma. Wij bevelen een grote prospectieve cohortstudie met een follow-up duur van vijf jaar onder beeldschermwerkers die nog nooit aspecifieke KANS hebben gehad, sterk aan.

Een zorgvuldige beschrijving van wat wordt bedoeld met "aspecifieke KANS" is een conditio sine qua non.

Als onafhankelijke variabelen zouden moeten worden meegenomen: PCS, MPS, TSK (TAMPA scale for kinesiophobia), STAI (State / Trait Anxiety Inventory) 1 \& 2, JSS (Job Stress Survey), zelfgerapporteerde fysieke fitheid (GFE) alsook sociodemografische factoren. De volgende uitkomstmaten zouden moeten worden gebruikt: DASH op beperkingenniveau, gezondheidsgerelateerde kwaliteit van leven, klinische status en werkstatus.

In het bijzonder dienen de interacties tussen jobstress, pijncatastroferend gedrag en neurotisch perfectionisme en hun effect op het beloop van de aandoening te worden ontrafeld.

We geven de suggestie, mannen en vrouwen apart te analyseren. 
Een grote prospectieve studie kan van nut zijn om een gevalideerd afkappunt voor de PCS voor deze specifieke patiëntengroep te vinden en de validering van de "zelfgerapporteerde fysieke fitheidsschaal" uit te breiden naar andere leeftijdsgroepen.

Bovendien zou een dergelijke prospectieve studie gelegenheid bieden om waardevolle economische en daaraan gerelateerde "kwaliteit van leven"- gegevens op een gestandaardiseerde wijze te verzamelen. Daarmee kunnen dan kosteneffectiviteitsstudies worden gemodelleerd die de kosteneffectiviteit van toekomstige interventies bij de behandeling van aspecifieke KANS kunnen voorspellen.

Meer klinische interventies zouden moeten worden geëvalueerd door middel van gerandomiseerde trials om te kunnen verwijzen naar evidence-based behandelingen voor deze patiëntencategorie. 
Curriculum vitae

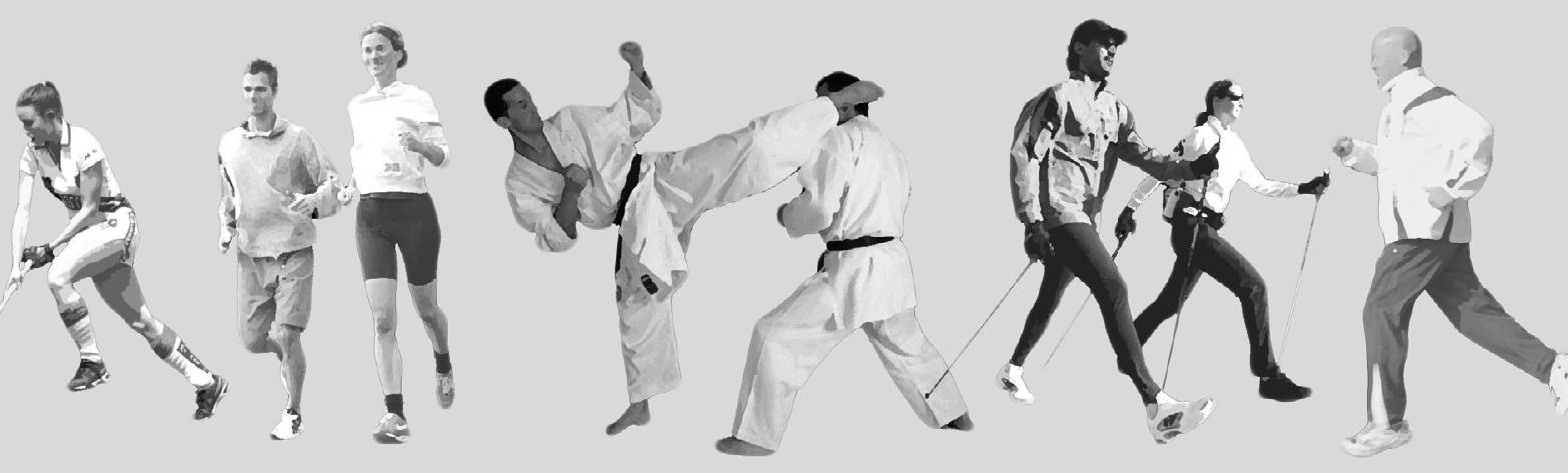


Marjon van Eijsden was born as Marjon Besseling on April 5, 1949 in Amsterdam. She grew up in the centre of Amsterdam and obtained her gymnasium $\beta$ diploma in 1968 at the Pius X Lyceum in Amsterdam.

She studied medicine at the Amsterdam Municipal University and obtained her medical degree April 1976.

After practicing in general practice in Amsterdam some years, she started her specialization in the field of physical medicine and rehabilitation in February 1979 at the circuit Rotterdam Zuiderziekenhuis - De Hoogstraat (Leersum). From 1983-1990 she practiced as a rehabilitation doctor at the university hospital of Rotterdam (Dijkzigt).

Since 1990 she has practiced in the same capacity at the university hospital Maastricht (nowadays Maastricht University Medical Centre+/ MUMC+).

In 2002 she began devoting more attention to the field of non-specific work-related upper limb disorders (WRULD) in musicians and computer screen workers, with her scientific work in this field resulting in this thesis.

Marjon is widowed and has 3 studying children.

Since 1976 Marjon has been involved in sports for the disabled, initially as a team doctor for the Dutch team and, later on as a national and international classifier.

Marjon plays the viola in the university orchestra of Maastricht.

She founded the multidisciplinary consulting team for performing artists in the university hospital Maastricht.

She participates in rowing and Sekwondo (Taekwondo for seniors).

She is a board member of the Foundation St. John Hospital Ghana and of the Foundation Masters on Stage.

Marjon van Eijsden werd geboren als Marjon Besseling op 5 april 1949 te Amsterdam. Ze groeide op in hartje Amsterdam en behaalde in 1968 haar gymnasium $\beta$ diploma aan het Pius X Lyceum te Amsterdam.

Ze studeerde geneeskunde aan de destijds Gemeentelijke Universiteit van Amsterdam en ontving april 1976 haar artsdiploma.

Na enkele jaren in Amsterdam als huisarts te hebben gewerkt, begon ze februari 1979 aan haar opleiding tot revalidatiearts in het circuit Rotterdam Zuiderziekenhuis - De Hoogstraat (Leersum). In de jaren 1983-1990 werkte ze als revalidatiearts in het academisch ziekenhuis (Dijkzigt) te Rotterdam. Sinds 1990 werkt ze als revalidatiearts in het academisch ziekenhuis Maastricht, (tegenwoordig Maastricht Universitair Medisch Centrum+/ MUMC+).

In 2002 begon ze als deskundige op het gebied van aspecifieke KANS (klachten arm, nek, schouder) bij musici en beeldschermwerkers met haar wetenschappelijk onderzoek betreffende dit onderwerp, resulterend in dit proefschrift.

Marjon is weduwe en heeft 3 studerende kinderen.

Sinds 1976 is Marjon betrokken bij de gehandicaptensport, aanvankelijk als teamarts van de nationale ploeg, daarna als nationaal en internationaal classificatiearts. 
Marjon speelt als altist in het universiteitsorkest Maastricht.

Ze richtte een multidisciplinair spreekuur voor de kunsten op in het azM.

Ze roeit en doet aan Sekwondo (Taekwondo voor senioren).

Ze is bestuurslid van de Stichting St. John Hospital Ghana en van de Stichting Masters on Stage. 



\section{List of Publications}

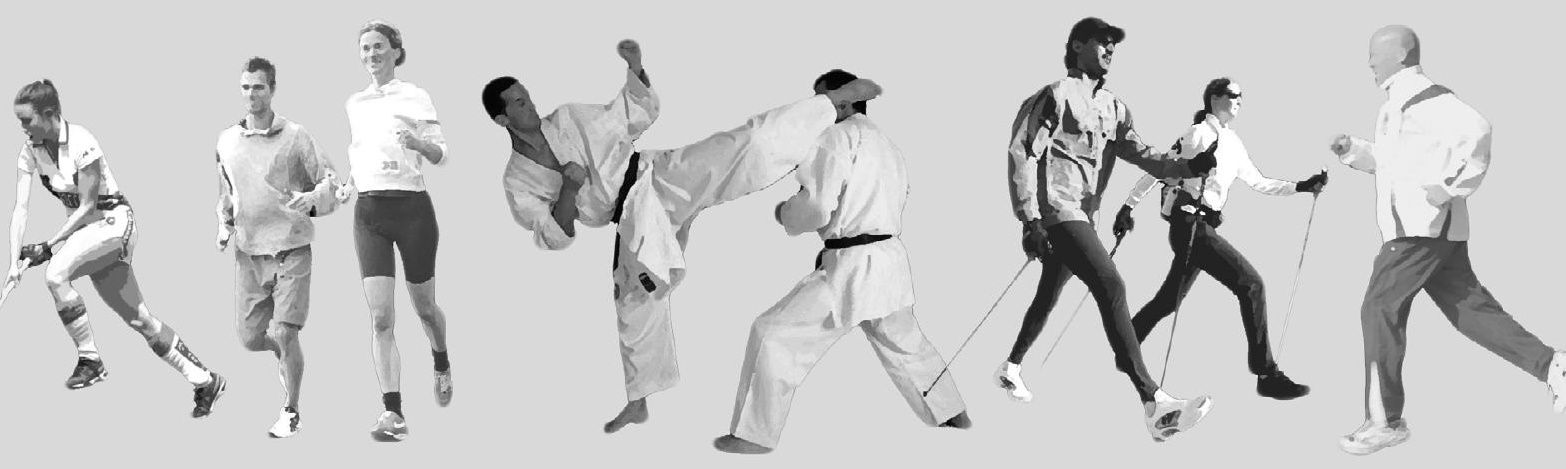


Van Eijsden-Besseling M.D.F. The (non) sense of the present-day classification system of sports for the disabled, regarding paralysed and amputee athletes. Paraplegia 1985; Vol.23 (5), pages 288-94.

Blanken W.C.G., van der Rijst H †, Mulder P.G.H., van Eijsden-Besseling M.D.F., Lankhorst G.J. Interobserver and intraobserver reliability of postural examination. Medical Problems of Performing Artists 1991; Vol 6 (3) pages 93-

Van Eijsden-Besseling M.D.F., Kuijers M, Kap B, Stam H., Terpstra-Lindeman E. Differences in posture and postural disorders between music and medical students. Medical Problems of Performing Artists 1993; Vol 8 (3), pages 110-

Bloemsaat J.G., Van Galen G.P., Ruijgrok J.M., Van Eijsden-Besseling M.D.F., Timmers R.M. Effects of cognitive load on forearm EMG response activity in individuals suffering from work- related upper extremity disorder. $4^{\text {th }}$ International Scientific Conference on Prevention of work-related musculoskeletal disorders. Amsterdam, 2001; pag 160.

Van Eijsden-Besseling M.D.F., Peeters F.P.M.L., Reijnen J.A., de Bie R.A. Perfectionism and coping strategies as risk factors for the development of non-specific workrelated upper limb disorders (WRULD). Occupational Medicine 2004; Vol.54 (2), pages 122-27.

Van Eijsden-Besseling M.D.F., Staal J.B., van Attekum A, de Bie R.A., van den Heuvel W.J.A. No difference between postural exercises and strength and fitness exercises for early, non-specific, work-related upper limb disorders in visual display unit workers: a randomised trial. Australian Journal of Physiotherapy 2008; Vol 54 (2), pages 95-101.

de Jong J., Vlaeyen J., Loo C., Van Eijsden-Besseling M.D.F., Bulté I. Catastrophic Misinterpretations in work-related upper extremity pain (WRUEP): Two studies evaluating The effects of exposure in vivo. European Journal of Pain Lisboa 2009; Vol. 13 Abstract no. 938. congress Pain in Europe.

Van Eijsden-Besseling M.D.F., Gerhards S.A., de Bie R.A., Severens J.L. Costeffectiveness of postural exercise therapy versus physiotherapy in screen workers with early non-specific work-related upper limb disorders; a randomized controlled trial TrialsJournal 2009; 10; 103-

Van Eijsden-Besseling M.D.F., Van den Bergh K.A.M., Staal J.B., de Bie R.A., Van den Heuvel W.J.A. The course of non-specific work-related upper limb disorders and the influence of demographic factors, psychologic factors, and physical fitness on clinical status and disability. Archives of Physical Medicine and Rehabilitation 2010; 91: 862-67.

Van Eijsden-Besseling M.D.F., Van Attekum A, de Bie R.A., Staal J.B. Pain Catastrophizing and lower physical fitness in a sample of computer screen workers with early non-specific upper limb disorders; a case- control study. Accepted by Industrial Health Jan 2010; in press. 
Van Eijsden-Besseling M.D.F., Van den Bergh K.A.M., Staal J.B., de Bie R.A., Van den Heuvel W.J.A. The influence of work- and treatment- related factors on clinical status and disability in patients with non-specific work-related upper limb disorders. Accepted by journal WORK May 2010; in press.

Baadjou V.A., Van Eijsden-Besseling M.D.F., Samama-Polak A.L.W., Smeets R.J.E.M., Lima Passos V., Westerterp K.R. Energy expenditure in brass and woodwind Instrumentalists; the effect of body posture. Submitted: Archives of Physical Medicine and Rehabilitation, oktober 2010.

\section{Co-author Book Chapters}

Peereboom K.J. c.s. (2005 / 2006) RSI Handboek (RSI Handbook) 4 th Edition. The Hague: Sdu Editors. Chapter 6 and 7, pages 85-118.

Van Eijsden-Besseling M.D.F., Samama-Polak A.L.W. ( 1998 / 2001) Behandeling en Preventie van RSI (Treatment and Prevention of RSI) 1th and 2th Edition. Assen : Van Gorcum Editors.

Van Asbeck F.W.A c.s. (2007) Handboek Dwarslaesierevalidatie (Handbook Rehabilitation of Spinal Cord Injuries) 2th Edition. Houten: Bohn, Stafleu, van Loghum. Chapter 24, pages 329-345.

Riemsdijk J. (2006) The Golden Fingers Technique, the art of passagework for pianists. The Hague: AB music Productions and Editions. Chapter 3.5 and 3.6, pages 58-62. 



\section{Dankwoord}

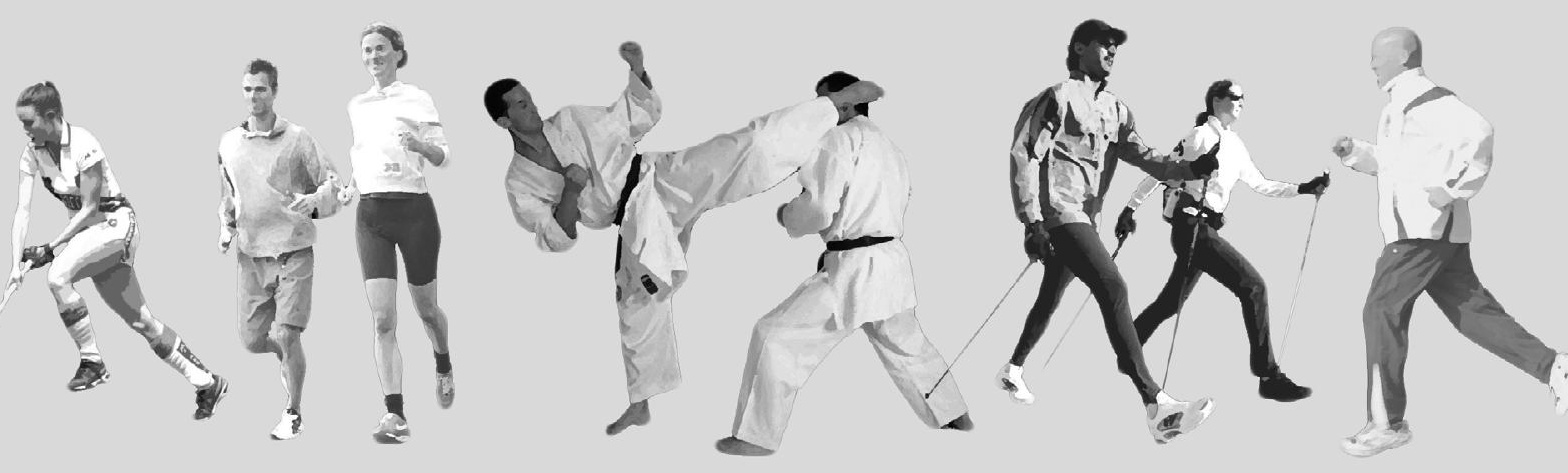


Dit is de moeilijkste taak die mij nog rest!

Want met een dergelijk uitgebreid zakelijk en sociaal netwerk - waar ik trouwens heel erg dankbaar voor ben - ga ik zeker mensen vergeten te noemen in dit dankwoord. Hen bied ik mijn mea culpa aan.

Heel wat mensen ben ik dank verschuldigd! In de eerste plaats jou Eline (Prof. dr. E. Lindeman), die mij in 1990 spontaan als collega verwelkomde in het academisch ziekenhuis Maastricht en mij in de 90er jaren de gelegenheid bood om de 2-jarige wetenschappelijke SGO-opleiding te volgen.

Dan jij Ans (mw. A.L.W. Samama-Polak), die mij als de eerste oefentherapeute Mensendieck gespecialiseerd in het behandelen van musici, misschien al wel 20 jaar geleden voorstelde om te promoveren. Ik zou dan jouw "houdingshypothese" betreffende musici kunnen bewijzen. En dank aan jou Toon (Prof. dr. A. Huson) toen je als getalenteerd amateurdwarsfluitist mij begin jaren 90 een eerste promotiegelegenheid bood, ware het niet dat onze revalidatieafdeling in die dagen een krappe bezetting had en de patiëntenpraktijk terecht voorging. Tot op heden ben je belangstelling blijven tonen, ook al richtte het onderzoek zich op beeldschermwerkers in plaats van op musici.

Ans, we zijn met het musicionderzoek een heel klein stukje op de goede weg, maar het valt niet mee met musici genoeg power te krijgen om een hypothese te kunnen bewijzen. In 1998 kwam de $1^{\mathrm{e}}$ en in 2001 de $2^{\mathrm{e}}$ druk uit van ons rode boekje "Behandeling en Preventie van RSI", zij het met betrekking tot beeldschermwerkers, waarvan er heel wat meer zijn dan musici. Jij wordt een van mijn paranimfen, waarbij je me telkenmale vroeg op te willen schieten met mijn onderzoek bij stijgen van jouw leeftijd. Misschien breken we een record en ben je de oudste paranimf ooit, die bovendien nog werkt als oefentherapeut voor de musici en beeldschermwerkers! Het is enig om jouw voicemail af te luisteren!

Wijlen mijn geliefde echtgenoot Paul, jij merkte aan mij dat die "promotiestap" een vurig gewenste zou zijn in mijn medische carrière, als specialist werkzaam in een academisch ziekenhuis. Je hebt me tot je dood in 2002 toe aangespoord het promotieonderzoek op de rails te zetten en tot een goed einde te zullen brengen.

"Jij weet het meeste van RSI in Nederland, dus dat kun je niet laten zitten" en "Zorg ervoor dat je het voor mij afmaakt!" Dit proefschrift is dan ook geschreven in opdracht aan jou, wijlen mijn geliefde Paul. Zelf had je de instelling dat je als werktuigbouwkundig ingenieur in het zakenleven sneller vooruitkwam zonder een dr-titel en in jouw geval was dat ook zo!

Wat erg toch dat je deze dag niet lijfelijk aanwezig zult zijn, maar misschien kijk je van boven op me toe op deze voor mij zo belangrijke $10^{\mathrm{e}}$ december, ooit de dag waarop we verkering kregen!

Jij Jaap (Prof. dr. J. Troost), bood me enkele maanden voor Paul's overlijden de daadwerkelijke kans en riep me op je kamer. Je vroeg of ik nog wilde promoveren en op mijn onmiddellijke ja-antwoord, reageerde je met: "je kunt morgen beginnen". Je bent een man van weinig woorden, maar deze "stevige", voor mij zo belangrijke woorden 
ben ik nooit vergeten! Deze kans werd ondersteund door jou Wim (Prof. dr. W.J.A.van den Heuvel), door moeite te doen het onderzoek gefinancierd te krijgen o.a. vanuit het profileringsfonds en het Instituut voor Revalidatievraagstukken te Hoensbroek.

Ik heb bijna een jaar lang 4 dagen per week het onderzoek van thuis uit kunnen opzetten, terwijl ik 1 dag per week poli deed in het ziekenhuis (azM). Deze constructie was een redding voor ons gezin, zowel voor als na het overlijden van Paul. In 2003 draaide het schema om: 4 dagen in het ziekenhuis en 1 dag per week promotieonderzoek doen. Tijdens een congres in Athene kreeg ik nog een extra hart onder de riem van jou Henk (Prof. dr. H.J. Stam) met wie ik destijds samen in de Hoogstraat revalidatiearts werd, die mij kent en zei: "je hebt het doorzettingsvermogen ervoor".

Het selecteren van aspecifieke RSI-, tegenwoordig KANS- patiënten voor de trial was niet zo eenvoudig als het leek. Jij Ton (Dr. A. van Attekum), bedrijfsarts aan de Universiteit Maastricht en mij nog bekend van de jaarlijkse Ardennenwandeling vanuit de KNMG, bood me aan de patiënten te selecteren en includeren. RSI of KANS is per slot van rekening een werkgerelateerde aandoening. Ook bood jij hulp bij het selecteren van controles voor een case-control studie die mijns inziens op het laatst nog echt nodig was om mijn bewijsvoering kracht bij te zetten.

Het allereerste artikel schreef ik al in 2002 en kreeg daar hulp bij van jou Judith (Drs. J.A.W. Reijnen), inmiddels zelf revalidatiearts. Bij de trial kreeg ik hulp van jou Judith (Drs. J.G. Dierkes), inmiddels ook in opleiding tot revalidatiearts. (Wilt u later een dochter die revalidatiearts wordt, noem haar Judith).

Bij de retrospectieve studie kreeg ik hulp van jou Karien (K.A.M. van den Bergh, PhD, $\mathrm{MSc}$ ), inmiddels zelf onlangs gepromoveerd aan de Erasmus Universiteit te Rotterdam. Bij de kosten-effectiviteitsstudie kreeg ik hulp van jou Sylvia (S.A.Gerhards, MSc), inmiddels ook goed op weg met je promotieonderzoek als aio aan de Universiteit van Maastricht. Ik dank jullie allen heel hartelijk voor jullie inzet! Jullie zijn bijna allemaal coauteur van de inmiddels gepubliceerde artikelen van mijn proefschrift.

Wat stelt een Engelstalig proefschrift voor, dat niet op de Engelse schrijftaal is gescreend door een "native speaker"? Gelukkig heb ik ook die in mijn netwerk. Veel dank dan ook aan Drs. Paul Andrew Smith, Drs. Alice Watt en vooral mijn vriendin Drs. Mickey Chenault, die zoveel uren besteedde aan het zo zuiver mogelijk vertalen van dit proefschrift in het Engels.

Maar ook de Nederlandse vertaling van de "Summary" moet in orde zijn. Jeannique (J. Geurten), heel veel dank voor jouw kritische "taalgevoelige" blik.

Groot is mijn dank aan jullie, heren promotoren, Wim (Prof. dr. W.J.A. van den Heuvel), Rob, (Prof. dr. R.A. de Bie), Hans (Prof. dr. J.L. Severens) en copromotor Bart (Dr. J.B. Staal), die mij zo goed hebben bijgestaan door de jaren heen. Wat moet het moeilijk zijn geweest voor jullie mannelijke promotoren om een oudere vrouwelijke promovendus met de nodige werk- en levenservaring te moeten begeleiden! 
Vier mannen, op jullie beurt haantjes, maar de hen heeft steeds aangenaam met jullie uit de voeten gekund en heeft heel veel van jullie wijze lessen geleerd! Het was daarnaast ook een gezellige tijd waarin we veel hebben gelachen, vooral met jou Rob en Bart die vlakbij mij op de gang zaten en die altijd wel even een (wetenschappelijk of privé) luisterend oor hadden. Ondertussen maakte jij Rob "ongemerkt" notities voor mijn laudatio! Die zou de langste uit je carrière worden. Ik laat me verrassen.

Dank ook aan de leden van de leescommissie Martin (Prof. dr. M.H. Prins), Peter (Prof. dr. P. H.T.G. Heuts), Monique (Prof. dr. M.H.W. Frings-Dresen), Rob (Prof. dr. R.J.E.M. Smeets), onze kersverse hoogleraar Revalidatiegeneeskunde in het MUMC+ en Geert (Prof. dr. G. H.I.M. Walenkamp), die de moeite hebben genomen zich verder in mijn onderwerp te verdiepen.

Buiten de leescommissieleden en jou Jaap Troost, nodig ik graag jou Gerard (Prof. dr. G.P. van Galen), experimenteel psycholoog, uit om zitting te nemen in de corona, omdat we in de jaren 90 vaak beiden lezingen gaven op "RSI-congressen" en ik geloof in het onderzoek dat je verrichtte naar de oorzaak van aspecifieke KANS.

Ook zeker wil ik alle therapeuten bedanken die de patiënten uit mijn trial hebben behandeld nadat we eerst met zijn allen daartoe behandelprotocollen hadden opgesteld. Dank voor jullie geweldige motivatie en hulp! Ria Crienen, Alice Vaessen, Monique Poolen en Irene Jansen-Gruijters als oefentherapeuten Mensendieck/Cesar en Marnix Klerken, Rian Dekker, Ton Schambergen en Karin van Haveren als fysiotherapeuten. Dank jullie wel voor al het extra werk dat jullie voor mij verrichtten!

Ook dank aan jullie, Edith Hagedoren en Edith Sillen voor het afnemen van de vragenlijsten en het verzamelen van de gegevens. En dank aan Annemie Mordant van Instituut Memic, die het aanspreekpunt was voor de verwerking van de data.

Wat bijzonder om jou Let (Let Spek) als gezellige buurvrouw in Ouddorp aan zee te hebben, terwijl je als graficus en websitebouwer me spontaan aanbood om de omslag van mijn proefschrift "als vriendendienst" voor me te zullen maken. Dank je wel! Ook zo bijzonder is het dat jouw echtgenoot Gjalt (Ir. G. Huppes) als ergonoom samen met mij coauteur was van de eerste drukken van het "Handboek RSI" en we vroeger samen lezingen hielden op congressen over RSI.

En dan niet te vergeten mijn drie lieve kinderen, Claire, Marlene en Jan-Paul en huisvriendin Jeanne zonder wiens steun ik dit proefschrift ook niet voltooid zou hebben. Jullie waren echt trots op me dat ik er mee door was gegaan. Zelf ben ik er trots op dat jij Claire, de oudste en zelf bijna arts, mijn tweede paranimf zult zijn!

Tot slot wil ik al mijn vrienden, zowel die in mijn omgeving als verder weg, bedanken die met belangstelling de vorderingen bij de totstandkoming van dit proefschrift hebben gevolgd. Een bezoek aan hen, her en der, gaf een heerlijke afleiding. 
Promoveren is een dure aangelegenheid. De sponsoren van mijn proefschrift, te weten Fa.Livit Orthopedie, Fa. Smeets (orthopedisch schoenmaker), Fa. Defauwes (orthopedisch schoenmaker) en de VvOCM (Vereniging voor Oefentherapeuten Cesar en Mensendieck) ben ik dan ook zeer erkentelijk. 


\section{Introduction}

Previous studies have shown that non-specific work-related upper limb disorders (WRULD) among computer screen workers develop as a result of extended screen work. ${ }^{1-3 .}$ However, contrary to this, a recent longitudinal cohort study among office workers in the Netherlands showed that long duration of computer work did not predict the occurrence of upper limb disorders. ${ }^{4}$ In general, previous research on existing associations between physical, ${ }^{4,5}$ psychosocial $^{4,6-8}$ and psychological ${ }^{4,7,9}$ risk factors, and the development of upper limb disorders showed mixed results. Psychosocial factors, especially moderate to low reward and low task variation, appeared to have an association with the onset of upper limb disorders. ${ }^{4,7}$ A large cross-sectional study among bank employees showed that job stress was strongly associated with the development of upper limb disorders. ${ }^{8}$ With respect to psychological risk factors, especially overcommitment, ${ }^{4,7}$ psycho neuroticism and neurotic perfectionism ${ }^{9}$ showed a relationship with the onset of upper limb disorders. In a study among PhD students with upper limb disorders it had been shown that a high score on the Trait Anxiety Inventory (STAI 2) was associated with sooner absenteeism from work and self-perceived disability. ${ }^{10}$ Demographic data further indicate that persons suffering from non-specific WRULD are often highly educated, have long working days, and are over 30 years of age with an over-representation of women. ${ }^{4,11,12}$ It appears that beyond sociodemographic factors, primarily psychosocial and psychological factors play a role in the onset and course of upper limb disorders.

We conducted a randomized trial among computer screen workers with early nonspecific upper limb disorders in which one group received postural exercise therapy and the other group regular physiotherapy. We showed that at one year follow-up still $45 \%$ suffered from upper limb complaints. ${ }^{12}$ A remarkable finding in this study was the high score at baseline on the Pain Catastrophizing Scale (PCS) for both groups. ${ }^{12}$ Since physically oriented interventions, also in early stages of non-specific upper limb disorders, ${ }^{12}$ are not able to eliminate upper limb disorders, further research needs to focus on psychosocial and psychological factors. With regards to low back pain, Sullivan previously demonstrated the relation between pain catastrophizing and chronic pain, while Vlaeyen explains why pain becomes chronic during the process of catastrophizing. $^{13,14}$

In order to gain more insight into the relationships between psychological-, physical-, demographic characteristics and beginning upper limb disorders, we conducted a casecontrol study among computer screen workers by means of comparing the baseline characteristics of the participants in our previously conducted randomized controlled trial with the baseline characteristics of a control group of non-cases.

The main research question in the present study is therefore: are computer screen workers with early non-specific work-related upper limb disorders (WRULD) more sus- 
ceptible to catastrophizing behavior, more anxious and neurotic perfectionists and less physically fit compared to non-cases?

\section{Subjects and methods}

The baseline characteristics of 88 employed computer screen workers with early nonspecific upper limb disorders who participated in a randomized controlled trial ${ }^{12}$ (cases) were compared with the characteristics of a control group of 31 employed computer screen workers (controls).

As a result, the inclusion criteria for participants in this randomized controlled trial and for being a case in this case-control study were: being a computer screen worker employed for more than 3 months and working at least 4 hours per day and 20 hours per week, between 20 and 45 years of age and experiencing early non-specific upper limb disorders with a duration of symptoms between 2 weeks and 3 months. ${ }^{12}$ Early nonspecific work-related upper limb disorders (WRULD) were defined as: pains and tingles in upper back, neck, shoulders, arms or hands related and restricted to computer screen-work, not yet present during other daily activities and not labelled as a specific diagnosis such as tennis elbow or carpal tunnel syndrome. The inclusion of the cases took place between May 2003 and February 2005. They were recruited by means of advertisements in local newspapers, through personal contact with occupational physicians of large companies, and by mailing to general practitioners. ${ }^{12}$ The control group consisted of computer screen workers who did not have any past or present upper limb disorders. They were recruited among employees of several departments, staff and PhD students of Maastricht University between November 2007 and June 2008. In order to be included they had to perform computer work for at least 4 hours per day and 20 hours per week for at least 3 months to make them comparable to the cases. Recruitment took place by advertisements at the different departments. Potential participants for the control group were recruited and finally selected by the same occupational physician (AvA) who performed the selection of the participants of the randomized controlled trial in 2003, 2004 and 2005.

All participants of the present study completed a baseline questionnaire that consisted of a general section on socio-demographic characteristics and specific questionnaires on psychological and physical risk factors. The time taken to fill out the questionnaire was approximately twenty minutes. Socio-demographic characteristics comprised sex, age and level of education. Participants were labeled as "highly educated" if they had at least a bachelor's degree.

\section{Psychological and physical risk factors}

Additionally to the aforementioned socio-demographic factors, validated specific questionnaires were used to assess psychological and physical risk factors. These potential 